\title{
AU2 AU1 Redox- and Ligand Binding-Dependent Conformational Ensembles in the Human Apoptosis-Inducing Factor Regulate Its Pro-Life and Cell Death Functions
}

AU3 Raquel Villanueva, ${ }^{1}$ Silvia Romero-Tamayo, ${ }^{1}$ Ruben Laplaza, ${ }^{1,2}$ Juan Martínez-Olivan,1 Adrián Velázquez-Campoy, ${ }^{1,3-5}$ Javier Sancho,,4 ${ }^{1,4}$ atricia Ferreira, ${ }^{1}$ and Milagros Medina ${ }^{1}$

\section{Abstract}

Aims: The human apoptosis-inducing factor (hAIF) supports OXPHOS biogenesis and programmed cell death, with missense mutations producing neurodegenerative phenotypes. hAIF senses the redox environment of cellular compartments, stabilizing a charge transfer complex (CTC) dimer that modulates the protein interaction network. In this context, we aimed to evaluate the subcellular $\mathrm{pH}, \mathrm{CTC}$ formation, and pathogenic mutations effects on hAIF stability, and a thermal denaturation high-throughput screening (HTS) assay to discover AIF binders.

AU4 Results: Apoptotic hAIF ${ }_{\Delta 1-101}$ is not stable at intermembrane mitochondrial space (IMS) pH, but the 77-101 residues confer stability to the mitochondrial isoform. hAIF and its CTC populate different conformational ensembles with redox switch to the CTC producing a less stable and compact protein. The pathogenic G308E, $\Delta \mathrm{R} 201$, and E493V mutations modulate hAIF stability; particularly, $\Delta \mathrm{R} 201$ causes a population shift to a less stable conformation that remodels active site structure and dynamics. We have identified new molecules that modulate the hAIF NADH/NAD ${ }^{+}$association/dissociation equilibrium and regulate its catalytic efficiency.

Innovation: Biophysical methods allow evaluating the regulation of hAIF functional ensembles and to develop an HTS assay to discover small molecules that might modulate hAIF stability and activities.

Conclusions: The mitochondrial soluble 54-77 portion stabilizes hAIF at the IMS pH. NADH-redox-linked conformation changes course with strong $\mathrm{NAD}^{+}$binding and protein dimerization, but they produce a negative impact in overall hAIF stability. Loss of functionality in the R201 deletion is due to distortion of the active site architecture. We report molecules that may serve as leads in the development of hAIF bioactive compounds. Antioxid. Redox Signal. 00, 000-000.

Keywords: apoptosis-inducing factor, ligand/redox-linked allosteric conformation, thermal stability, pathogenic mutations, high-throughput screening

\section{Introduction}

AU5 $r$ maintenance of mitochondrial function, being also a caspase- independent programmed cell death (PCD) effector $(29,42$, $43,45,64)$. Recent research is compiling evidence of the critical roles of the AIF redox state and of the redoxdependent monomer-dimer equilibrium in both functions. The human AIF (hAIF) precursor is synthesized in the

\footnotetext{
${ }^{1}$ Departamento de Bioquímica y Biología Molecular y Celular, Facultad de Ciencias, Instituto de Biocomputación y Física de Sistemas Complejos (GBsC-CSIC and BIFI-IQFR Joint Units), Universidad de Zaragoza, Zaragoza, Spain.

${ }^{2}$ Departamento de Química Física, Universidad de Santiago de Compostela, Santiago de Compostela, Spain.

${ }^{3}$ Fundación ARAID, Diputación General de Aragón, Zaragoza, Spain.

${ }^{4}$ Aragon Institute for Health Research (IIS Aragon), Zaragoza, Spain.

${ }^{5}$ Biomedical Research Networking Centre for Liver and Digestive Diseases (CIBERehd), Madrid, Spain.
} 


\section{Innovation}

The apoptosis-inducing factor (AIF) supports OXPHOS biogenesis and programmed cell death, sensing the redox environment, and undergoing redox-linked allosteric switches that modulate its interaction network with other biomolecules. Our study provides a comprehensive understanding of hAIF stability under several situations that mimic physiological conditions: subcellular $\mathrm{pH}$, NADH-redox-linked conformational switches, and germline loss-of-function mutations. We also pave the way to identify hAIF binders that can modulate its stability or functionality in the treatment of hAIF X-linked rare diseases.

cytosol and imported into the intermembrane mitochondrial space (IMS), where the N-terminal region is enzymatically removed producing the $\mathrm{hAIF}_{\Delta 1-54}$ mitochondrial mature form. The N-terminal transmembrane helix (residues $\sim 60$ 78) tethers $\mathrm{hAIF}_{\Delta 1-54}$ to the inner mitochondrial membrane, whereas the soluble protein moiety folds toward the IMS and incorporates the redox FAD (oxidized form of flavin adenine dinucleotide) cofactor $(48,64,72)$. hAIF assists biogenesis of respiratory chain complexes through its NADH-oxidoreductase activity, by contributing to the IMS import of the coiled-coil-helix-coiled-coil-helix domain containing-4protein $(\mathrm{CHCHD} 4)(25,41,58,66)$. Certain apoptotic stimuli induce a second $\mathrm{N}$-terminal cleavage, yielding a soluble protein, $\mathrm{hAIF}_{\Delta 1-101}$, that translocates to the cytoplasm, where it can interact with heat-shock protein 70 (Hsp70) (53), thioredoxin 1 (58), or endonuclease cyclophilin A (CypA) $(10,73)$. Finally, hAIF $_{\Delta 1-101}$ can translocate to the nucleus where it forms, upon recruiting CypA and histone H2AX, a DNA-degradosome that induces chromatinolysis $(2,10,64)$.

Binding of NADH to hAIF elicits its reduction and the stabilization of a long-lived oxygen-stable $\mathrm{FADH}^{-} \mathrm{NAD}^{+}$ charge transfer complex (CTC) $(17,18,55,56)$. This process triggers protein dimerization, uncouples a 50-residue region at the protein $\mathrm{C}$-terminal apoptotic domain that becomes disordered in the CTC crystal structure (regulatory C-loop, 509-560), and creates a second noncatalytic and allosteric NADH binding site. In the oxidized enzyme, $\mathrm{hAIF}_{\text {ox }}$, the Cloop 517-533 residues fold in two short $\alpha$-helices, diminishing the isoalloxazine solvent accessibility $(17,18,55,56)$. The NADH-driven allosteric conformational changes propagate from the CTC active site through very specific molecular pathways that are claimed to control hAIF association with protein partners and DNA, and, as a consequence, its participation in mitochondrial homeostasis and PCD $(8,25$, 57). Thus, hAIF is envisaged as a redox and/or NADH sensor that might modulate certain signal-transduction pathways $(55,62)$. We are also witnessing the discovery of an increasing number of hAIF allelic variants linked to a range of human rare diseases, mainly neurodegenerative mitochondrial disorders and inherited peripheral neuropathies $(1,4,15$, $22,26,30,44,50,52,74$ ). Most of them (as $\Delta \mathrm{R} 201, \mathrm{~F} 210 \mathrm{~S}$, V243L, G262S, G308E, G338E, and Q479R) produce severe mitochondriopathies associated with substantial decrease of the CTC lifetime, reduced expression of respiratory chain complexes, and OXPHOS failure. In contrast, the E493V mutation increases cell death via apoptosis, causing the Cowchock syndrome without affecting OXPHOS. Mutations are distributed through the hAIF structure, but the most deleterious ones tend to compromise structural elements involved in the binding of the adenine moieties of the $\mathrm{NAD}(\mathrm{H})$ coenzymes or the FAD cofactor $(18,57,62)$. In vitro studies with some of these variants envisage defective folding, decreased stability, or higher propensity to FAD release (22, 57).

The NADH-driven allosteric behavior and the disease causing mutations indicate that the hAIF redox-dependent structural stability and conformation control its physiological functions. Thus, knowing how subcellular localization, ligand binding, redox state, or allelic mutations can regulate these parameters will help to understand the hAIF in vivo behavior. In this context, we evaluate here the hAIF stability under conditions that potentially mimic different conformational traits influenced by intracellular environment (subcellular compartments $\mathrm{pH}, \mathrm{NADH}-$ redox-dependent state) and by missense pathogenic mutations. In addition, we develop and validate an FAD fluorescence-based thermal denaturation high-throughput screening (HTS) assay to search for compounds that might alter hAIF stability. To date, only one small molecule, aurintricarboxylic acid (ATA), has been identified to bind hAIF by using a photonic crystal biosensor screening (11). In this study, we propose some molecules that may serve as a starting point in the development of hAIF with low cellular toxicity.

\section{Results}

\section{The $\mathrm{pH}$ of subcellular compartments modulates hAIF} folding and conformation

hAIF functions in different subcellular compartments with particular $\mathrm{pH}$ environments that might influence its molecular properties. To evaluate this effect, we have selected $\mathrm{pH}$ 6.2 as typical of the IMS (49), 7.0 as representative for apoptotic cytosol (39), 7.4 for cytosol and nucleus $(36,54)$, and 8.0 for the mitochondrial matrix $(36,47)$, and physiological ionic strength. Within the $\mathrm{pH} 7.0-8.0$ range, $\mathrm{hAIF}_{\Delta 1-101 \text { ox }}$ $\mathrm{UV}$-visible spectra indicate that the FAD cofactor is in the oxidized state, properly incorporated, and in a similar electronic environment, whereas incubation with NADH brings about the FAD cofactor reduction with the appearance of a CTC band (Supplementary Fig. S1A; Supplementary Data $\varangle$ SF1 are available online at www.liebertpub.com/ars). At pH 6.2, the $\mathrm{A}_{280} / \mathrm{A}_{450}$ and $\mathrm{A}_{380} / \mathrm{A}_{450}$ ratios increase for $\mathrm{hAIF} \mathrm{AI}_{\Delta-101 \mathrm{ox}}$, a drift dominates the CTC spectrum, and turbidity is observed, facts indicative of low stability and some aggregation level. Since this IMS pH is relevant in our study, we have produced the $\mathrm{hAIF}_{\Delta 1-77}$ isoform, lacking the membraneanchoring helix but containing the IMS soluble portion. Spectra of $\mathrm{hAIF}_{\Delta 1-77 \mathrm{ox}}$ confirm it is folded (Supplementary Fig. S1B). Henceforth, studies at $\mathrm{pH} 6.2$ will take $\mathrm{hAIF}_{\Delta 1-77}$ as IMS representative, whereas hAIF $_{\Delta 1-101}$ will be the model for other subcellular compartments. NADH presteady-state hAIF reduction kinetics corroborate CTC formation $\left(\mathrm{hAIF}_{\Delta 1-}\right.$ 101rd: $\mathrm{NAD}^{+}$and $\mathrm{hAIF}_{\Delta 1-77 \mathrm{rd}}: \mathrm{NAD}^{+}$species (18)) with reduction rates within a factor of 1.5 (Supplementary Fig. S2 and $\varangle$ SF2 Table 1).

$\mathrm{hAIF}_{\Delta 1-101 \mathrm{ox}}$ and $\mathrm{hAIF}_{\Delta 1-77_{\mathrm{ox}}}$ far-UV CD spectra are dominated by a broad negative band with minima at $\sim 222$ and 
Table 1. Effect of pH on the Presteady Kinetic RATES For the AERobic Reduction OF HAIF ox $_{\text {By NADH }}$

\begin{tabular}{lcccc}
\hline & & \multicolumn{3}{c}{$k_{\text {obs }}\left(\mathrm{s}^{-1}\right)$} \\
\cline { 3 - 5 } Protein & $p H$ & $1 \mathrm{mM}$ & $\begin{array}{c}\text { [NADH] } \\
2.5 \mathrm{mM}\end{array}$ & $5 \mathrm{mM}$ \\
\hline $\mathrm{hAIF}_{\Delta 1-101 \mathrm{ox}}$ & 8.0 & $0.53 \pm 0.01$ & $0.88 \pm 0.02$ & $1.17 \pm 0.01$ \\
& 7.4 & $0.37 \pm 0.01$ & $0.62 \pm 0.01$ & $0.82 \pm 0.01$ \\
& 7.0 & $0.35 \pm 0.03$ & $0.63 \pm 0.01$ & $0.84 \pm 0.01$ \\
$\mathrm{hAIF}_{\Delta 1-77 \mathrm{ox}}$ & 6.2 & $0.60 \pm 0.05$ & $0.85 \pm 0.07$ & $1.10 \pm 0.05$
\end{tabular}

Assays were performed in $50 \mathrm{~m} M$ phosphate buffer at a final ionic strength of $150 \mathrm{mM}$ and $25^{\circ} \mathrm{C}$. Final concentrations were $\sim 10 \pm 2 \mu M$ protein and $1,2.5$, or $5 \mathrm{~m} M$ for NADH. $(n=3, \pm \mathrm{SE})$.

hAIF, human apoptosis-inducing factor; NADH, reduced nicotinamide adenine dinucleotide.

F1 $\sim 208 \mathrm{~nm}$ (Fig. 1A), in agreement with its high $\alpha$-helix content (18). Formation of the CTC slightly decreases the $208 \mathrm{~nm}$ minimum relative intensity (Fig. 1B), probably related to the C-loop two short $\alpha$-helices unfolding (18). The hAIF Al-101ox near-UV/vis CD shows sharp (wider in $\mathrm{hAIF}_{\Delta 1-77 \mathrm{ox}}$ ) and broad maxima at $\sim 300$ and $\sim 365 \mathrm{~nm}$, respectively, as well as
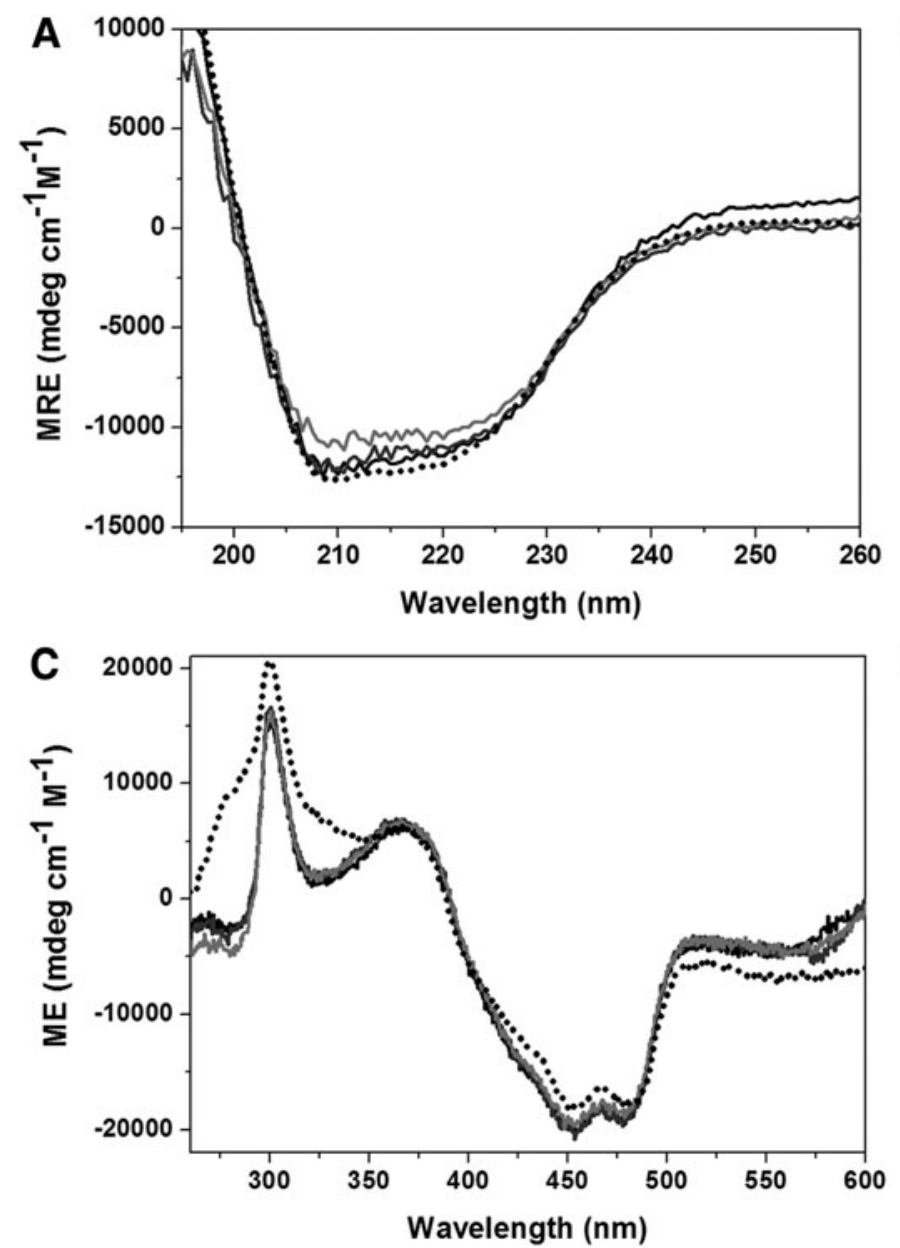

minima at $\sim 453$ and $\sim 477 \mathrm{~nm}$, with minor $\mathrm{pH}$ effects (Fig. 1C). CTC formation results in lack of near-UV signal at $300 \mathrm{~nm}$ and of 350-500 nm features of the oxidized flavin, but shows bands at $\sim 405$ and $\sim 600 \mathrm{~nm}$ consistent with CTC stabilization (Fig. 1D). Far-UV and near-UV signals are lost at denaturing temperatures $\left(90^{\circ} \mathrm{C}\right)$, indicating that protein becomes unfolded.

Then, we have evaluated the $\mathrm{pH}$ effect on fluorescence emission (Supplementary Fig. S1C). WT hAIF ox samples display emission maxima at $\sim 337 \mathrm{~nm}$ with higher quantum yield at $\mathrm{pH}$ 8.0. CTC spectra are dominated by a $\sim 460 \mathrm{~nm}$ band related to intrinsic NADH fluorescence, whereas the aromatic band intensity decreases due to energy transfer because of the tryptophan-coenzyme proximity. When exciting at flavin band I, fluorescence is particularly low, indicative of a strong quenching of flavin emission upon its binding to the protein. Denaturing temperatures increase fluorescent emission, consistent with flavin release.

Thermal stability of hAIF is highly modulated by formation of the CTC

Then, we have recorded thermal unfolding curves to evaluate the stability of WT hAIF $_{\Delta 1-101}$, oxidized, and when
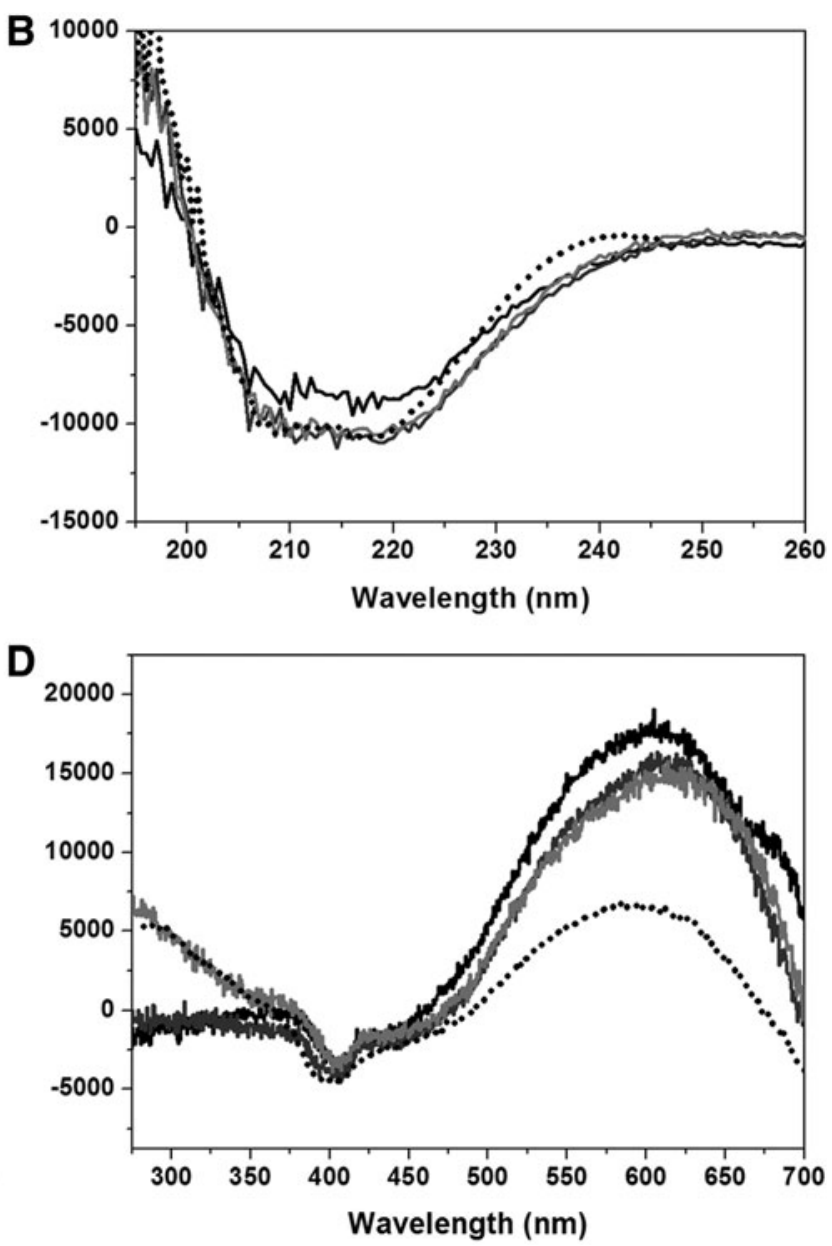

FIG. 1. Circular dichroism spectra of WT hAIF. Far-UV CD spectra of (A) $1 \mu M \mathrm{hAIF}_{\Delta 1-101 \mathrm{ox}}$ or hAIF h1-77ox $_{\text {(dashed }}$ line) and (B) a mixture of $1 \mu M \mathrm{hAIF}_{\Delta 1-101 \text { ox }}$ or $\mathrm{hAIF}_{\Delta 1-77 \text { ox }}$ (dashed line) with $100 \mu M \mathrm{NADH}$. Near-UV/vis CD spectra of (C) $20 \mu \mathrm{M} \mathrm{hAIF}_{\Delta 1-101 \mathrm{ox}}$ or $\mathrm{hAIF}_{\Delta 1-77 \mathrm{ox}}$ (dashed line) and (D) a mixture of $20 \mu \mathrm{M} \mathrm{hAIF}_{\Delta 1-101 \mathrm{ox}}$ or $\mathrm{hAIF}_{\Delta 1-77 \mathrm{ox}}$ (dashed line) with $2 \mathrm{mM}$ NADH. Spectra were recorded at $25^{\circ} \mathrm{C}$ in $50 \mathrm{~m} M$ potassium phosphate, $\mathrm{pH} 8.0$ (black line), 7.4 (dark gray line), 7.0 (gray line), and pH 6.2 (black dotted line) at a final ionic strength of $150 \mathrm{mM}$. hAIF, human apoptosis-inducing factor. 
forming the CTC, in the $\mathrm{pH} 7.0-8.0$ range, as well as those of $\mathrm{hAIF}_{\Delta 1-77}$ at $\mathrm{pH}$ 6.2. Far-UV CD, near-UV/vis CD, and flavin

F2 fluorescence unfolding curves are shown in Figure 2A and B and Supplementary Fig. S3. hAIF ${ }_{\Delta 1-1010 x}$ curves indicate a three-state unfolding mechanism $(\mathrm{N} \leftrightarrow \mathrm{I} \leftrightarrow \mathrm{U})$, allowing determination of temperatures of midpoint denaturation $\left(\mathrm{T}_{\mathrm{m} 1}\right.$ and $\left.\mathrm{T}_{\mathrm{m} 2}\right)$ and unfolding enthalpy changes $\left(\Delta \mathrm{H}_{1}\right.$ and $\left.\Delta \mathrm{H}_{2}\right)$

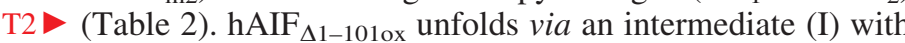
$\mathrm{T}_{\mathrm{m} 1}$ revealed by the near-UV transition, and the flavin fluorescence change taking place essentially at $\mathrm{T}_{\mathrm{m} 2}$. Therefore, the $\mathrm{N} \leftrightarrow \mathrm{I}$ transition is caused by loss of tertiary interactions and the I state retains the isoalloxazine folded environment Noticeably, a modestly lower population of I state is detected at $\mathrm{pH} 8.0$ (mitochondrial matrix) when compared with cytosolic and nuclear $\mathrm{pH}$, whereas $\mathrm{T}_{\mathrm{m} 1}$ is $3^{\circ} \mathrm{C}$ lower and the unfolding enthalpy change, $\Delta \mathrm{H}_{1}$, is $\sim 40 \%$ larger (Table 2). hAIF $_{\Delta 1-77 \text { ox }}$ unfolds via a four-state unfolding mechanism $\left(\mathrm{N} \leftrightarrow \mathrm{I}_{0} \leftrightarrow \mathrm{I} \leftrightarrow \mathrm{U}\right)$ at $\mathrm{pH} 6.2$ (Supplementary Fig. S3C). NearUV data suggest loss of overall tertiary structure at lower temperatures and stabilization of an additional intermediate $\left(\mathrm{I}_{0}, \mathrm{~T}_{\mathrm{m} 0}\right)$ that retains secondary structure and FAD binding, whereas $\mathrm{T}_{\mathrm{m} 1}$ (now $\mathrm{I}_{0} \rightarrow \mathrm{I}$ transition) decreases compared with the apoptotic hAIF ${ }_{\Delta 1-101 \text { ox }}$ values (Table 2). Finally, both $\mathrm{pH}$ 6.2 and the 77-101 tail have a thermal stabilizing effect for flavin being retained $\left(\mathrm{T}_{\mathrm{m} 2}\right)$, despite unfolding of secondary and tertiary elements starts at lower temperatures.

Formation of the dimeric $\mathrm{hAIF}_{\Delta 1-101 \mathrm{rd}}: \mathrm{NAD}^{+}$and $\mathrm{hAIF}_{\Delta 1-}$ 77rd: $\mathrm{NAD}^{+} \mathrm{CTC}$ exerts an important impact on the overall protein unfolding mechanism and thermal stability. A twostate process is observed for $\mathrm{hAIF}_{\Delta 1-101 \mathrm{rd}}: \mathrm{NAD}^{+}$, with $\mathrm{T}_{\mathrm{m}}$ for CTC unfolding $\left(\mathrm{T}_{\mathrm{mCTC}}\right)$ being $\sim 7^{\circ} \mathrm{C}$ lower than $\mathrm{T}_{\mathrm{m} 1}$ and up to $13^{\circ} \mathrm{C}$ lower than $\mathrm{T}_{\mathrm{m} 2}$ (Table 2). However, a three-state process describes $\mathrm{hAIF}_{\Delta 1-77 \mathrm{rd}}: \mathrm{NAD}^{+} \mathrm{CTC}$ unfolding, with loss of tertiary interactions while retaining secondary structure and flavin binding. Thus, collectively, coenzyme binding and flavin reduction have a deleterious effect on the stability of $\mathrm{N}$ and, particularly, I states, favoring FAD release and unfolded conformers formation. Noticeably, the CTC unfolding enthalpy $\left(\Delta \mathrm{H}_{\mathrm{CTC}}\right)$ of $\mathrm{hAIF}_{\Delta 1-101 \mathrm{ox}}$ approximates the sum of $\Delta \mathrm{H}_{1}$ and $\Delta \mathrm{H}_{2}$ at $\mathrm{pH} 7.0$ and 7.4 , whereas at $\mathrm{pH} 8.0$
$\Delta \mathrm{H}_{\mathrm{CTC}}$ is lower. To gain insight into the lower CTC stability relative to $\mathrm{hAIF}_{\Delta 1-101 \mathrm{ox}}$, we built structural models containing the missing $\mathrm{C}$-loop residues in the $\mathrm{X}$-ray structure (18). Models were minimized and relaxed by short molecular dynamics (MD) simulations (Fig. 2 and Supplementary Figs. S4 $<$ SF4 and S5). Overlapping of hAIF $\mathrm{Al}_{-101 \mathrm{ox}}$ and CTC models along $<$ SF5 MD relaxation on starting models showed similar RMSD $(\mathrm{C} \alpha)$ values (Fig. $2 \mathrm{G}$ ), with the slightly higher CTC value contributed by C-loop disorder and larger flexibility (Fig. 2H). Evolution of RMSDs for the core protein suggests that, with C-loop exception, both protein forms maintain the fold at $298 \mathrm{~K}$ as well as the active site architectures (Supplementary Fig. S4). The CTC structure shows larger radius of gyration, decrease in the H-bonds network, and slight increases in molecular and solvent accessible surface areas (Fig. 2I and Supplementary Fig. S5). This agrees with R201E531 and W196-R529 interactions clapping the C-loop to the 196-201 $\beta$-hairpin in $\mathrm{hAIF}_{\Delta 1-101 \mathrm{ox}}$, and contributing to 529 533 residues folding into an $\alpha$-helix. Contrarily, in the CTC this region contributes to the $\mathrm{C}$-loop disorder, making this ensemble less compact than the oxidized form and pointing out to this fact as the main reason for its lower stability.

\section{Some allelic pathogenic mutations alter hAIF ${ }_{\Delta 1-101}$ stability}

We have also evaluated the impact of missense $\Delta \mathrm{R} 201$, G308E, and E493V mutations on protein-FAD interaction integrity and hAIF ${ }_{\Delta 1-101}$ stability (Fig. 2E and Supplemen- 4 SF6 tary Fig. S6A-C). G308E and E493V mutations produce modest spectral perturbations (Supplementary Figs. S6 and $\mathrm{S} 7)$, as expected from low impact in their crystal structures $4 \mathrm{SF} 7$ $(50,57,61,62)$. Nonetheless, small changes in shape and position of $380-400 \mathrm{~nm}$ features in their CTC vis-CD as well as low flavin fluorescence quenching in the G308E CTC are noticed (Supplementary Figs. S6H and S7D). In contrast, the R201 deletion clearly alters the protein spectroscopic properties: it modifies the flavin band I (Supplementary Fig. S6D), increases the fluorescence quantum yield of at least one tryptophan (Supplementary Fig. S6E), attenuates FAD

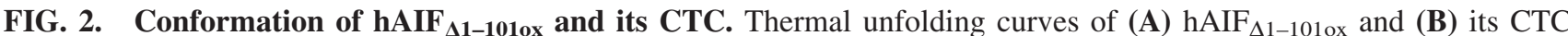
(1:100 protein $\mathrm{hAIF}_{\Delta 1-101 \text { ox }}: \mathrm{NADH}$ ratio) at $\mathrm{pH}$ 8.0. Thermal denaturation was monitored by far-UV CD (210 nm, white circles $)$ and near-UV CD $(300 \mathrm{~nm}$, black squares $)$ for hAIF Al-101 , or by far-UV CD $(210 \mathrm{~nm}$, white circles $)$ and vis CD in the CTC (in B, $410 \mathrm{~nm}$ due to the lack of the $300 \mathrm{~nm}$ peak, black squares). Both samples were also monitored by flavin fluorescence emission (black triangles). The curves are shown roughly normalized from 0 to 1 , and their global fits to twotransition (for $\mathbf{A}$ ) and one-transition (for $\mathbf{B}$ ) unfolding models are represented by the continuous lines. Curves were recorded in $50 \mathrm{~m} M$ potassium phosphate at a final ionic strength of $150 \mathrm{~m} M$. Final snapshots of representative structural models for

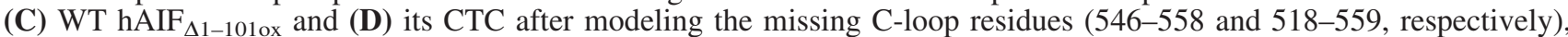
minimization routine, and $15 \mathrm{~ns}$ of MD relaxation at $300 \mathrm{~K}$. Protein chain is represented as cartoon with the oxidoreductase domains in violet and its 191-202 $\beta$-hairpin in hot pink (R201 and W196 side chains in sticks), whereas the apoptotic domain is drawn in light blue with the C-loop (509-560 segment) in orange. FAD and NAD ${ }^{+}$are shown in sticks with carbons in orange and green, respectively. Details of the active site environments in (E) hAIF $\mathrm{F}_{\Delta 1-1010 x}$ and $(\mathbf{F})$ its CTC Relevant residues are shown in sticks. Relevant interactions in the $\mathrm{hAIF}_{\Delta 1-101 \mathrm{ox}}$ model are shown in blue dashed lines. Gray surfaces show water accessible cavities in the active site environment. (G) RMSD $(\mathrm{C} \alpha)$ of hAIF ${ }_{\Delta 1-101 \text { ox }}$ (gray line) and of its CTCs models along representative MD relaxations when overlapped on their corresponding starting models (after modeling of the missing C-loop residues and before minimization). Red and blue lines, respectively, represent the RMSD when considering only overlapping of the $128-508$ core residues ( $388 \mathrm{C} \alpha$ atoms, red line). (H) RMSF of backbone atoms along a representative MD of the WT CTC model. Higher values for the black line in (G) are due mainly to the higher fluctuation in the position of the C-loop in the CTC. (I) Radius of gyration of hAIF $_{\Delta 1-101 \text { ox }}$ and of its CTC models along the MD production, colors as in $(\mathbf{G})$. CTC, charge transfer complex; FAD, oxidized form of flavin adenine dinucleotide. To see this illustration in color, the reader is referred to the web version of this article at www.liebertpub.com/ars 

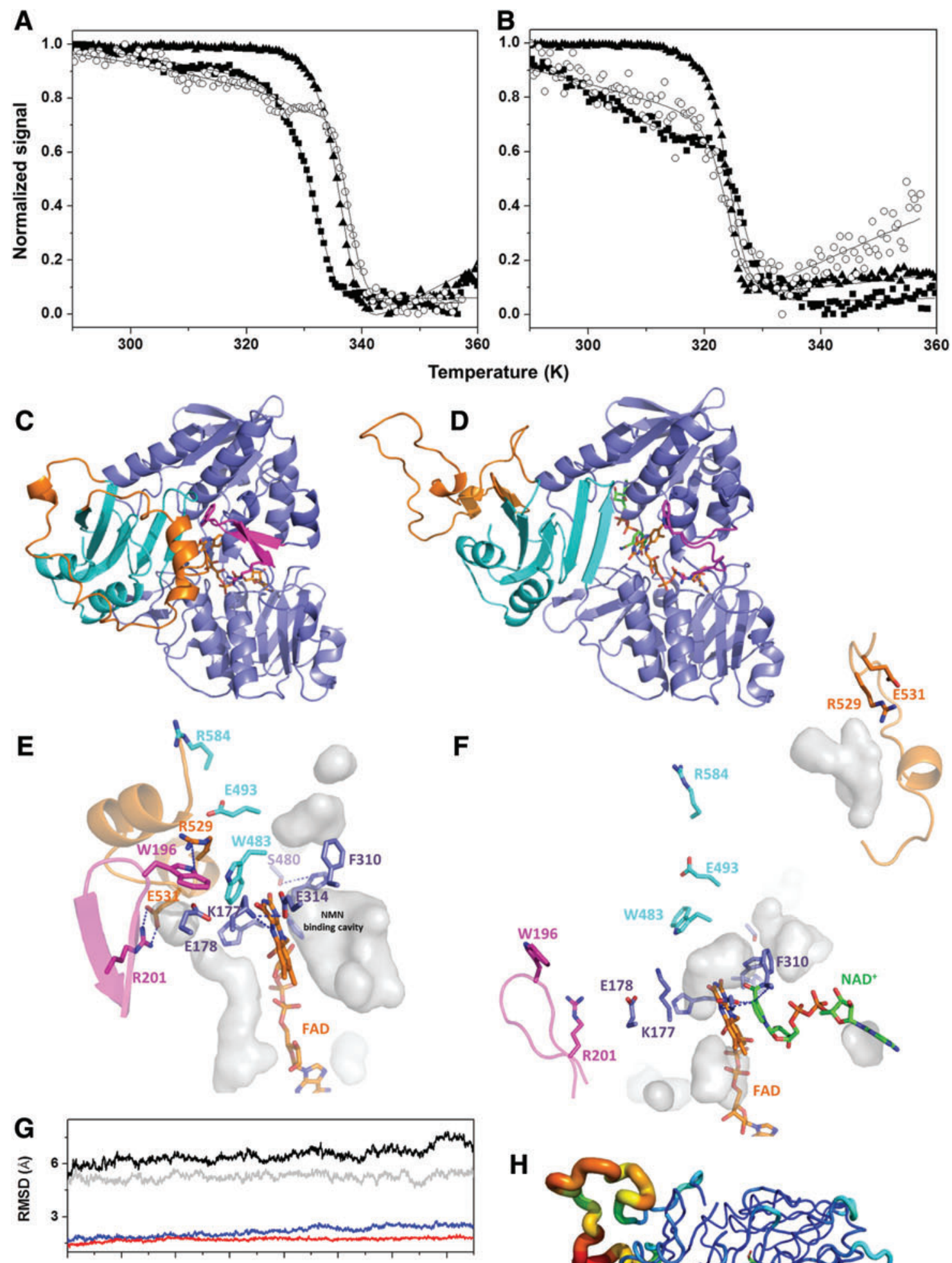

$\mathbf{F}$
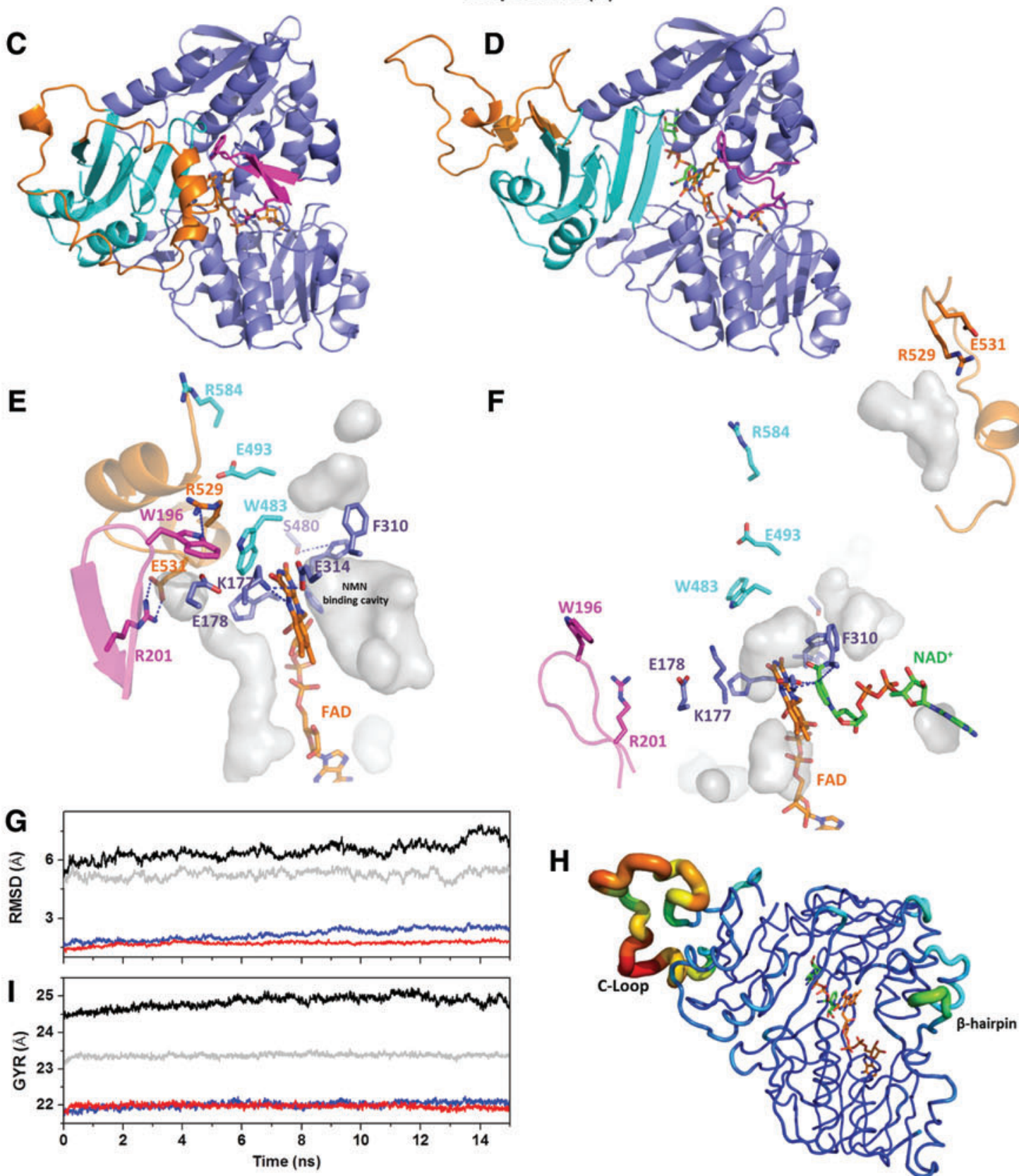

H

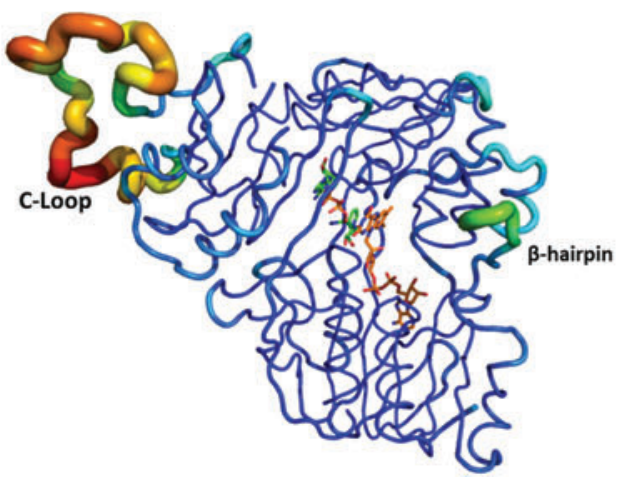


Table 2. Effect of pH on the Thermal Stability of Wild Type HAIF W1-101ox $_{1}$, haIF $_{\Delta 1-77 o x}$, and of Their Charge Transfer Complexes

\begin{tabular}{|c|c|c|c|c|c|c|c|c|}
\hline \multirow[b]{2}{*}{$p H$} & \multicolumn{4}{|c|}{$h A I F_{\Delta 1-1010 x}$} & \multicolumn{2}{|c|}{$C T C\left(h A I F_{\Delta 1-101 r d}: N A D^{+}\right)$} & \multirow[b]{2}{*}{$T_{m C T C}-T_{m 1}$} & \multirow[b]{2}{*}{$T_{m C T C}-T_{m 2}$} \\
\hline & $T_{m 1}(K)$ & $T_{m 2}(K)$ & $\Delta H_{l}(\mathrm{kcal} / \mathrm{mol})$ & $\Delta \mathrm{H}_{2}(\mathrm{kcal} / \mathrm{mol})$ & $T_{m C T C}(K)$ & $\Delta H_{C T C}(\mathrm{kcal} / \mathrm{mol})$ & & \\
\hline 8.0 & $332 \pm 1$ & $337 \pm 1$ & $87 \pm 6$ & $140 \pm 10$ & $324 \pm 1$ & $120 \pm 10$ & $-8 \pm 2$ & $-13 \pm 2$ \\
\hline 7.4 & $334 \pm 2$ & $336 \pm 1$ & $52 \pm 8$ & $110 \pm 10$ & $327 \pm 1$ & $180 \pm 10$ & $-7 \pm 2$ & $-10 \pm 2$ \\
\hline \multirow[t]{3}{*}{7.0} & $337 \pm 1$ & $338 \pm 1$ & $46 \pm 3$ & $110 \pm 10$ & $327 \pm 1$ & $180 \pm 10$ & $-7 \pm 2$ & $-11 \pm 2$ \\
\hline & \multicolumn{4}{|c|}{$h A I F_{\triangle 1-77 o x}$} & \multicolumn{2}{|c|}{$C T C\left(h A I F_{\Delta 1-77 r d}: N A D^{+}\right)$} & & \\
\hline & $T_{m o}(K) T_{m}$ & $(K) T_{m 2}$ & $\begin{array}{c}\Delta H_{O} \\
\text { K) }(\mathrm{kcal} / \mathrm{mol})(\mathrm{kcc}\end{array}$ & 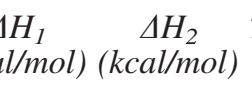 & $\begin{array}{cc}T_{m O C T C} & T_{m C T C} \\
(K) & (K)\end{array}$ & $\begin{array}{cc}\Delta H_{O C T C} & \Delta H_{l} \\
(\mathrm{kcal} / \mathrm{mol}) & (\mathrm{kcal})\end{array}$ & $\begin{array}{l}T C \\
\text { lol) } T_{m C T C}-T_{m}\end{array}$ & $T_{m C T C}-T_{m 2}$ \\
\hline 6.2 & $318 \pm 1 \quad 32$ & $3 \pm 3 \quad 343=$ & $69 \pm 4$ & $150 \pm 20$ & $322 \pm 2329 \pm 2$ & $2160 \pm 20 \quad 150$ & $1 \pm 5$ & $-13 \pm 4$ \\
\hline
\end{tabular}

Values were obtained by global fitting of the near-CD, far-UV CD, and fluorescence thermal denaturation curves to two, three, or four species unfolding mechanisms. Data were obtained in $50 \mathrm{~m} M$ potassium phosphate at a final ionic strength of $150 \mathrm{~m} M$, from 283.15 to 363.15 K. Protein concentrations were $\sim 1 \mu M, \sim 2 \mu M$, and $\sim 20 \mu M$ for far-UV CD, fluorescence, and near-UV CD, respectively. $(n=3, \pm \mathrm{SD})$

fluorescence quenching (Supplementary Fig. S6F), and modifies shape and intensity of the near-UV and vis $\mathrm{CD}$ signals (Supplementary Fig. S7C). This is consistent with the mutation perturbing overall protein folding and FAD incorporation $(22,50)$. Noticeably, $\triangle \mathrm{R} 201 \mathrm{CTC}$ increases FAD fluorescence quenching when compared with $\Delta \mathrm{R} 201$ hAIF $_{\Delta 1-101 \text { ox }}$ (Supplementary Fig. S6H).

The mutations have a negative impact on thermal stability SF8 F3 when compared with WT (Fig. 3 and Supplementary Fig. S8, Table 3), particularly evident in $\Delta \mathrm{R} 201\left(\Delta \mathrm{T}_{\mathrm{m} 1}=-27.7^{\circ} \mathrm{C}\right.$ and $\left.\Delta \mathrm{T}_{\mathrm{m} 2}=-24.8^{\circ} \mathrm{C}\right)$. R201 ablation also modifies the unfolding events, so that the FAD cofactor is released in the first transition $(\mathrm{N} \rightarrow \mathrm{I})$ (Fig $3 \mathrm{~A}$ and Supplementary Fig. S8A). Therefore, $\mathrm{T}_{\mathrm{m}}$ for flavin release $\left(\mathrm{T}_{\mathrm{mFAD}}\right)$ decreases by $\sim 33^{\circ} \mathrm{C}$ in $\Delta \mathrm{R} 201 \mathrm{hAIF}_{\Delta 1-101 \text { ox }}$ compared with $\mathrm{WT}$, indi- cating destabilization of the redox active center. To test the structural impact of this mutation, we have produced a $\Delta \mathrm{R} 201 \mathrm{hAIF}_{\Delta 1-101 \text { ox }}$ homology model. Our equilibration routine courses with an overall structure relaxation that was not observed in the WT case, whereas the organization of this structure is maintained in the MD runs to optimize the system (Fig. 4, Supplementary Fig. S4 and S5). Thus, this $\Delta$ R201 $<$ F4 model predicts important structural and dynamic rearrangements at the oxidoreductase domain, in agreement with R201 defining the $\beta$-hairpin length and interactions. These rearrangements alter the network that links the FAD cofactor, the active site residues, the central $\beta$-strand, the apoptotic domain, the C-loop, and the $\beta$-hairpin itself (Fig. 4, Supplementary Fig. S4 and S5). Increases in radius of gyration, size and number of protein internal cavities, and molecular and
A

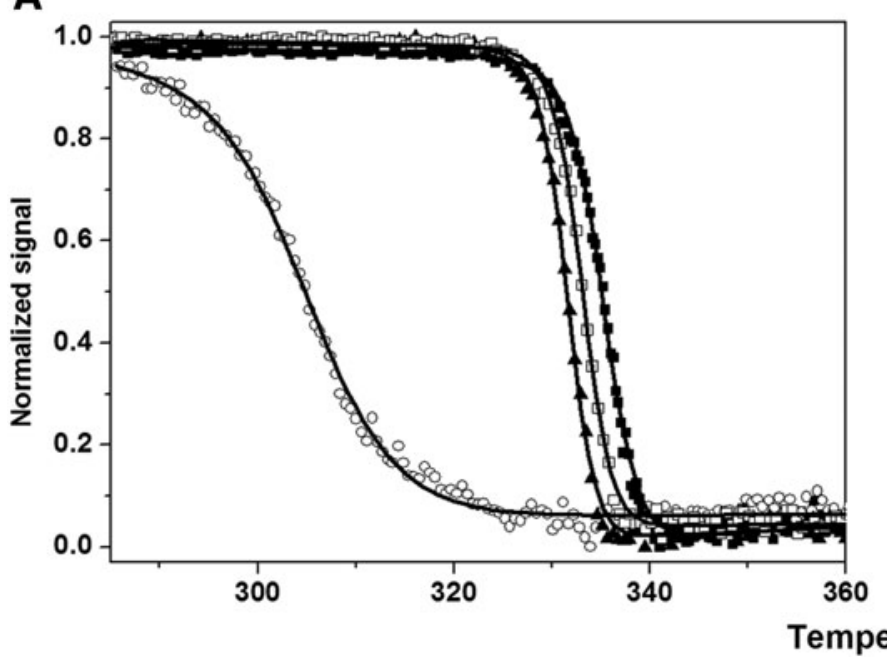

B

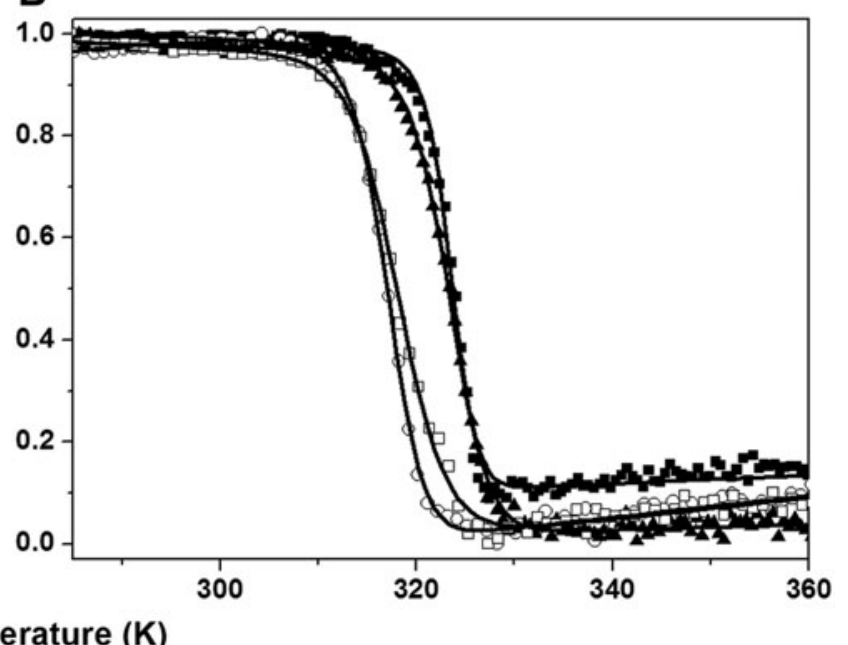

FIG. 3. Effect of $\triangle \mathrm{R201A}$, G308E, and $\mathrm{E} 493 \mathrm{~V} \mathrm{hAIF}_{\Delta 1-101}$ pathogenic mutations on the temperature for FAD

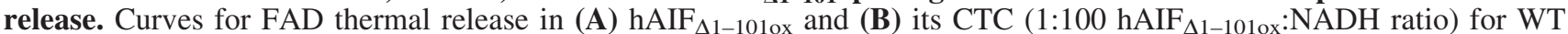
(black squares), $\Delta \mathrm{R} 201$ (open circles), G308E (black triangles), and E493V (open squares), as monitored by flavin fluorescence emission. The curves are shown roughly normalized from 0 to 1 , and the fit to a two-state unfolding model is represented by the continuous lines. Data were obtained in $50 \mathrm{~m} M$ potassium phosphate, $\mathrm{pH}$ 8.0, at a final ionic strength of $150 \mathrm{~m} M$. Protein concentration was $\sim 2 \mu M$. WT, wild type. 
Table 3. Effect of $\Delta$ R201, G308E, and E493V hAIF ${ }_{\Delta 1-101}$ Mutations on the Thermal Stability of HAIF ${ }_{\Delta 1-1010 x}$ AND of Its Charge Transfer Complex

\begin{tabular}{|c|c|c|c|c|c|c|c|c|c|c|}
\hline & \multicolumn{4}{|c|}{$h A I F_{\Delta 1-1010 x}$} & \multicolumn{4}{|c|}{$C T C\left(h A I F_{\Delta 1-101 r d}: N A D^{+}\right)$} & \multirow[b]{2}{*}{$\mathrm{T}_{\mathrm{m} 1 \mathrm{CTC}}-\mathrm{T}_{\mathrm{m} 1}$} & \multirow[b]{2}{*}{$\mathrm{T}_{\mathrm{m} 1 \mathrm{CTC}}-\mathrm{T}_{\mathrm{m} 2}$} \\
\hline & $T_{m I}(K)$ & $T_{m 2}(K)$ & $\begin{array}{c}\Delta H_{1} \\
(\mathrm{kcal} / \mathrm{mol})\end{array}$ & $\begin{array}{c}\Delta \mathrm{H}_{2} \\
(\mathrm{kcal} / \mathrm{mol})\end{array}$ & $\begin{array}{c}T_{m 1 C T C} \\
(K)\end{array}$ & $\begin{array}{c}T_{m 2 C T C} \\
(K)\end{array}$ & $\begin{array}{c}\triangle H_{1 C T C} \\
(\mathrm{kcal} / \mathrm{mol})\end{array}$ & $\begin{array}{c}\Delta H_{2 C T C} \\
(\mathrm{kcal} / \mathrm{mol})\end{array}$ & & \\
\hline WT & $332 \pm 1$ & $337 \pm 1$ & $87 \pm 6$ & $140 \pm 1$ & $324 \pm 1$ & & $120 \pm 10$ & & $-8 \pm 2$ & $-13 \pm 2$ \\
\hline$\Delta \mathrm{R} 201$ & $304 \pm 1^{\mathrm{a}}$ & $312 \pm 1$ & $64 \pm 9^{a}$ & $98 \pm 9$ & $316 \pm 1$ & $338 \pm 1$ & $93 \pm 8$ & $37 \pm 6$ & $12 \pm 2$ & $4 \pm 2$ \\
\hline G308E & $328 \pm 1$ & $332 \pm 1^{a}$ & $130 \pm 10$ & $160 \pm 20^{\mathrm{a}}$ & $323 \pm 1$ & & $140 \pm 10$ & & $-5 \pm 2$ & $-9 \pm 2$ \\
\hline E493V & $329 \pm 1$ & $334 \pm 1$ & $150 \pm 10$ & $180 \pm 10$ & $318 \pm 1^{b}$ & & $85 \pm 4$ & & $-11 \pm 2$ & $-16 \pm 2$ \\
\hline
\end{tabular}

Data were obtained by global fitting of the near-CD, far-UV CD, and fluorescence thermal denaturation curves to two or three species unfolding mechanisms. Data were obtained in $50 \mathrm{~m} M$ potassium phosphate, $\mathrm{pH} 8.0$, at a final ionic strength of $150 \mathrm{~m} M$, from 283.15 to $363.15 \mathrm{~K}$. Protein concentrations were $\sim 1 \mu M$, $\sim 2 \mu M$, and $\sim 20 \mu M$ for far-UV CD, fluorescence, and near-UV CD, respectively. ( $n=3$, $\pm \mathrm{SD})$.

${ }^{\mathrm{a}}$ Data revealed by the FAD fluorescence denaturation curve.

${ }^{b}$ Data revealed by the far-UV and FAD fluorescence denaturation curves. Denaturation curve in the vis at $420 \mathrm{~nm}$ shows a $\mathrm{T}_{\mathrm{m}}$ of $329 \pm 1$ and $\Delta \mathrm{H}$ of $150 \pm 10$

solvent accessible surface areas are also predicted (Fig. 4 and Supplementary Fig. S4F), as well as a considerable reduction in the number of internal H-bonds (Supplementary Fig. S5E). Such facts agree with increased susceptibility to proteolytic cleavage and partial FAD loss (22). Therefore, lack of R201 is expected to prevent the $\beta$-hairpin-C-loop interaction, to destabilize the 529-533 helix and to release R529 from its stacking to W196. As a consequence, FAD binding debilitates (Fig. 4G), and the active site and C-terminal loop of the oxidoreductase domain lose compactness. Such hypothesis agrees with $\Delta$ R201 unfolding data relative to the WT (earlier flavin release, lower conformational stability and unfolding enthalpies, and less structured active site). The effects of G308E and E493V mutations on denaturation profiles and on $\mathrm{T}_{\mathrm{m}}$ values are milder $\left(3-5^{\circ} \mathrm{C}\right.$ decreases) (Table 3 and Supplementary Fig. S8B, C). Nevertheless, an increasing contribution of the secondary structure of G308E to the $\mathrm{N} \rightarrow \mathrm{I}$ transition suggests that in this variant the isoalloxazine environment might be the region that unfolds the last (Supplementary Fig. S8B).

All, but particularly $\Delta$ R201 and E493V CTCs, are less stable than the WT CTC (Table 3 and Supplementary Fig. S8D-F). Formation of G308E and E493V CTCs decreases protein stability, and $\mathrm{E} 493 \mathrm{~V}$ vis-CD data also suggest aggregation upon denaturation. On the contrary, although the $\triangle \mathrm{R} 201 \mathrm{CTC}$ is still considerably less stable than the WT CTC, thermal stabilization is observed when compared with its oxidized state, with some secondary and tertiary interactions remaining after flavin release (Supplementary Fig. S8B). Thus, NADH binding and flavin reduction favor the $\Delta \mathrm{R} 201$-folded state. This suggests that $\mathrm{NAD}^{+}$makes the active site more compact, stabilizing the overall structure and, particularly, the FAD site. In agreement, our predicted structural $\Delta \mathrm{R} 201 \mathrm{CTC}$ model was considerably more compact than the oxidized model (Fig. 4, Supplementary Figs. S4 and S5). Thus, the CTC shifts the $\Delta$ R201 conformational equilibrium to a more structured ensemble than that of the oxidized state.

Finally, the $\Delta \mathrm{R} 201$ variant also decreases unfolding enthalpy relative to the WT, consistent with the mutant being less structured. On the contrary, the higher unfolding enthalpies of G308E and E493V hAIF ${ }_{\Delta 1-101 \text { ox }}$, and G308E CTC might relate to them being more prone to aggregate on un- folding. The decreased E493V CTC enthalpy suggests that this form might be less structured, in agreement with its modestly lower $\mathrm{T}_{\mathrm{mCTC}}$.

\section{HTS allowed the identification of molecules potentially binding $h A I F_{\triangle 1-101}$}

Since fluorescence changes along thermal denaturation allow evaluating $\mathrm{hAIF}_{\Delta 1-101}$ stability, displacements in $\mathrm{T}_{\mathrm{mFAD}}$ induced by different molecules appear a feasible approach to identify ligands in HTS plate assays (13). We have used NADH (the hAIF coenzyme), the NAD ${ }^{+}$product, and ATA [described to interact with hAIF ox (11)] as controls to optimize the method. In agreement with previous sections, incubation of $\mathrm{hAIF}_{\Delta 1-1010 \mathrm{x}}$ in a well plate with NADH excess diminishes $\mathrm{T}_{\mathrm{mFAD}}$ by $14^{\circ} \mathrm{C} \pm 0.5^{\circ} \mathrm{C}\left(\Delta \mathrm{T}_{\mathrm{mFAD}}\right)$ (Fig. $\left.5 \mathrm{~A}\right)$. No $<\mathrm{F} 5$ dose-dependent response curve is observed, possibly because of formation of (i) the CTC and (ii) the monomer-dimer transition. Incubation with $\mathrm{NAD}^{+}$has no effect on $\mathrm{T}_{\mathrm{mFAD}}$, consistent with its low affinity for $\mathrm{hAIF}_{\mathrm{ox}}$ (18). ATA decreases $\mathrm{T}_{\mathrm{mFAD}}$ similarly to $\mathrm{NADH}$, induces quenching of flavin fluorescence, and produces a dose-response curve (Supplementary Fig. S9) that allows estimating a $K_{\mathrm{d}}{ }^{\text {ATA }}$ of 4 SF9 $10 \pm 4 \mu M$ (in the range of that reported by isothermal titration calorimetry (ITC), $19 \pm 5 \mu M$ (11)). Therefore, NADH and ATA produce a ligand-induced perturbation consistent with binding and $\mathrm{hAIF}_{\Delta 1-101}$ destabilization (Fig. 5A).

Based on these results, we have screened for compounds potentially binding $\mathrm{hAIF}_{\Delta 1-1010 x}$ using the HitFinder Collection (Maybridge) and the Prestwick Chemical Library (Prestwick Chemical). Our assessment method identifies as hits those compounds that shift the $\mathrm{T}_{\mathrm{mFAD}}$ more than $3^{\circ} \mathrm{C}$ in the same direction by both "midpoint of unfolding" and "inflection point location" methods $(13,68)$. Most of the assayed compounds do not alter $\mathrm{T}_{\mathrm{mFAD}}$, a few compounds increase it by one evaluation method, and a few more compounds shift it to lower values (Supplementary Fig. S10). We have not found any compound $\varangle$ SF10 increasing $\mathrm{T}_{\mathrm{mFAD}}$ more than $3^{\circ} \mathrm{C}$ by both evaluation methods. However, we have identified 11 compounds $(\mathrm{C} 1$ to $\mathrm{C} 11)$ shifting $\mathrm{T}_{\mathrm{mFAD}}$ between $-3^{\circ} \mathrm{C}$ and $-23^{\circ} \mathrm{C}$ by both methods (Fig. $5 \mathrm{~B}$ and Supplementary Table S1), which might be postulated as hAIF 4 ST1 binders. However, other phenomena, such as protein chemical denaturation or aggregation, might be implicated in $\mathrm{T}_{\mathrm{mFAD}}$ 
A
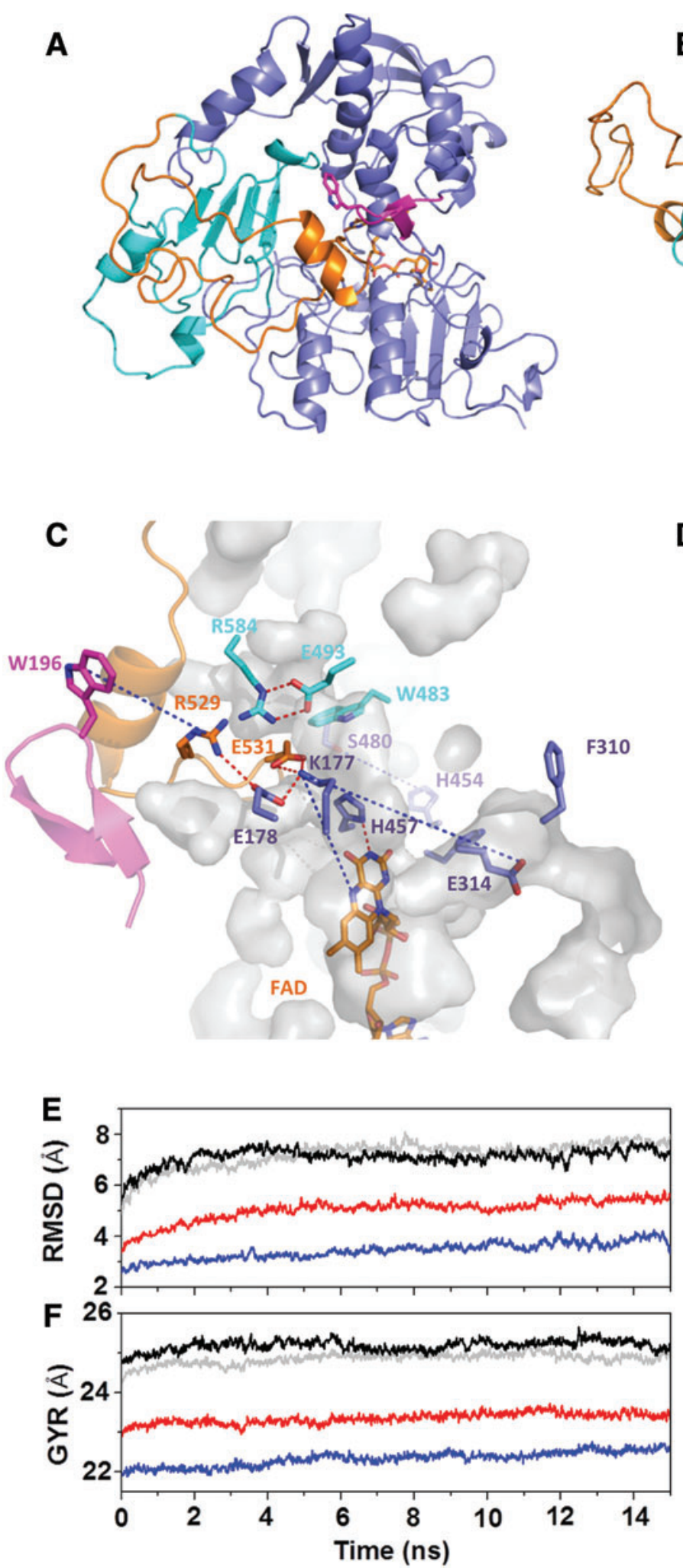

B

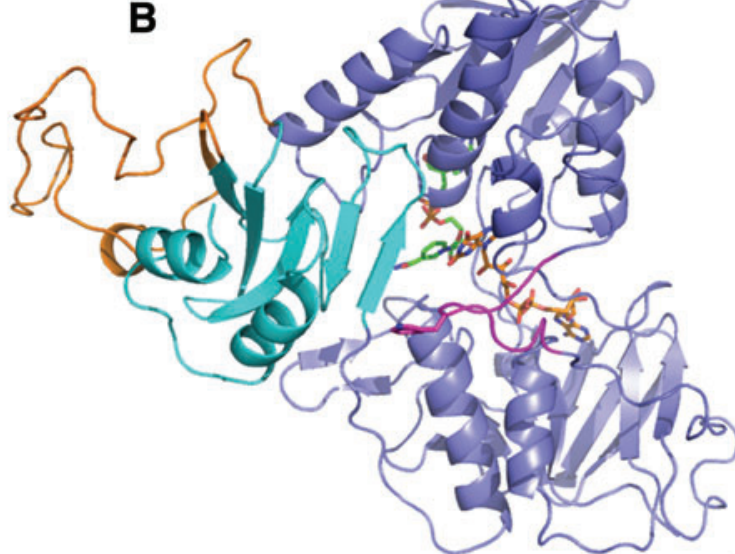

D

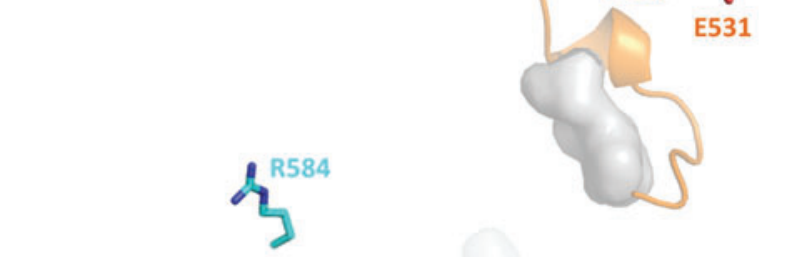

FIG. 4. Predicted hAIF ${ }_{\text {1-101ox }}$ conformational changes by R201 deletion. Overall representative structural models for (A) $\Delta \mathrm{R} 201 \mathrm{hAIF}_{\Delta 1-101 \mathrm{ox}}$ and (B) its CTC after modeling of the missing C-loop residues and deletion of R201, minimization, and $15 \mathrm{~ns}$ of MD relaxation at $300 \mathrm{~K}$. Protein chain is represented as cartoon with the oxidoreductase domains in violet and its 191$202 \beta$-hairpin in hot pink (R201 and W196 side chains shown in sticks), and the apoptotic domain in light blue with the C-loop (509-560 segment) in orange. FAD is shown in sticks with orange carbons. Active site environment in (C) $\Delta \mathrm{R} 201 \mathrm{hAIF}_{\Delta 1-1010 x}$

AU10 and (D) its CTC. Relevant residues are shown in sticks. Relevant interactions in the WT model are shown in blue dashed lines, whereas the $\Delta$ R201 structures also shown in blue the increase of the corresponding WT distances and in red dashed lines new interactions. Gray surfaces show water accessible cavities in the active site environment. (E) RMSD (C $\alpha)$ of $\Delta \mathrm{R}_{201} \mathrm{hAIF}_{\Delta 1-}$ $1010 x$ (gray line) and its CTCs (black line) models along MD when overlapped on their corresponding modeled structures before minimization. (F) Radius of gyration of $\triangle \mathrm{R} 201 \mathrm{hAIF}_{\Delta 1-101 \text { ox }}$ (gray line) and its CTCs along the MD. (G) Position of FAD (C in orange) in five replicas after applying the minimization routine to the $\Delta \mathrm{R} 201 \mathrm{hAIF}_{\Delta 1-101 \text { ox }}$ homology model, relative to the FAD position in the initial homology modeling (FAD with $\mathbf{C}$ in green) and in the template (4bv6, $\mathbf{C}$ in blue). To see this illustration in color, the reader is referred to the web version of this article at www.liebertpub.com/ars 

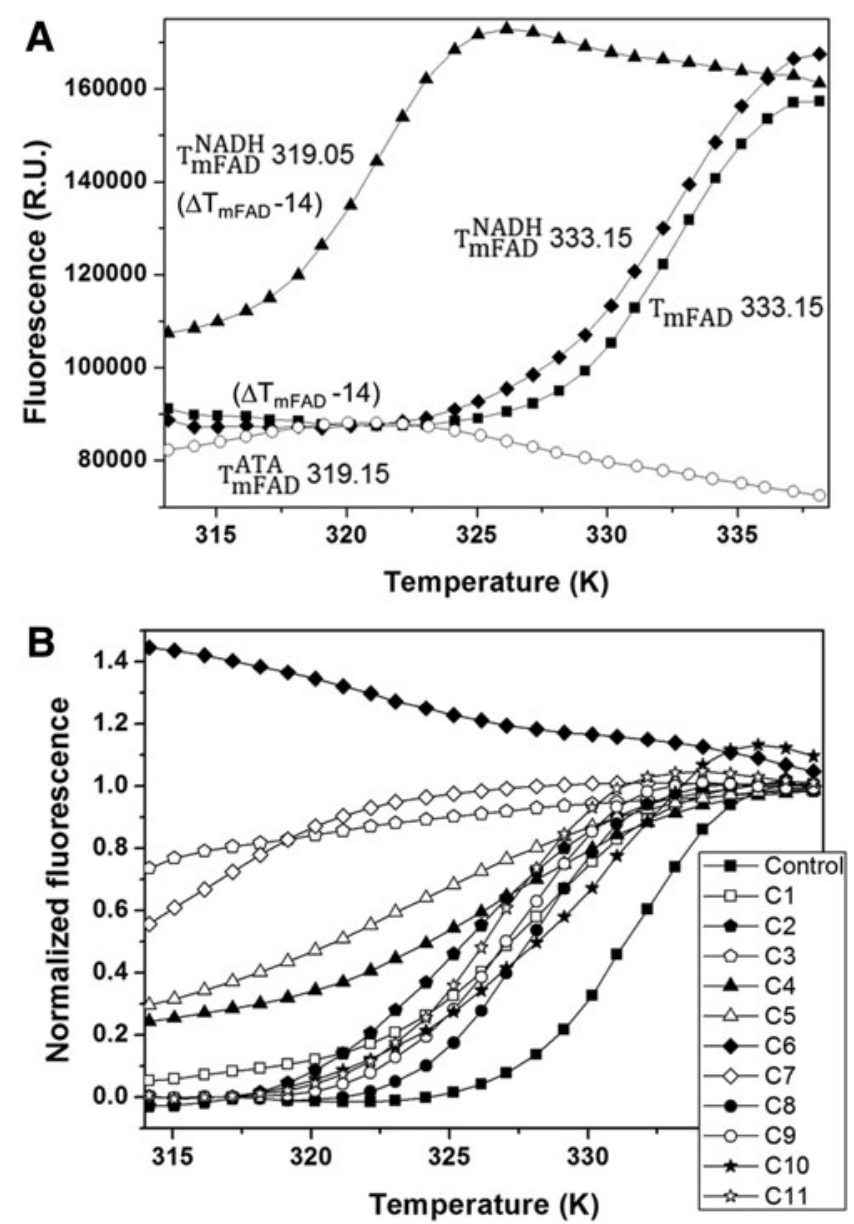

FIG. 5. Effect of binders in the thermal stability of hAIF $_{\Delta 1-101}$. (A) FAD fluorescence unfolding curves in samples containing $\mathrm{hAIF}_{\Delta 1-1010 \mathrm{x}}$ in the absence of ligands $(\boldsymbol{\square})$, and in the presence of $100 \mu M$ NADH ( $\mathbf{\Delta}), 100 \mu M$ $\mathrm{NAD}^{+}(\diamond)$, and $500 \mu \mathrm{M}$ ATA $(\mathrm{O})$. (B) FAD fluorescence unfolding curves in samples containing each of the 11 compounds selected by HTS as potential $\mathrm{hAIF}_{\Delta 1-101}$ binders. hAIF ${ }_{\Delta 1-101 \text { ox }}$ samples incubated with $500 \mu M$ of $\mathrm{C} 1, \mathrm{C} 2$, $\mathrm{C} 3, \mathrm{C} 4$, or C5, or with $100 \mu \mathrm{M}$ of C6, C7, C8, C9, C10, or C11 respectively, showed shifts in $\mathrm{T}_{\mathrm{mFAD}}$ of $-3.0 \pm 0.6$, $-5.0 \pm 0.1,-20 \pm 1,-3.0 \pm 0.6,-5.0 \pm 0.1,-23 \pm 3,-14 \pm 1$, $-5.0 \pm 0.1,-5.0 \pm 0.6,-6.0 \pm 0.3$, and $-6.0 \pm 0.1^{\circ} \mathrm{C}$ respectively. In all cases, $1 \mu M$ hAIF $_{\Delta 1-101}$ was placed on each well of 96-well plates together with the ligands, and the changes in fluorescence emission at $530 \mathrm{~nm}$ (excitation at $450 \mathrm{~nm}$ ) were followed during an increasing temperature ramp. Figure shows roughly normalized flavin fluorescence. The experiments were carried out in $50 \mathrm{~m} M$ potassium phosphate, $\mathrm{pH}$ 8.0.

shifts. Six compounds $(\mathrm{C} 1, \mathrm{C} 2, \mathrm{C} 5, \mathrm{C} 8, \mathrm{C} 9$, and $\mathrm{C} 11)$ out of the 11 produce a dose-response $\Delta \mathrm{T}_{\mathrm{mFAD}}$ indicative of binding, postulating an affinity ranking $\mathrm{C} 8 \approx \mathrm{C} 11 \approx \mathrm{C} 5 \approx \mathrm{C} 9>\mathrm{C} 1 \gg>>\mathrm{C} 2$ ( $K_{\mathrm{d}}$ values in the 3-200 $\mu M$ range).

\section{Effect of HTS hits on cellular viability}

Human HeLa cells have been exposed to a range of concentrations of these HTS hits. C1 (up to $1 \mathrm{mM}$ ) has no effect on cell viability. For the rest, we observe sigmoidal decreases in cell viability with increasing concentrations, which allow determining the compound concentration for $50 \%$ cell viability $\left(\mathrm{EC}_{50}\right)$ (Supplementary Fig. S11). The toxicity ranges $\varangle$ SF11 for our HTS hits vary, $\mathrm{C} 9$ and $\mathrm{C} 8$ being the more toxic $\left(\mathrm{EC}_{50}\right.$, $1.3 \pm 0.1$ and $15 \pm 3 \mu M$ respectively), C5 producing an intermediate effect $(112 \pm 14 \mu M)$, and $\mathrm{C} 11$ and $\mathrm{C} 2$ being the less toxic compounds $(279 \pm 10$ and $684 \pm 45 \mu M$, respectively). It is worthy to mention that $\mathrm{C} 9$ contains some pan assay interference compound groups and $\mathrm{C} 8$ produces protein precipitation.

To evaluate whether binding of HTS hits to hAIF might have a protective effect against AIF-dependent PCD, we have also incubated HeLa cells with C1, C2, C5, C8, C9, and C11 for 24 hours, and then added $\mathrm{N}$-methyl- $\mathrm{N}^{\prime}$-nitrosoguanidine (MNNG), an alkylating agent that provokes AIF-dependent PCD (9). After 24 hours of MNNG treatment, loss of cell 4 AU6 viability reaches $\sim 100 \%$, independently on the HTS hits absence or presence. Hence, hits fail to prevent AIF-induced PCD.

Effects of selected HTS hits on the molecular and redox properties of $h A I F_{\Delta 1-101}$

Based on the $\Delta \mathrm{T}_{\mathrm{mFAD}}$ and cell viability effects, we have selected $\mathrm{C} 2$ and $\mathrm{C} 11$, and included in addition ATA [only producing a slight effect on macrophage cell viability after 24 hours $(31,65)$ ], to comparatively evaluate their influence on the molecular and redox $\mathrm{hAIF}_{\Delta 1-101}$ properties. $\mathrm{C} 2$ and C11 do not affect the $\mathrm{hAIF}_{\Delta 1-101 \text { ox }}$ visible spectrum, whereas hAIF $_{\Delta 1-101 \text { ox }}$ mixing with ATA shows a spectrum combining

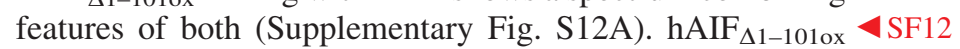
far-UV CD spectra suggest no major ATA effects on secondary structure (Supplementary Fig. S12B), whereas the spectra with $\mathrm{C} 2$ and $\mathrm{C} 11$ cannot be recorded due to their low solubility in the absence of dimethyl sulfoxide (DMSO). C2 and particularly ATA induce large changes in the $\mathrm{hAIF}_{\Delta 1-}$ 1010x near-UV/vis CD (Supplementary Fig. S12C): both preventing detection of the $\sim 300 \mathrm{~nm}$ peak [as in the CTC, Fig. 1D)] and ATA also decreasing the flavin signal intensity. ATA also produces noticeable effects in $\mathrm{hAIF}_{\Delta 1-101 \text { ox }}$ fluorescence, dominating the spectrum (broad peak centered at $\sim 440 \mathrm{~nm}$ that increases fluorescence yield in the presence of protein) and eliminating tryptophan emission (Supplementary Fig. S12D). Such observations indicate quenching of tryptophan fluorescence by energy transfer to ATA. C2 also quenches tryptophan fluorescence, whereas the effect of $\mathrm{C} 11$ is milder. Therefore, binding of ATA or C2 affects the environment of one or several tryptophan residues. Finally, ATA slightly increases flavin fluorescence, suggesting an effect on the $\mathrm{hAIF}_{\Delta 1-101 \text { ox }}$ isoalloxazine environment (Supplementary Fig. S12E).

We have intended to evaluate affinity of $\mathrm{hAIF}_{\Delta 1-101 \mathrm{ox}}$ for each of these compounds by ITC and by difference spectroscopy, but the high amounts of ligands required to detect interaction make impossible such determination and indicate low interaction enthalpy. ATA also decreases $\mathrm{hAIF}_{\Delta 1-101 \mathrm{ox}}$ stability, while $\mathrm{C} 2$ and $\mathrm{C} 11$ change, in addition the unfolding mechanism to a two-species mechanism and $\mathrm{C} 2$ apparently stabilizes some structure after flavin release (Fig. 6A-C and $<$ F6 Supplementary Table S2). We have also evaluated potential binding modes of these compounds by protein-ligand docking simulations, since attempts to cocrystallize failed. Our 
A

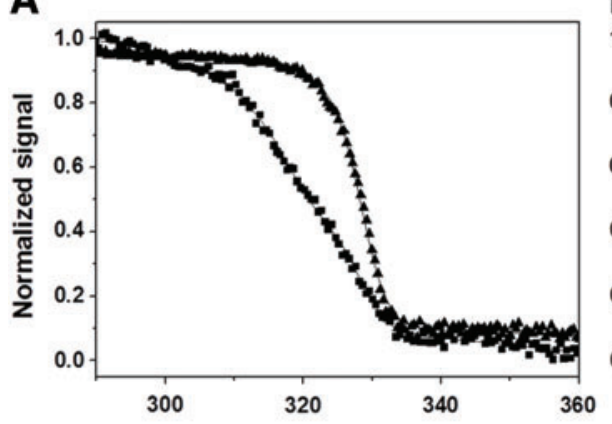

B

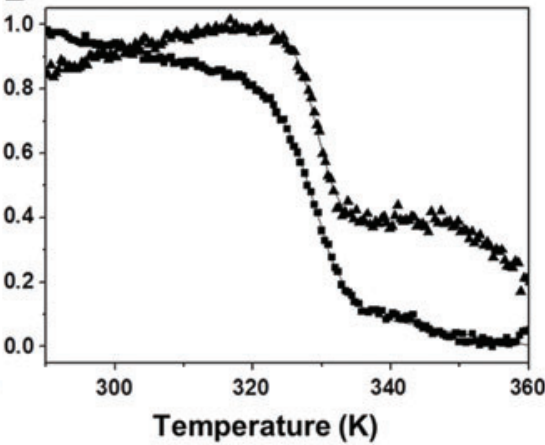

C

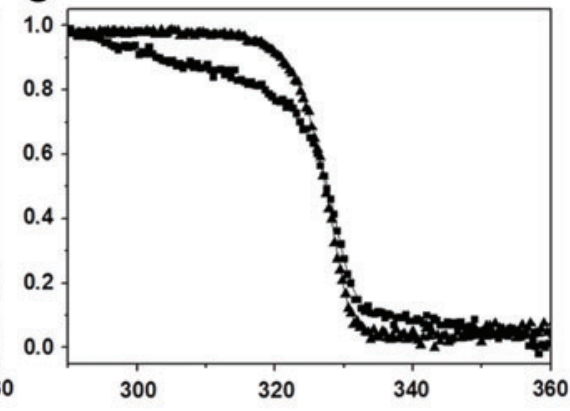

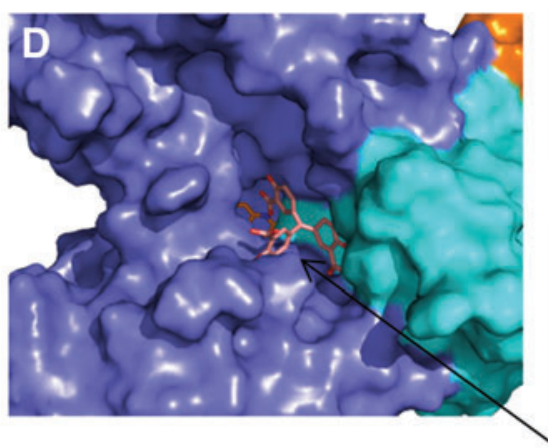
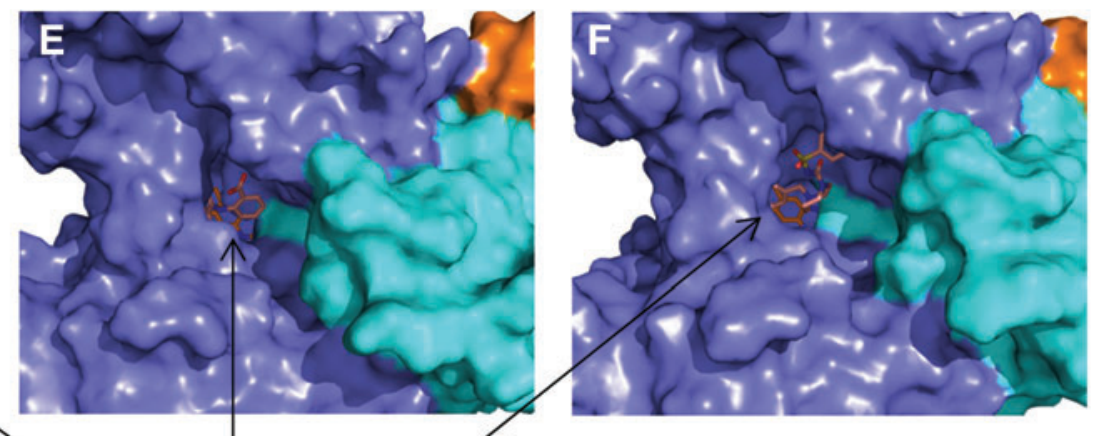

Redox NADH binding channel

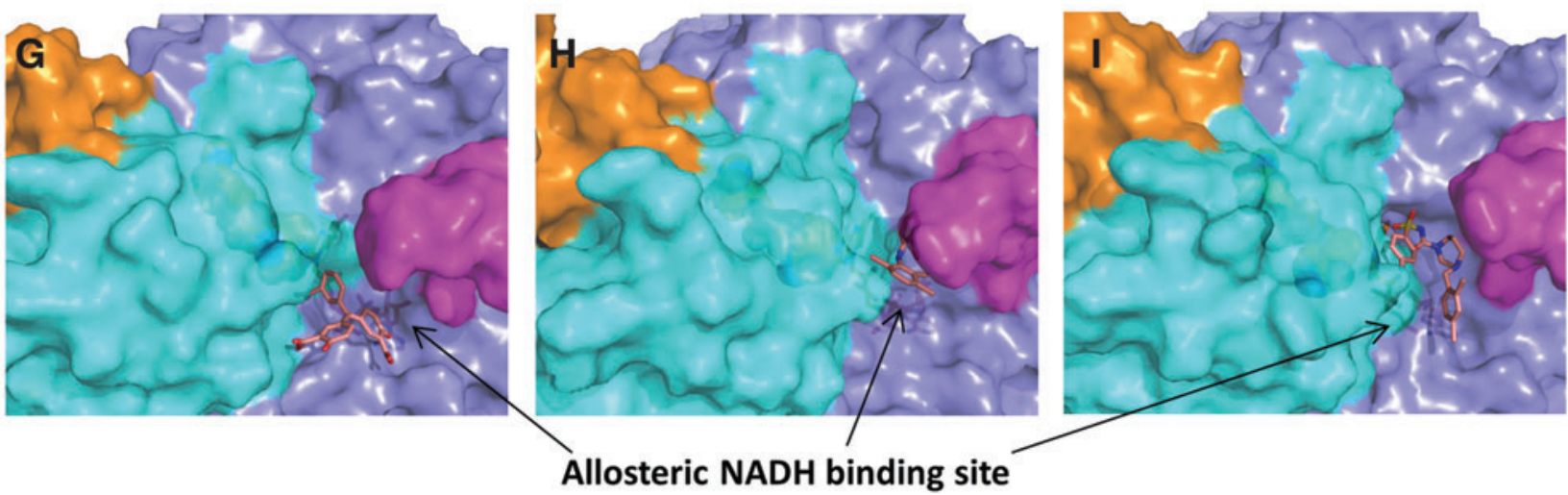

FIG. 6. Effect of selected HTS hits on $\mathbf{h A I F}_{\Delta 1-1010 x}$ thermal unfolding and predicted binding modes. Thermal denaturation of $\mathrm{hAIF}_{A 1-1010 x}$ in the presence of (A) ATA, (B) C2, and (C) C11 was monitored by near-UV CD (300 nm, black squares), and flavin fluorescence emission (black triangles). The curves are shown roughly normalized from 0 to 1 , and their global fits to a two-transition (ATA) or one-transition (C2, C11) unfolding model are represented by the continuous lines. Curves were recorded in $50 \mathrm{~m} M$ potassium phosphate, $\mathrm{pH} 8.0$, at a final ionic strength of $150 \mathrm{~m} M$ in the presence of $500 \mu M$ of each compound. Models for the best docking pose of (D) ATA, (E) C2, and (F) C11 to the hAIF L1- $_{-}$ 101 ox receptor and of $(\mathbf{G}) \mathrm{ATA},(\mathbf{H}) \mathrm{C} 2$, and (I) $\mathrm{C} 11$ to the $\mathrm{hAIF}_{\Delta 1-101 \mathrm{rd}}: \mathrm{NAD}^{+}$receptor. Models were optimized by minimization and short MD equilibration routines. ATA, C2, and $\mathrm{C} 11$ are shown in pink CPK sticks. Other color codes are as in Figure 2. ATA, aurintricarboxylic acid. To see this illustration in color, the reader is referred to the web version of this article at www.liebertpub.com/ars

Table 4. EFFect of Selected Compounds on the Steady State Kinetic Parameters of The HAIF ${ }_{\Delta 1-101}$ DCPIP DIAPHORASE ACTIVITY

\begin{tabular}{lcccc}
\hline HIT & $\begin{array}{r}{[H I T]} \\
(\mu M)\end{array}$ & $k_{\text {cat }}\left(s^{-1}\right)$ & $K_{m}(\mu M)$ & $k_{\text {cat }} / K_{m}\left(s^{-1} m M^{-1}\right)$ \\
\hline - & & $2.4 \pm 0.1$ & $430 \pm 20$ & $5.6 \pm 0.2$ \\
ATA & 100 & $1.0 \pm 0.1$ & $99 \pm 6$ & $10 \pm 1$ \\
C2 & 500 & $2.1 \pm 0.1$ & $310 \pm 10$ & $6.8 \pm 0.2$ \\
C11 & 100 & $2.1 \pm 0.1$ & $600 \pm 20$ & $3.5 \pm 0.1$ \\
\hline
\end{tabular}

Assays were performed in $50 \mathrm{~m} M$ potassium phosphate, $\mathrm{pH} 8.0$, $1 \%$ DMSO at $25^{\circ} \mathrm{C} .(n=3, \pm \mathrm{SE})$. highest scoring docking clusters point to our three chemicals preferentially locating at the $\mathrm{hAIF}_{\Delta 1-101 \text { ox }}$ redox $\mathrm{NADH}$ substrate binding channel (Fig. 6D-E). On the contrary, the $\mathrm{NADH}$ allosteric site is the preferred site in the CTC structure when the $\mathrm{NAD}^{+}$product occupies the redox binding channel (Fig. 6H, I).

Finally, Table 4 summarizes the effect of ATA, C2, and $4 \mathrm{~T} 4$ $\mathrm{C} 11$ on the $\mathrm{hAIF}_{\Delta 1-101 \mathrm{x}}$ kinetic parameters. ATA increases by nearly twice the $\mathrm{hAIF}_{\Delta 1-101 \mathrm{ox}}$ efficiency to oxidize $\mathrm{NADH}$, apparently by favoring its association. $\mathrm{C} 2$ and $\mathrm{C} 11$ modify enzyme efficiency positively and negatively, respectively, by $25-30 \%$ as a consequence of changes in $K_{\mathrm{m}}{ }^{\mathrm{NADH}}$. Therefore, $\mathrm{C} 2, \mathrm{C} 11$, and particularly ATA modify 
the $\mathrm{hAIF}_{\Delta 1-101}$ catalytic efficiency by modulating the coenzyme association/dissociation equilibrium.

\section{Discussion}

The data here presented prove that the proteolytic processing of hAIF drives its subcellular localization and provides structural plasticity for its adaptation to specific subcellular $\mathrm{pH}$ conditions. The apoptotic $\mathrm{hAIF}_{\Delta 1-101}$ isoform is stable in vitro, able to oxidize $\mathrm{NADH}$, and similarly folded at mitochondrial matrix, cytosol, apoptotic cytosol, and nuclei $\mathrm{pH}$, but is unstable at the IMS $\mathrm{pH}$. Nonetheless, the IMS isoform is a longer protein, $\mathrm{hAIF}_{\Delta 1-54}$, tethered to the inner mitochondrial membrane. Evaluation of its truncated soluble isoform, $\mathrm{hAIF}_{\Delta 1-77}$, confirms that the 77-101 traits stabilize the mitochondrial isoform. Although the $\mathrm{pH}$ impact on hAIF spectroscopic properties is in general mild, changes in the near-UV CD peak are noticeable under different conditions (Fig. 1C, D). In the hAIF ${ }_{\Delta 1-77 \text { ox }}$ and $\Delta \mathrm{R} 201_{\text {ox }}$ forms, this peak differs in shape and intensity, whereas it disappears when the CTC is formed, or when ATA or C2 bind (Fig. 1D, Supplementary Figs. S7C and S12C). Since ATA and C2 are predicted to bind at the WT $\mathrm{hAIF}_{\Delta 1-101 \text { ox }}$ redox $\mathrm{NADH}$ binding site (Fig. 6D, E), we expect induced redoxindependent changes in solvent accessibility of at least one tryptophan when ligands block the NADH channel or when the C-loop is released. The effect of $\mathrm{pH}$ on the $\mathrm{hAIF}_{\Delta 1-101 \text { ox }}$ stability is modest, although the nonphysiological mitochondrial matrix $\mathrm{pH}$ slightly shifts $\mathrm{T}_{\mathrm{m} 1}$ and $\Delta \mathrm{H}_{\mathrm{m} 1}$ (Table 2). hAIF $_{\Delta 1-77 \text { ox }}$ unfolding curves indicate that the 77-101 region stabilizes the active site at $\mathrm{pH} 6.2$, but they also point to other protein regions being more dynamic (Supplementary Fig. S3C, D). The lower stability and lack of I state along $\mathrm{hAIF}_{\Delta 1-101 \mathrm{rd}}: \mathrm{NAD}^{+} \mathrm{CTC}$ unfolding may seem surprising (Fig. 2B), since protein interaction with small ligands generally increases stability due to the coupling of preferential binding to the $\mathrm{N}$ state with unfolding equilibrium $(6,60)$. Nonetheless, differences between these two structures go beyond the simple coenzyme binding. Contrary to hAIF ${ }_{\Delta 1-}$ 101 ox , the CTC structure is a dimer with high flexibility in the regulatory C-loop (18) (with properties of an intrinsically disordered region (70)), lack of contacts between apoptotic and FAD-binding domains, and facilitated access to the flavin (Fig. 2). In this context, the ATA, C2, and C11 destabilizing effect (Fig. 6) indicates that their binding might also induce $\mathrm{C}$-loop release. This suggests that the $\mathrm{T}_{\mathrm{m}}$ decrease induced by these compounds might relate to their preferential binding to partially, or totally, unfolded conformations that become progressively populated along unfolding.

Relationships between the effects of mutations on proteins molecular functional properties and phenotypes manifestations are in general complex, but understanding them is key to improve diseases treatments (59). Destabilizing mutations may impair intracellular stability, function, regulation, and protein-protein interactions simultaneously and to different extents $(21,40)$. Considering the hAIF capacity to interact with several partners that modulate its cellular localization and activities, mutations causing biochemical alterations might differently compromise their in vivo functions. Structural bases of such intracellular interactions are in most cases hardly known, but those involving hAIF C-loop recognition are expected to be redox controlled. $\Delta \mathrm{R} 201$ was the first loss- of-function mutation described in the aifml gene causing progressive mitochondrial encephalomyopathy (22). Our unfolding data and structural models indicate very drastic impacts on $\mathrm{hAIF}_{\Delta 1-101 \mathrm{ox}}$ stability and conformation (Fig. 4 and Supplementary Fig. S8). Break of the R201-E531 salt bridge perturbs various functional sites, confirming the $\beta$ hairpin-C-loop connection as a key element to retain a compact active site (Fig. 4 and Supplementary Fig. S8). The loss of active site compactness affects active site dynamics as well as the AIF allosteric architecture switching (8). This agrees with drastic alterations on the mutant redox properties and with OXPHOS failure playing a major role in the lethal $\triangle \mathrm{R} 201$ phenotypes $(22,50)$. Since the OXPHOS productive AIF-CHCHD4 interaction relies on the entire hAIF structure and is favored in the protein reduced state (25), the conformational stability decrease in the $\Delta \mathrm{R} 201$ redox active center would impact CHCHD4 recognition. Interestingly, formation of the CTC stabilizes the $\Delta$ R201 variant (Figs. 3 and 4).

Differences in the switch to the CTC between WT and $\Delta \mathrm{R} 201$ variants will have major effects on hAIF in vivo redox conformational dynamics, as well as on the interaction networks with other physiological partners. Our models predict conformational changes in the $\Delta \mathrm{R} 201_{\text {ox }}$ variant at the region proposed for Hsp70 recognition, residues 150-268 $(24,37)$, which might modulate hAIF retention in the cytoplasm. Regarding the degradosome: (i) the CypA site in $\mathrm{hAIF}_{\text {ox }}$ is mapped as containing the 370-397 3-stranded $\beta$-sheet (NADH domain) $(16,73)$ that apparently is only slightly altered in our $\Delta \mathrm{R} 201_{\text {ox }}$ model, but not in its CTC model. Since CypA affinity improves in the WT CTC state, a similar effect might be occurring in $\triangle \mathrm{R} 201 \mathrm{CTC}$; (ii) the nuclear $\mathrm{H} 2 \mathrm{AX}$ binds to the 544-554 Pro-rich C-loop motif, flexible in WT and $\Delta$ R201 isoforms $(3,69)$; and (iii) finally, DNA putatively nonspecifically wraps around the FAD and C-terminal domains (71), with the $\Delta \mathrm{R} 201$ mutation apparently increasing its in vitro affinity (22). Nevertheless, considering that H2AX and DNA binding is contributed by the hAIF intrinsically disordered region, with disorder modulating the binding, the impact of $\Delta \mathrm{R} 201$ mutation might be low in the in vivo overall degradosome assembly, in agreement with PCD being hardly affected by this missense mutation. Noticeably, among the studied AIF variants, $\Delta$ R201 is the only one stabilized by coenzyme binding (Fig. 3) and one of the few in which patients supplemented with the FAD riboflavin precursor improved clinical conditions by partially correcting OXPHOS failure (22). Thus, the FAD and NADH natural ligands might $<$ AU7 synergically contribute to in vivo partially overcome the $\Delta$ R201 unfolding negative effect by enhancing protein stability. Such observation has important implications in the search of potential ligands correcting stability and function.

G308E and E493V variants had little effects on $\mathrm{hAIF}_{\Delta 1-101}$ stability. G308E substitution (Supplementary Fig. S6) slows down CTC formation and abolishes the enzyme ability to discriminate between NADH and NADPH $(57,61,62)$. This leads to prenatal OXPHOS-related encephalopathy, muscle atrophy, and early death. G308E oxidized structures (Supplementary Fig. S6) show that Glu308 stabilizes a different Glu336 conformer that modulates the 334-336, 365-370, and 380-388 interaction networks, which agree with its modest differences in stability (Table 3$)(57,61,62)$. In its CTC form, those changes alter the interaction network of the coenzyme adenine moiety and produce its reorientation (62), envisaging 
the possibility of distinct CTC conformers. The G308E mutation causes a severe complex I + IV deficiency and reduced CHCHD4 binding (4). Altogether, the loss of functionality in this variant appears related to the lower accumulation of its CTCs, rather than to an overall conformational stability lost. The E493V mutation enhances hAIF apoptotic activity, but it alters neither the interaction with CHCHD4 nor the respiratory mitochondrial activity (50). Mild changes in stability agree with the mutation having no effect on protein folding or cellular expression. Nevertheless, in vitro this variant has increased propensity to NADH oxidation and CTC reoxidation $(50,57)$, in line with its reduced unfolding enthalpy and aggregation propensity (Table 3). Thus, the E493V mutation would favor the hAIF monomeric form and its nuclear translocation. E493 is not solvent accessible, but assists folding of the regulatory Cloop and contributes to binding of the allosteric NADH. Thus, although the E493V substitution has apparently low impact on the reductase domain, it reduces the CTC dimer stability (18) and makes it less structured than in the WT. This might also have an impact on the allosteric NADH binding and/or C-loop conformation. Since disordered regions and quaternary organizations are involved in signaling, recognition, regulation, or nuclear translocation (70), we can consider that these facts affect the E493V variant interplay with its partners and, in turn, favor its nuclear translocation and DNA degradation.

Considering this, the dynamics of the domain-domain and FAD-protein interactions appear to be key elements in $\mathrm{hAIF}_{\Delta 1-}$ 101ox stabilization. $\mathrm{hAIF}_{\Delta 1-101 \mathrm{ox}}$ and its CTC must be considered very different conformational ensembles from the stability and structural points of view, with the architecture switch toward the CTC producing a less stable and compact protein that contains an intrinsically disordered region. Such mechanisms are contributors to control hAIF physiological actions by either cellular NADH levels or interaction with other biomolecules ( 8 , 70). Altogether, the available information gives a comprehensive picture of stability and local dynamics in aspects of the hAIF function such as the redox-derived allosteric properties and ability to form quaternary assemblies, which will influence the interactions network and the in vivo phenotypes consequence of missense mutations. In this context, the flavin redox state and the coenzyme binding are key elements to modulate hAIF dynamics and C-loop ensembles. Some of these hAIF properties might be also modulated by small ligands, setting a molecular framework to discover molecules able to bind hAIF. These molecules might have a rescuing function of pathogenic variants by shielding deleterious effects on protein stability and ligand recognition, but they might also be modulators of the structural protein plasticity. To date, only ATA has been described as able to bind to AIF, but its promiscuity makes of it a bad drug candidate $(31,65)$. The hits here identified provide a starting point to redesign and open a molecular framework to search for new pharmacological ligands targeting hAIF. Thus, this characterization provides deeper insights into the hAIF conformation as a mechanism to regulate its cellular functions, as well as some of the molecular and cellular pathogenesis associated with its defects.

\section{Materials and Methods}

\section{Proteins production}

hAIF $_{\Delta 1-101}$ samples were expressed in and purified from Escherichia coli as N-terminal $\mathrm{His}_{6}$-tag proteins as previ- ously described (18), introducing an additional chromatography step using a Superdex ${ }^{\mathrm{TM}} 200$ 10/300 GL (GE Health Care, Chicago, IL) column in $50 \mathrm{~m} M$ potassium phosphate (Panreac Aplichem, Barcelona, Spain), pH 8.0, $150 \mathrm{mM}$ sodium chloride (Panreac Aplichem). The purified protein was dialyzed and concentrated (up to $\sim 500 \mu M$ ), and then diluted to the desired concentration in $50 \mathrm{~m} M$ potassium phosphate at the corresponding $\mathrm{pH}, 8.0,7.4,7.0$, or 6.2 , at a final ionic strength of $150 \mathrm{~m} M$ (described as physiological $(12,63)$ ). pET28a-hAIF ${ }_{\Delta 1-101}$ plasmids containing the $\Delta$ R201, G308E, and E493V mutations, as well as pET28a-hAIF ${ }_{\Delta 1-77}$, were obtained from Mutagenex (Suwanee, GA). Several independent purifications of each hAIF variant were used to reproduce experiments, confirming that results are batch independent.

Before the HTS experiments, the $\mathrm{His}_{6}$-tag was removed by adding $0.2 \mathrm{U}$ of thrombin to $1 \mathrm{~mL}$ of $\mathrm{hAIF}_{\Delta 1-101}$ and loading the mixture into a $1 \mathrm{~mL}$ HiTrap Chelating HP column (GE Health Care) activated with $\mathrm{NiSO}_{4}$ (Probus S.A, Badalona, Spain). The column containing the mixture was incubated for 4 hours at room temperature and then overnight at $4{ }^{\circ} \mathrm{C}$. hAIF $_{\Delta 1-101}$ was eluted with $50 \mathrm{~m} M$ potassium phosphate, $\mathrm{pH}$ 8.0. Analytical grade chemicals and buffers were used in the study: NADH/NAD ${ }^{+}$(Sigma-Aldrich, 10107735001/N0632; San Luis, MO), ATA (Sigma-Aldrich; A1895), and DMSO (Sigma-Aldrich; B5879).

\section{Spectroscopic characterization}

UV-visible spectra were recorded at $25^{\circ} \mathrm{C}$ in a Cary 100 Bio (Agilent Technologies, Santa Clara, CA) spectrophotometer. Protein concentrations were determined using the molar absorbance extinction coefficient of the protein $\left(\varepsilon_{450}=\right.$ $13.7 \mathrm{~m} M^{-1} \mathrm{~cm}^{-1}$ ) (18). UV-vis difference spectroscopy measurements were carried out with compartmentalized cuvettes in $50 \mathrm{~m} M$ potassium phosphate, $\mathrm{pH} 8.0$, by titrating $\sim 20 \mu M$ of $\mathrm{hAIF}_{\Delta 1-101}$ with up to $2.9 \mathrm{~m} M$ of ATA. Fluorescence spectra were acquired in a thermostated Cary Eclipse Fluorescence spectrophotometer (Agilent Technologies) using $2 \mu M \mathrm{hAIF}_{\Delta 1-101}$. Protein fluorescence emission spectra were recorded upon excitation at $280 \mathrm{~nm}$, whereas flavin emission was collected after excitation at $450 \mathrm{~nm}$. Circular dichroism (CD) spectra were recorded in a thermostated Chirascan (Applied Photophysics Ltd., Leatherhead, United Kingdom). Far-UV CD spectra were acquired in a $0.1 \mathrm{~cm}$ path length cuvette using $1 \mu M \mathrm{hAIF}_{\Delta 1-101}$, whereas near$\mathrm{UV} / \mathrm{vis} \mathrm{CD}$ spectra were recorded in a $1 \mathrm{~cm}$ path length $\mathrm{cu}-$ vette using $20 \mu \mathrm{M} \mathrm{hAIF}_{\Delta 1-101}$. Fluorescence and CD spectra were acquired at $10^{\circ} \mathrm{C}$ (folded state) and $90^{\circ} \mathrm{C}$ (thermally denatured state), both in the absence and presence of a 100 fold excess of NADH.

\section{Kinetic measurements}

Steady-state kinetic analyses were carried out in a Cary 100 Bio spectrophotometer (Varian) and measured in airsaturated $50 \mathrm{~m} M$ potassium phosphate, $\mathrm{pH}$ 8.0, using NADH (Sigma-Aldrich; 1266615-56-8) and $95 \mu \mathrm{M}$ dichlorophenolindophenol (Sigma-Aldrich) (18). Reactions were followed at $620 \mathrm{~nm}\left(\Delta \varepsilon_{620 \mathrm{~nm}}=21 \mathrm{~m}^{-1} \mathrm{~cm}^{-1}\right)$ and parameters determined by data fitting to the Michaelis-Menten equation. Stopped flow measurements were carried out under aerobic conditions in an SX17.MV spectrometer (Applied 
Photophysics Ltd.) using a photodiode array detector and the Xscan software (18). The observed rates for the hydride transfer $(\mathrm{HT})$ event $\left(k_{\mathrm{obs}}\right)$ were calculated by global analysis and numerical integration methods (using all spectral data in the $400-800 \mathrm{~nm}$ region along time evolution) by fitting to either a single-step $(\mathrm{A} \rightarrow \mathrm{B})$ or a two-step $(\mathrm{A} \rightarrow \mathrm{B} \rightarrow \mathrm{C})$ model. When a saturation profile on NADH concentration was observed, $k_{\mathrm{obs}}$ values were fitted to the $k_{\mathrm{obs}}=k_{\mathrm{HT}} \cdot[\mathrm{S}] /\left(K_{\mathrm{d}}\right.$ $+[S]$ ) equation describing formation of an enzyme-substrate complex before the HT process, where $k_{\mathrm{HT}}$ is the limiting rate constant for HT from the pyridine nucleotide coenzyme to the FAD cofactor of hAIF, and $K_{\mathrm{d}}$ is the hAIF coenzyme dissociation constant.

\section{Thermal denaturation}

Thermal denaturation curves were followed by fluorescence emission of the aromatic residues and the flavin cofactor, far-UV CD, and near-UV/vis CD. Denaturation curves were recorded from $10^{\circ} \mathrm{C}$ to $90^{\circ} \mathrm{C}$ with scan rates of $1{ }^{\circ} \mathrm{C} / \mathrm{min}$ and $1.5^{\circ} \mathrm{C} / \mathrm{min}$, respectively, for $\mathrm{CD}$ and fluorescence assays, both in the absence and presence of a 100-fold excess of NADH (Sigma-Aldrich). hAIF ${ }_{\Delta 1-101}$ concentrations, wavelengths, and path lengths were $1 \mu M, 210$, and $1 \mathrm{~mm}$ in the far-UV CD $(220 \mathrm{~nm}$ when NADH was present); $20 \mu M$, $300 \mathrm{~nm}$, and $1 \mathrm{~cm}$ in the near-UV CD (or 420 and $600 \mathrm{~nm}$ when NADH was present); and $2 \mu M, 530 \mathrm{~nm}$ (excitation at $450 \mathrm{~nm}$ ), and $1 \mathrm{~cm}$ for flavin fluorescence. Unless otherwise stated, the individual experimental data sets were globally analyzed as one-transition process (i.e., two-step process, native $\leftrightarrow$ unfolded, $\mathrm{N} \leftrightarrow \mathrm{U}$ ) or two-transition process (i.e., three-state process, native $\leftrightarrow$ intermediate $\leftrightarrow$ unfolded, $\mathrm{N} \leftrightarrow \mathrm{I} \leftrightarrow \mathrm{U}$ ) by applying the following equations (51):

$$
S_{o b s}=\frac{S_{N}+m_{N} T+\left(S_{U}+m_{U} T\right) e^{-(\Delta G / R T)}}{1+e^{-(\Delta G / R T)}}
$$

folding $(13,19)$, using a FluoDia T70 thermostated plate reader fluorimeter (Photon Technology International, Edison, NJ). The FAD fluorescence emission at $530 \mathrm{~nm}$ (excitation at $450 \mathrm{~nm}$ ) was followed to determine $T_{m}$ for flavin release $\left(\mathrm{T}_{\mathrm{mFAD}}\right)$ of free WT hAIF $\mathrm{Wl}_{\Delta 101}$ and in the presence of known ligands and compounds from two different chemical libraries. A library of $\sim 10,000$ small molecules $(\mathrm{Mw}<500)$ with high chemical diversity, mostly satisfying Lipinski's rules (35) and dissolved at $4 \mathrm{mM}$ in DMSO, was selected from the HitFinder Collection (Maybridge Chemical Company, Altrincham, UK). The Prestwick Chemical Library (Prestwick Chemical, Graffenstaden, France), composed of 1120 compounds dissolved at $10 \mathrm{~m} M$ in DMSO and with known bioavailability and safety in humans, was also screened. The screening of the Maybridge library was performed in two phases (13). In the first phase, three compounds were added per well in 96-well plates, at a final concentration of $100 \mu M$ each, to $1 \mu M$ of WT hAIF W1-101 $_{\text {in }} 50 \mathrm{~m} M$ potassium phosphate buffer, pH 8.0 in a $100 \mu \mathrm{L}$ final volume. The compounds in the positive wells were screened again in a second round by testing each compound individually. The screening of the Prestwick library was carried out in a single step at a final compound concentration of $500 \mu M$ and $1 \mu M$ of WT $\mathrm{hAIF}_{\Delta 1-101}$ in $50 \mathrm{~m} M$ potassium phosphate, $\mathrm{pH} 8.0$ in a $100 \mu \mathrm{L}$ final volume. Internal reference control wells (WT $\mathrm{hAIF}_{\Delta 1-101 \mathrm{ox}}$ without compounds) were distributed on columns 1 and 12 in the plates, with the same concentration of protein and DMSO as the wells containing compounds. The unfolding curves obtained for each well were analyzed using homemade software that estimates the $\mathrm{T}_{\mathrm{mFAD}}$ of each well, using two methods (termed "midpoint of unfolding" and "inflection point location") designed to complement each other and to avoid false positives $(13,68)$. All the HTS hits were subsequently acquired from Sigma Aldrich or Maybridge and dissolved in 100\% DMSO to prepare stock solutions at 50 and $10 \mathrm{mM}$. The purity of all compounds was

$$
S_{o b s}=\frac{S_{N}+m_{N} T+\left(S_{I}+m_{I} T\right) e^{-\left(\Delta G_{1} / R T\right)}+\left(S_{U}+m_{U} T\right) e^{-\left(\left(\Delta G_{1}+\Delta G_{2}\right) / R T\right)}}{1+e^{-\left(\Delta G_{1} / R T\right)}+e^{-\left(\left(\Delta G_{1}+\Delta G_{2}\right) / R T\right)}}
$$

where $S_{\mathrm{obs}}$ is the measured protein signal at a given temperature $(T), S_{N}, S_{I}$, and $S_{U}$ are the signals (origin intercept) of native, intermediate, and unfolded protein conformations at $0 \mathrm{~K}$, respectively, and $\mathrm{m}_{\mathrm{N}}, \mathrm{m}_{\mathrm{I}}$, and $\mathrm{m}_{\mathrm{U}}$ are the slopes of the linear temperature dependence of those signals, respectively. In contrast, the free energy difference in Eq.1 or Eq.2 is as follows: $\quad \Delta G_{i}=\Delta H_{i}\left(1-\frac{1}{T_{i}}\right)+\Delta C_{P i}\left(T-T_{m i}-T \ln \frac{T}{T_{m i}}\right)^{2}$, where $\Delta \mathrm{H}_{\mathrm{i}}$ is the vant Hoff enthalpy for each unfolding transition, $\mathrm{T}_{\mathrm{mi}}$ is the midtransition temperature for each unfolding transition, $\Delta \mathrm{C}_{\mathrm{Pi}}$ is the heat capacity change for each unfolding transition, and $\mathrm{R}$ is the ideal gas constant.

\section{FAD fluorescence-based HTS}

The thermal stability of WT $\mathrm{hAIF}_{\Delta 1-101}$ was monitored on 96-well plates by following FAD fluorescence, which increases upon cofactor dissociation coupled to thermal un-
$>95 \%$, as indicated by the manufacturer by high-performance liquid chromatography, thin layer chromatography, nuclear magnetic resonance, infrared, or basic titration.

\section{Cell viability assays}

Cytotoxicity of the selected compounds was analyzed using HeLa cells cultured in Dulbecco's modified Eagle medium (Pan-Biotech GmbH, Aidenbach, Germany) supplemented with $50 \mathrm{U} / \mathrm{mL}$ penicillin (Pan-Biotech $\mathrm{GmbH}$ ), $50 \mathrm{mg} / \mathrm{mL}$ streptomycin sulfate (Pan Biotech), and $10 \%$ fetal calf serum (Pan-Biotech $\mathrm{GmbH}$ ) at $37^{\circ} \mathrm{C}$ in a $5 \% \mathrm{CO}_{2}$ atmosphere. Cells were cultured in $25 \mathrm{~mL}$ culture flasks and subcultured every 3 days. To test the toxicity of the compounds, HeLa cells were harvested and diluted to 7000 cells per well $(100 \mu \mathrm{L})$ in 96well plates. After incubation for 24 hours, the compounds were added at different concentrations ranging from $5 \mathrm{n} M$ to $1 \mathrm{~m} M$ 
(except $\mathrm{C} 2,50 \mathrm{n} M$ to $10 \mathrm{~m} M$ range). Cell viability after 24 hours of incubation was measured using CellTiter $96^{\circledR}$ $\mathrm{AQ}_{\text {ueous }}$ One Solution Cell Proliferation Assay (Promega, Madison, WI) following modified manufacturer recommendations, and absorbance was recorded at $490 \mathrm{~nm}$ to quantify the amount of formazan produced by the cell metabolism in a Sinergy HT (BioTek, Winooski, VT) plate reader. The values obtained for control wells lacking added compounds but treated with DMSO were considered to reflect $100 \%$ viability. $\mathrm{EC}_{50}$ was calculated for each compound by fitting the viability at the different concentrations of compounds to a sigmoidal dose-response function (38). To test the possible protective effect of the compounds against MNNG-induced cell death, 7000 cells per well were incubated in 96-well plates for 24 hours at $37^{\circ} \mathrm{C}$ and $5 \% \mathrm{CO}_{2}$. Next day, $0.5 \mathrm{mM}$ MNNG (Abcr GmbH AB 138809, Karlsruhe, Germany) was added on each well and the plate was incubated for 20 minutes. Then, the medium was replaced by fresh medium and the cells were incubated for another 24 hours either in the absence or presence of compounds.

\section{Production of structural models}

Models containing the missing C-loop residues (546-558 and $518-559$, respectively, for WT $\mathrm{hAIF}_{\Delta 1-1010 x}$ and $\mathrm{hAIF}_{\Delta 1-101 \mathrm{rd}}: \mathrm{NAD}^{+}$), as well as deletion of R201 in the $\Delta R 201$ variant, were built using as templates the coordinates of WT hAIF ${ }_{\Delta 1-101 \text { ox }}$ (PDB 4bv6) and of hAIF ${ }_{\Delta 1-101 \text { rd }}: \mathrm{NAD}^{+}$ (PDB 4bur) and the Swiss-Model server $(5,18)$. Cofactors or coenzymes were then reintroduced, and $50 \mathrm{ps}$ MD simulations, with Generalized-Born, Molecular Volume solvation (34) and CHARMM c39b1, were carried out to remove potential clashes. Protonation states were assessed using PROPKA 3.0 (46); H131, H457, and H478 were $\varepsilon$-protonated, whereas $\mathrm{H} 454$ and $\mathrm{H} 455$ were $\delta$-protonated. MD simulations were performed using CHARMM c39b1 and the charmm36 force field (7). Parameters for FAD and $\mathrm{FADH}^{-}$and other ligands were generated using the CgenFF server (67) and density functional theory (DFT). DFT calculations were performed with the Gaussian09 rev.D01 package (20) at the B3LYP/def2-SVP+GD3BJ level with a water-like polarizable continuum model $(20,23)$. A Monte Carlo scheme was used for neutralization, adding ions to $150 \mathrm{mM}$. A time step of $1 \mathrm{fs}$, NVT conditions, and a TIP3P water model were used. A standard workflow routine including solvation, neutralization, minimization plus heating, and equilibration for $200 \mathrm{ps}$ was performed to the models, with at least three replicas. Short $15 \mathrm{~ns}$ MD runs were then performed at $298.15 \mathrm{~K}$ to ensure thermodynamic and structural stability. The CHARMM software analysis tools were used to evaluate the resulting conformational ensembles. The GOLD 5.5 software (28) and the produced WT hAIF MD structures were used to obtain interaction models with ATA, C2, and C11. Binding sites were corroborated with the FPocket suite (33). Final docked structures were obtained using default parameters and 100 Genetic Algorithm runs with a consensus docking approach between the ChemPLP and the GoldScore functions. The top ranked pose of the best cluster was then used as the starting point for short MD simulations to refine protein-ligand interactions (Fig. 6D-H). Visual MD (27) and PyMol (14) were used to analyze and to visualize structural data.

\section{Data analysis and statistics}

Data were analyzed and shown in figures using Origin (OriginLab Corp., Northampton, MA) and Pro-K (Applied Photophysics Ltd.). Results are expressed as the mean \pm the standard deviation (SD) or as the mean \pm the standard error (SE). Chemical structures of the compounds were drawn using ChemDraw Professional 16 (PerkinElmer Informatics, Cambridge, MA). The FAF-Drug3 web server was used to identify putative pan assay interference compounds (32). The Molinspiration web server (www.molinspiration.com) was used to calculate theoretical $\log P$ values of Prestwick chemical library compounds and ATA. Corresponding values for compounds from the Maybridge chemical library were obtained from the collection database.

\section{Acknowledgments}

This work was supported by the Spanish Ministry of Economy, Industry and Competitiveness (MINECO) [BIO201675183-P AEI/FEDER, UE to M.M.; BFU2016-78231-P to J.S. \& A.V.-C.], and the Government of Aragón-FEDER [Grupos de Referencia Biología Estructural (E35_17R), and Protein Targets and Bioactive Compounds (E45_17R)]. A.V-C. thanks ARAID for financial support.

\section{Authors' Contributions}

P.F. and M.M. designed the research; R.V., S.R.-T., R.L, and A.V.-C. performed research and acquired the data; R.V., R.L, J.M.-O., A.V.-C., J.S., P.F., and M.M. analyzed data; and R.V., P.F., and M.M. wrote the article.

\section{Author Disclosure Statement}

No competing financial interests exist.

\section{References}

1. Ardissone A, Piscosquito G, Legati A, Langella T, Lamantea E, Garavaglia B, Salsano E, Farina L, Moroni I, Pareyson D, and Ghezzi D. A slowly progressive mitochondrial encephalomyopathy widens the spectrum of AIFM1 disorders. Neurology 84: 2193-2195, 2015.

2. Artus C, Boujrad H, Bouharrour A, Brunelle MN, Hoos S, Yuste VJ, Lenormand P, Rousselle JC, Namane A, England $\mathrm{P}$, Lorenzo HK, and Susin SA. AIF promotes chromatinolysis and caspase-independent programmed necrosis by interacting with histone H2AX. EMBO J 29: 1585-1599, 2010.

3. Baritaud M, Boujrad H, Lorenzo HK, Krantic S, and Susin SA. Histone H2AX: The missing link in AIF-mediated caspase-independent programmed necrosis. Cell Cycle 9: 3166-3173, 2010.

4. Berger I, Ben-Neriah Z, Dor-Wolman T, Shaag A, Saada A, Zenvirt S, Raas-Rothschild A, Nadjari M, Kaestner KH, and Elpeleg O. Early prenatal ventriculomegaly due to an AIFM1 mutation identified by linkage analysis and whole exome sequencing. Mol Genet Metab 104: 517-520, 2011.

5. Biasini M, Bienert S, Waterhouse A, Arnold K, Studer G, Schmidt T, Kiefer F, Gallo Cassarino T, Bertoni M, Bordoli L, and Schwede T. SWISS-MODEL: modelling protein tertiary and quaternary structure using evolutionary information. Nucleic Acids Res 42: W252-W258, 2014. 
6. Brandts JF and Lin LN. Study of strong to ultratight protein interactions using differential scanning calorimetry. Biochemistry 29: 6927-6940, 1990.

7. Brooks BR, Brooks CL, Mackerell AD, Nilsson L, Petrella RJ, Roux B, Won Y, Archontis G, Bartels C, Boresch S, Caflisch A, Caves L, Cui Q, Dinner AR, Feig M, Fischer S, Gao J, Hodoscek M, Im W, Kuczera K, Lazaridis T, Ma J, Ovchinnikov V, Paci E, Pastor RW, Post CB, Pu JZ, Schaefer M, Tidor B, Venable RM, Woodcock HL, Wu X, Yang W, York DM, and Karplus M. CHARMM: the biomolecular simulation program. J Comput Chem 30: 15451614, 2009.

8. Brosey CA, Ho C, Long WZ, Singh S, Burnett K, Hura GL, Nix JC, Bowman GR, Ellenberger T, and Tainer JA, 2016. Defining NADH-driven allostery regulating apoptosisinducing factor. Structure 24: 2067-2079, 2016.

9. Cabon L, Galán-Malo P, Bouharrour A, Delavallée L, Brunelle-Navas MN, Lorenzo HK, Gross A, and Susin SA. BID regulates AIF-mediated caspase-independent necroptosis by promoting BAX activation. Cell Death Differ 19: 245-256, 2012.

10. Candé C, Vahsen N, Kouranti I, Schmitt E, Daugas E, Spahr C, Luban J, Kroemer RT, Giordanetto F, Garrido C, Penninger JM, and Kroemer G. AIF and cyclophilin A cooperate in apoptosis-associated chromatinolysis. Oncogene 23: 1514-1521, 2004.

11. Chan LL, Pineda M, Heeres JT, Hergenrother PJ, and Cunningham BT. A general method for discovering inhibitors of protein-DNA interactions using photonic crystal biosensors. ACS Chem Biol 3: 437-448, 2008.

12. Cortese JD, Voglino AL, and Hackenbrock CR. Ionic strength of the intermembrane space of intact mitochondria as estimated with fluorescein-BSA delivered by low $\mathrm{pH}$ fusion. J Cell Biol 113: 1331-1340, 1991.

13. Cremades N, Velázquez-Campoy A, Martínez-Júlvez M, Neira JL, Pérez-Dorado I, Hermoso J, Jiménez P, Lanas A, Hoffman PS, and Sancho J. Discovery of specific flavodoxin inhibitors as potential therapeutic agents against Helicobacter pylori infection. ACS Chem Biol 4: 928-938, 2009.

14. Delano WL. The PyMOL Molecular Graphics System. San Carlos, CA: DeLano Scientific, 2002.

15. Diodato D, Tasca G, Verrigni D, D'Amico A, Rizza T, Tozzi G, Martinelli D, Verardo M, Invernizzi F, Nasca A, Bellacchio E, Ghezzi D, Piemonte F, Dionisi-Vici C, Carrozzo R, and Bertini E. A novel AIFM1 mutation expands the phenotype to an infantile motor neuron disease. Eur $J$ Hum Genet 24: 463-466, 2016.

16. Farina B, Di Sorbo G, Chambery A, Caporale A, Leoni G, Russo R, Mascanzoni F, Raimondo D, Fattorusso R, Ruvo $\mathrm{M}$, and Doti N. Structural and biochemical insights of CypA and AIF interaction. Sci Rep 7: 1138, 2017.

AU8 17. Ferreira P, Villanueva R, Martínez-Julvez M, and Medina M. Apoptosis-Inducing Factor 1, Mitochondrionassociated, 1. In: Encyclopedia of Signaling Molecules, edited by Choi S. 2018, pp. 361-366.

18. Ferreira P, Villanueva R, Martínez-Júlvez M, Herguedas B, Marcuello C, Fernandez-Silva P, Cabon L, Hermoso JA, Lostao A, Susin SA, and Medina M. Structural insights into the coenzyme mediated monomer-dimer transition of the pro-apoptotic apoptosis inducing factor. Biochemistry 53: 4204-4215, 2014.

19. Forneris F, Orru R, Bonivento D, Chiarelli LR, and Mattevi A. ThermoFAD, a Thermofluor-adapted flavin ad hoc de- tection system for protein folding and ligand binding. FEBS J 276: 2833-2840, 2009.

20. Frisch MJ, Trucks GW, Schlegel HB, Scuseria GE, Robb MA, Cheeseman JR, Scalmani G, Barone V, Petersson GA, Nakatsuji H, Li X., Caricato M, Marenich A, Bloino J, Janesko BG, Gomperts R, Mennucci B, Hratchian HP, Ortiz JV, Izmaylov AF, Sonnenberg JL, Williams-Young D, Ding F, Lipparini F, Egidi F, Goings J, Peng B, Petrone A, Henderson T, Ranasinghe D, Zakrzewski VG, Gao J, Rega N, Zheng G, Liang W, Hada M, Ehara M, Toyota K, Fukuda R, Hasegawa J, Ishida M, Nakajima T, Honda Y, Kitao O, Nakai H, Vreven T, Throssell K, Montgomery Jr JA, Peralta JE, Ogliaro F, Bearpark M, Heyd JJ, Brothers E, Kudin KN, Staroverov VN, Keith T, Kobayashi R, Normand J, Raghavachari K, Rendell A, Burant JC, Iyengar SS, Tomasi J, Cossi M, Millam JM, Klene M, Adamo C, Cammi R, Ochterski JW, Martin RL, Morokuma K, Farkas O, Foresman JB, and Fox DJ. Gaussian 09, Revision D.01. Wallingford CT: Gaussian, Inc., 2016.

21. Gersting SW, Kemter KF, Staudigl M, Messing DD, Danecka MK, Lagler FB, Sommerhoff CP, Roscher AA, and Muntau AC. Loss of function in phenylketonuria is caused by impaired molecular motions and conformational instability. Am J Hum Genet 83: 5-17, 2008.

22. Ghezzi D, Sevrioukova I, Invernizzi F, Lamperti C, Mora M, D'Adamo P, Novara F, Zuffardi O, Uziel G, and Zeviani M. Severe X-linked mitochondrial encephalomyopathy associated with a mutation in apoptosis-inducing factor. Am J Hum Genet 86: 639-649, 2010.

23. Grimme S, Ehrlich S, and Goerigk L. Effect of the damping function in dispersion corrected density functional theory. $J$ Comput Chem 32: 1456-1465, 2011.

24. Gurbuxani S, Schmitt E, Cande C, Parcellier A, Hammann A, Daugas E, Kouranti I, Spahr C, Pance A, Kroemer G, and Garrido C. Heat shock protein 70 binding inhibits the nuclear import of apoptosis-inducing factor. Oncogene 22: 6669-6678, 2003.

25. Hangen E, Féraud O, Lachkar S, Mou H, Doti N, Fimia GM, Lam NV, Zhu C, Godin I, Muller K, Chatzi A, Nuebel E, Ciccosanti F, Flamant S, Bénit P, Perfettini JL, Sauvat A, Bennaceur-Griscelli A, Ser-Le Roux K, Gonin P, Tokatlidis K, Rustin P, Piacentini M, Ruvo M, Blomgren K, Kroemer $\mathrm{G}$, and Modjtahedi N. Interaction between AIF and CHCHD4 Regulates Respiratory Chain Biogenesis. Mol Cell 58: 1001-1014, 2015.

26. Heimer G, Eyal E, Zhu X, Ruzzo EK, Marek-Yagel D, Sagiv D, Anikster Y, Reznik-Wolf H, Pras E, Oz Levi D, Lancet D, Ben-Zeev B, and Nissenkorn A. Mutations in AIFM1 cause an X-linked childhood cerebellar ataxia partially responsive to riboflavin. Eur J Paediatr Neurol 22: 93-101, 2018.

27. Humphrey W, Dalke A, and Schulten K. VMD: visual molecular dynamics. J Mol Graph 14: 33-38, 27-38, 1996.

28. Jones G, Willett P, Glen RC, Leach AR, and Taylor R. Development and validation of a genetic algorithm for flexible docking. J Mol Biol 267: 727-748, 1997.

29. Kadam AA, Jubin T, Mir HA, and Begum R. Potential role of Apoptosis Inducing Factor in evolutionarily significant eukaryote, Dictyostelium discoideum survival. Biochim Biophys Acta 1861: 2942-2955, 2017.

30. Kettwig M, Schubach M, Zimmermann FA, Klinge L, Mayr JA, Biskup S, Sperl W, Gärtner J, and Huppke P. From ventriculomegaly to severe muscular atrophy: 
expansion of the clinical spectrum related to mutations in AIFM1. Mitochondrion 21: 12-18, 2015.

31. Kuban-Jankowska A, Sahu KK, Niedzialkowski P, Gorska M, Tuszynski JA, Ossowski T, and Wozniak M. Redox process is crucial for inhibitory properties of aurintricarboxylic acid against activity of YopH: virulence factor of Yersinia pestis. Oncotarget 6: 18364-18373, 2015.

32. Lagorce D, Sperandio O, Baell JB, Miteva MA, and Villoutreix BO. FAF-Drugs3: a web server for compound property calculation and chemical library design. Nucleic Acids Res 43: W200-W207, 2015.

33. Le Guilloux V, Schmidtke P, and Tuffery P. Fpocket: an open source platform for ligand pocket detection. $B M C$ Bioinformatics 10: 168, 2009.

34. Lee MS, Salsbury FR, and Brooks CL. Novel generalized Born Methods. J Chem Phy 116: 10606-10614, 2002.

35. Lipinski CA, Lombardo F, Dominy BW, and Feeney PJ. Experimental and computational approaches to estimate solubility and permeability in drug discovery and development settings. Adv Drug Deliv Rev 46: 3-26, 2001.

36. Llopis J, McCaffery JM, Miyawaki A, Farquhar MG, and Tsien RY. Measurement of cytosolic, mitochondrial, and Golgi $\mathrm{pH}$ in single living cells with green fluorescent proteins. Proc Natl Acad Sci U S A 95: 6803-6808, 1998.

37. Lui JC and Kong SK. Heat shock protein 70 inhibits the nuclear import of apoptosis-inducing factor to avoid DNA fragmentation in TF-1 cells during erythropoiesis. FEBS Lett 581: 109-117, 2007.

38. López LC, Dos-Reis S, Espargaró A, Carrodeguas JA, Maddelein ML, Ventura S, and Sancho J. Discovery of novel inhibitors of amyloid $\beta$-peptide 1-42 aggregation. $J$ Med Chem 55: 9521-9530, 2012.

39. Matsuyama S, Llopis J, Deveraux QL, Tsien RY, and Reed JC. Changes in intramitochondrial and cytosolic $\mathrm{pH}$ : early events that modulate caspase activation during apoptosis. Nat Cell Biol 2: 318-325, 2000.

40. Medina-Carmona E, Neira JL, Salido E, Fuchs JE, Palomino-Morales R, Timson DJ, and Pey AL. Site-to-site interdomain communication may mediate different loss-offunction mechanisms in a cancer-associated NQO1 polymorphism. Sci Rep 7: 44532, 2017.

41. Meyer K, Buettner S, Ghezzi D, Zeviani M, Bano D, and Nicotera P. Loss of apoptosis-inducing factor critically affects MIA40 function. Cell Death Dis 6: e1814, 2015.

42. Miramar MD, Costantini P, Ravagnan L, Saraiva LM, Haouzi D, Brothers G, Penninger JM, Peleato ML, Kroemer G, and Susin SA. NADH oxidase activity of mitochondrial apoptosis-inducing factor. J Biol Chem 276: 16391-16398, 2001.

43. Modjtahedi N, Giordanetto F, Madeo F, and Kroemer G. Apoptosis-inducing factor: vital and lethal. Trends Cell Biol 16: 264-272, 2006.

44. Morton SU, Prabhu SP, Lidov HGW, Shi J, Anselm I, Brownstein CA, Bainbridge MN, Beggs AH, Vargas SO, and Agrawal PB. AIFM1 mutation presenting with fatal encephalomyopathy and mitochondrial disease in an infant. Cold Spring Harb Mol Case Stud 3, 2017.

45. Natarajan SK and Becker DF. Role of apoptosis-inducing factor, proline dehydrogenase, and NADPH oxidase in apoptosis and oxidative stress. Cell Health Cytoskelet 2012: 11-27, 2012.

46. Olsson MHM, Søndergaard CR, Rostkowski M, and Jensen JH. PROPKA3: Consistent Treatment of Internal and Sur- face Residues in Empirical pKa Predictions. J Chem Theory Comput 7: 525-537, 2011.

47. Orij R, Postmus J, Ter Beek A, Brul S, and Smits GJ. In vivo measurement of cytosolic and mitochondrial $\mathrm{pH}$ using a $\mathrm{pH}$-sensitive GFP derivative in Saccharomyces cerevisiae reveals a relation between intracellular $\mathrm{pH}$ and growth. Microbiology 155: 268-278, 2009.

48. Otera H, Ohsakaya S, Nagaura Z, Ishihara N, and Mihara $\mathrm{K}$. Export of mitochondrial AIF in response to proapoptotic stimuli depends on processing at the intermembrane space. EMBO J 24: 1375-1386, 2005.

49. Porcelli AM, Ghelli A, Zanna C, Pinton P, Rizzuto R, and Rugolo M. pH difference across the outer mitochondrial membrane measured with a green fluorescent protein mutant. Biochem Biophys Res Commun 326: 799-804, 2005.

50. Rinaldi C, Grunseich C, Sevrioukova IF, Schindler A, Horkayne-Szakaly I, Lamperti C, Landouré G, Kennerson ML, Burnett BG, Bönnemann C, Biesecker LG, Ghezzi D, Zeviani $\mathrm{M}$, and Fischbeck KH. Cowchock syndrome is associated with a mutation in apoptosis-inducing factor. Am J Hum Genet 91: 1095-1102, 2012.

51. Sancho J. The stability of 2-state, 3-state and more-state proteins from simple spectroscopic techniques... plus the structure of the equilibrium intermediates at the same time. Arch Biochem Biophys 531: 4-13, 2013.

52. Sancho P, Sánchez-Monteagudo A, Collado A, MarcoMarín C, Domínguez-González C, Camacho A, Knecht E, Espinós C, and Lupo V. A newly distal hereditary motor neuropathy caused by a rare AIFM1 mutation. Neurogenetics 18: 245-250, 2017.

53. Schmitt E, Parcellier A, Gurbuxani S, Cande C, Hammann A, Morales MC, Hunt CR, Dix DJ, Kroemer RT, Giordanetto F, Jäättelä M, Penninger JM, Pance A, Kroemer G, and Garrido C. Chemosensitization by a non-apoptogenic heat shock protein 70-binding apoptosis-inducing factor mutant. Cancer Res 63: 8233-8240, 2003.

54. Seksek O and Bolard J. Nuclear $\mathrm{pH}$ gradient in mammalian cells revealed by laser microspectrofluorimetry. J Cell Sci 109 (Pt 1): 257-262, 1996.

55. Sevrioukova IF. Apoptosis-inducing factor: structure, function, and redox regulation. Antioxid Redox Signal 14: 2545-2579, 2011.

56. Sevrioukova IF. Redox-linked conformational dynamics in apoptosis-inducing factor. J Mol Biol 390: 924-938, 2009.

57. Sevrioukova IF. Structure/Function Relations in AIFM1 Variants Associated with Neurodegenerative Disorders. $J$ Mol Biol 428: 3650-3665, 2016.

58. Shelar SB, Kaminska KK, Reddy SA, Kumar D, Tan CT, $\mathrm{Yu}$ VC, Lu J, Holmgren A, Hagen T, and Chew EH. Thioredoxin-dependent regulation of AIF-mediated DNA damage. Free Radic Biol Med 87: 125-136, 2015.

59. Shendure J and Akey JM. The origins, determinants, and consequences of human mutations. Science 349: 14781483, 2015.

60. Shrake A and Ross PD. Origins and consequences of ligand-induced multiphasic thermal protein denaturation. Biopolymers 32: 925-940, 1992.

61. Sorrentino L, Calogero AM, Pandini V, Vanoni MA, Sevrioukova IF, and Aliverti A. Key Role of the Adenylate Moiety and Integrity of the Adenylate-Binding Site for the $\mathrm{NAD}(+) / \mathrm{H}$ Binding to Mitochondrial Apoptosis-Inducing Factor. Biochemistry 54: 6996-7009, 2015.

62. Sorrentino L, Cossu F, Milani M, Aliverti A, and Mastrangelo E. Structural bases of the altered catalytic 
properties of a pathogenic variant of apoptosis inducing factor. Biochem Biophys Res Commun 490: 1011-1017, 2017.

63. Stein A, Whitlock JP, and Bina M. Acidic polypeptides can assemble both histones and chromatin in vitro at physiological ionic strength. Proc Natl Acad Sci U S A 76: 50005004, 1979.

64. Susin SA, Lorenzo HK, Zamzami N, Marzo I, Snow BE, Brothers GM, Mangion J, Jacotot E, Costantini P, Loeffler M, Larochette N, Goodlett DR, Aebersold R, Siderovski DP, Penninger JM, and Kroemer G. Molecular characterization of mitochondrial apoptosis-inducing factor. Nature 397: 441-446, 1999.

65. Tsi CJ, Chao Y, Chen CW, and Lin WW. Aurintricarboxylic acid protects against cell death caused by lipopolysaccharide in macrophages by decreasing inducible nitric-oxide synthase induction via IkappaB kinase, extracellular signal-regulated kinase, and p38 mitogen-activated protein kinase inhibition. Mol Pharmacol 62: 90-101, 2002.

66. Vahsen N, Candé C, Brière JJ, Bénit $\mathrm{P}$, Joza N, Larochette $\mathrm{N}$, Mastroberardino PG, Pequignot MO, Casares N, Lazar V, Feraud O, Debili N, Wissing S, Engelhardt S, Madeo F, Piacentini M, Penninger JM, Schägger H, Rustin P, and Kroemer G. AIF deficiency compromises oxidative phosphorylation. EMBO J 23: 4679-4689, 2004.

67. Vanommeslaeghe K, Hatcher E, Acharya C, Kundu S, Zhong S, Shim J, Darian E, Guvench O, Lopes P, Vorobyov I, and Mackerell AD. CHARMM general force field: A force field for drug-like molecules compatible with the CHARMM all-atom additive biological force fields. $J$ Comput Chem 31: 671-690, 2010.

68. Velazquez-Campoy A, Sancho J, Abian O, and Vega S. Biophysical screening for identifying pharmacological chaperones and inhibitors against conformational and infectious diseases. Curr Drug Targets 17: 1492-1505, 2016.

69. Wang Y, Kim NS, Haince JF, Kang HC, David KK, Andrabi SA, Poirier GG, Dawson VL, and Dawson TM. Poly(ADP-ribose) (PAR) binding to apoptosis-inducing factor is critical for PAR polymerase-1-dependent cell death (parthanatos). Sci Signal 4: ra20, 2011.

70. Xie H, Vucetic S, Iakoucheva LM, Oldfield CJ, Dunker AK, Uversky VN, and Obradovic Z. Functional anthology of intrinsic disorder. 1. Biological processes and functions of proteins with long disordered regions. J Proteome Res 6: 1882-1898, 2007.

71. Ye H, Cande C, Stephanou NC, Jiang S, Gurbuxani S, Larochette N, Daugas E, Garrido C, Kroemer G, and Wu H. DNA binding is required for the apoptogenic action of apoptosis inducing factor. Nat Struct Biol 9: 680-684, 2002.

72. Zhang Y, Han T, Zhu Q, Zhang W, Bao W, Fu HJ, Yang J, Huang XJ, Wei JX, Meng YL, Zhao J, Cao YX, Jia LT, and Yangi AG. The proapoptotic activity of C-terminal domain of apoptosis-inducing factor (AIF) is separated from its $\mathrm{N}$ terminal. Biol Res 42: 249-260, 2009.

73. Zhu C, Wang X, Deinum J, Huang Z, Gao J, Modjtahedi N, Neagu MR, Nilsson M, Eriksson PS, Hagberg H, Luban J, Kroemer G, and Blomgren K. Cyclophilin A participates in the nuclear translocation of apoptosis-inducing factor in neurons after cerebral hypoxia-ischemia. J Exp Med 204: 1741-1748, 2007.

74. Zong L, Guan J, Ealy M, Zhang Q, Wang D, Wang H, Zhao Y, Shen Z, Campbell CA, Wang F, Yang J, Sun W, Lan L, Ding D, Xie L, Qi Y, Lou X, Huang X, Shi Q, Chang S,
Xiong W, Yin Z, Yu N, Zhao H, Wang J, Wang J, Salvi RJ, Petit C, Smith RJ, and Wang Q. Mutations in apoptosisinducing factor cause $\mathrm{X}$-linked recessive auditory neuropathy spectrum disorder. J Med Genet 52: 523-531, 2015.

Address correspondence to: 4 AU9 Dr. Patricia Ferreira Departamento de Bioquímica y Biología Molecular y Celular Facultad de Ciencias Universidad de Zaragoza Pedro Cerbuna 12 Zaragoza 50009 Spain

E-mail: ferreira@unizar.es

Dr. Milagros Medina Departamento de Bioquímica y Biología Molecular y Celular Facultad de Ciencias Universidad de Zaragoza Pedro Cerbuna 12 Zaragoza 50009 Spain

E-mail: mmedina@unizar.es

Date of first submission to ARS Central, September 19, 2018; date of final revised submission, October 25, 2018; date of acceptance, November 11, 2018.

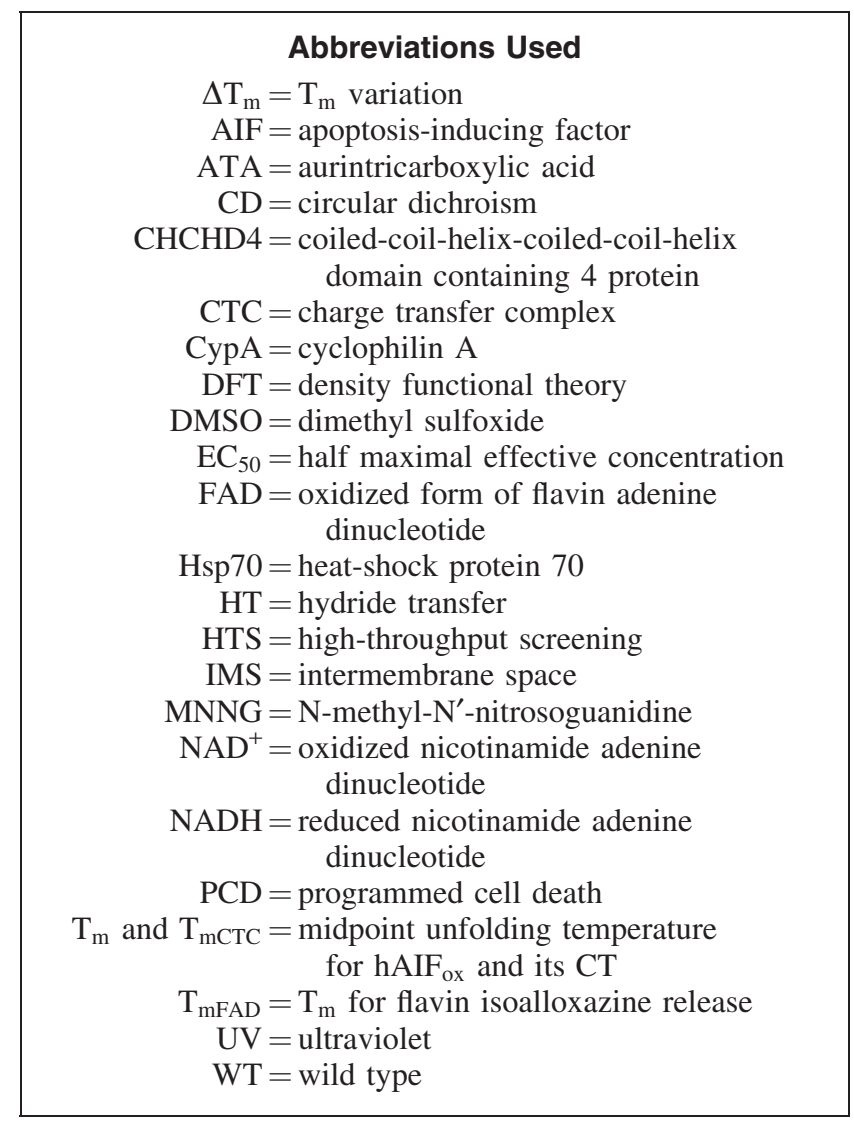




\section{Supplementary Data}
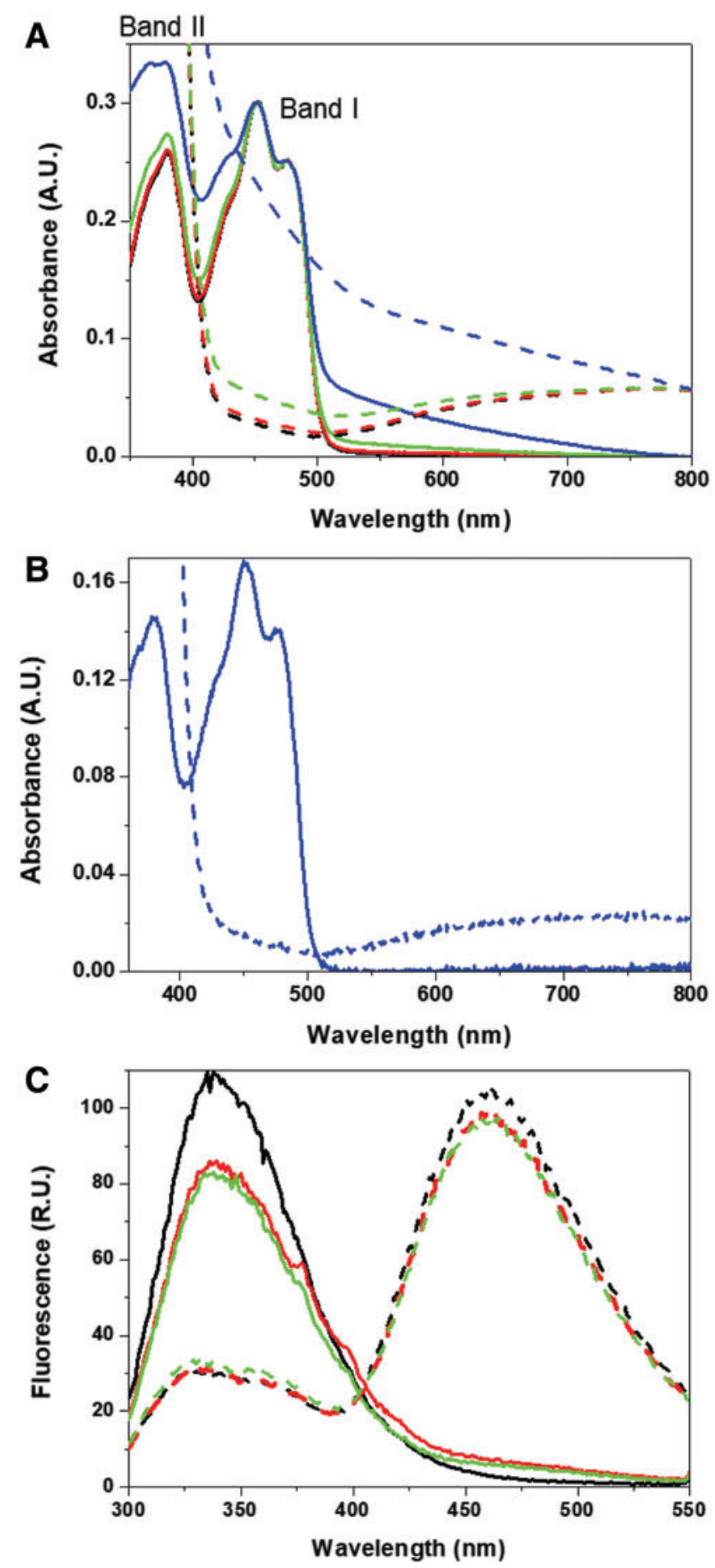

SUPPLEMENTARY FIG. S1. Spectroscopic properties of WT hAIF as a function of pH. Absorption spectra of (A) $\operatorname{hAIF}_{\Delta 1-101 \text { ox }}(\sim 22 \mu M)$ and $(\mathbf{B}) \operatorname{hAIF}_{\Delta 1-77 \text { ox }}(\sim 15 \mu M)$ at $25^{\circ} \mathrm{C}$. Position of band $\mathrm{I}$ and band II and $\mathrm{A}_{280} / \mathrm{A}_{450}$ and $\mathrm{A}_{380} / \mathrm{A}_{450}$ ratios provide information about similar or dissimilar electronic environments for the FAD cofactor. (C) Fluorescence emission spectra of $\mathrm{hAIF}_{\Delta 1-101 \mathrm{ox}}(2 \mu \mathrm{M})$ in the aromatic region at $10^{\circ} \mathrm{C}$ with excitation wavelength $280 \mathrm{~nm}$. Spectra were recorded in $50 \mathrm{~m} M$ potassium phosphate, $\mathrm{pH} 8.0$ (black lines), 7.4 (red lines), 7.0 (green lines), or 6.2 (blue lines), at a final ionic strength of $150 \mathrm{~m} M$. Samples containing hAIF ox $_{\text {are shown as }}$ continuous lines, and those containing $\mathrm{hAIF}_{\mathrm{ox}}$ mixtures with NADH in a 1:100 protein:NADH ratio are shown as dashed lines. FAD, oxidized form of flavin adenine dinucleotide; hAIF, human apoptosis-inducing factor; WT, wild type. 

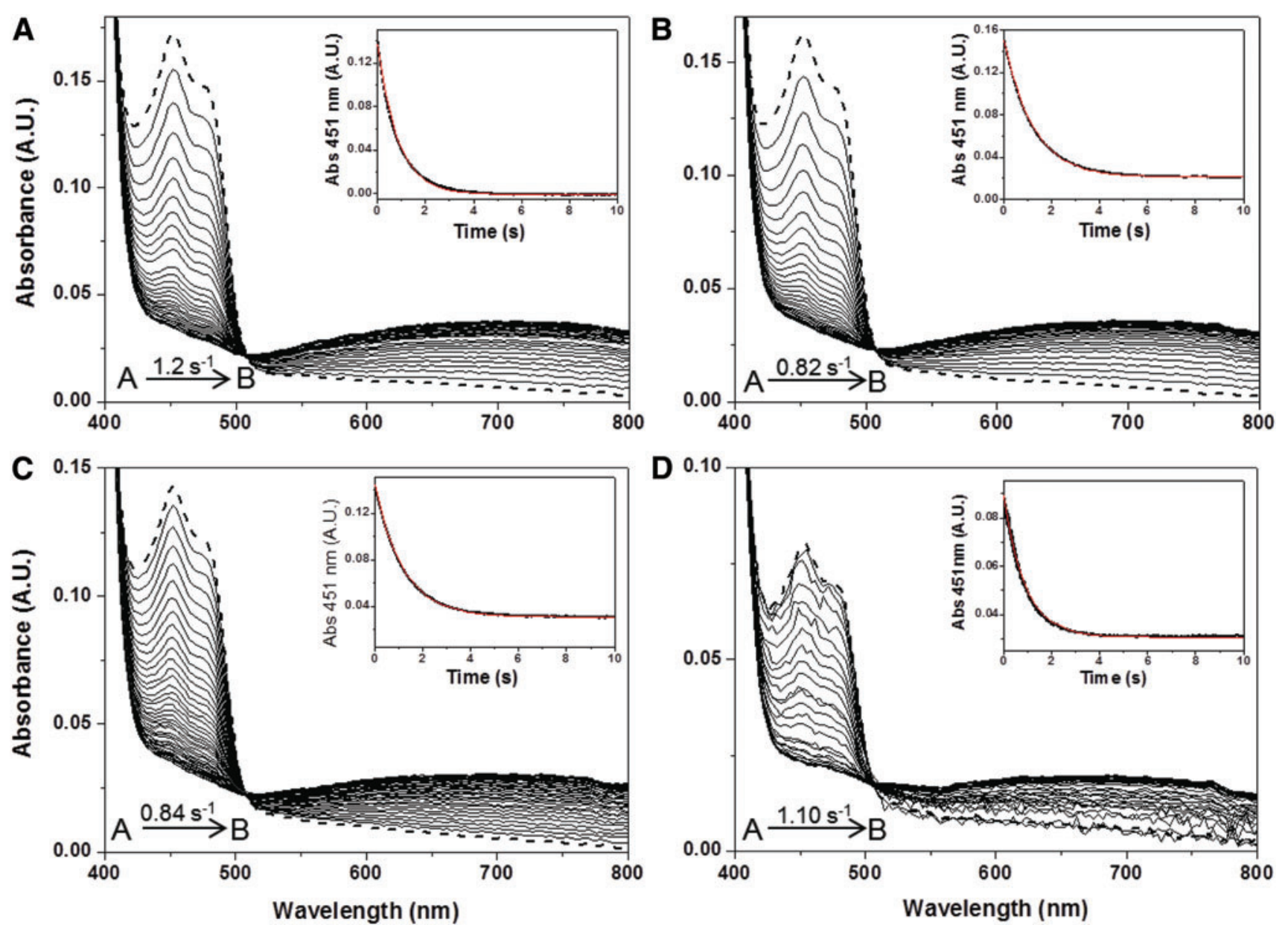

SUPPLEMENTARY FIG. S2. Spectral evolution upon reduction of hAIF $\mathrm{AI1-1010x} / \mathrm{hAIF}_{\Delta 1-77 \mathrm{ox}}(10 \pm 2 \mu M)$ by NADH $(5 \mathrm{~m} M)$ at (A) pH 8.0, (B) $\mathrm{pH} \mathrm{7.4,} \mathrm{(C)} \mathrm{7.0,} \mathrm{and} \mathrm{(D)} \mathrm{pH} \mathrm{6.2.} \mathrm{Measurements} \mathrm{were} \mathrm{carried} \mathrm{out} \mathrm{at} 25^{\circ} \mathrm{C}$ in $50 \mathrm{~m} M$ potassium phosphate at a final ionic strength of $150 \mathrm{~m} M$. The insets show the absorption evolution at $451 \mathrm{~nm}$ with the fit to a two species process (red line). Dashed lines correspond to the spectra of oxidized protein before mixing. 


\section{A}
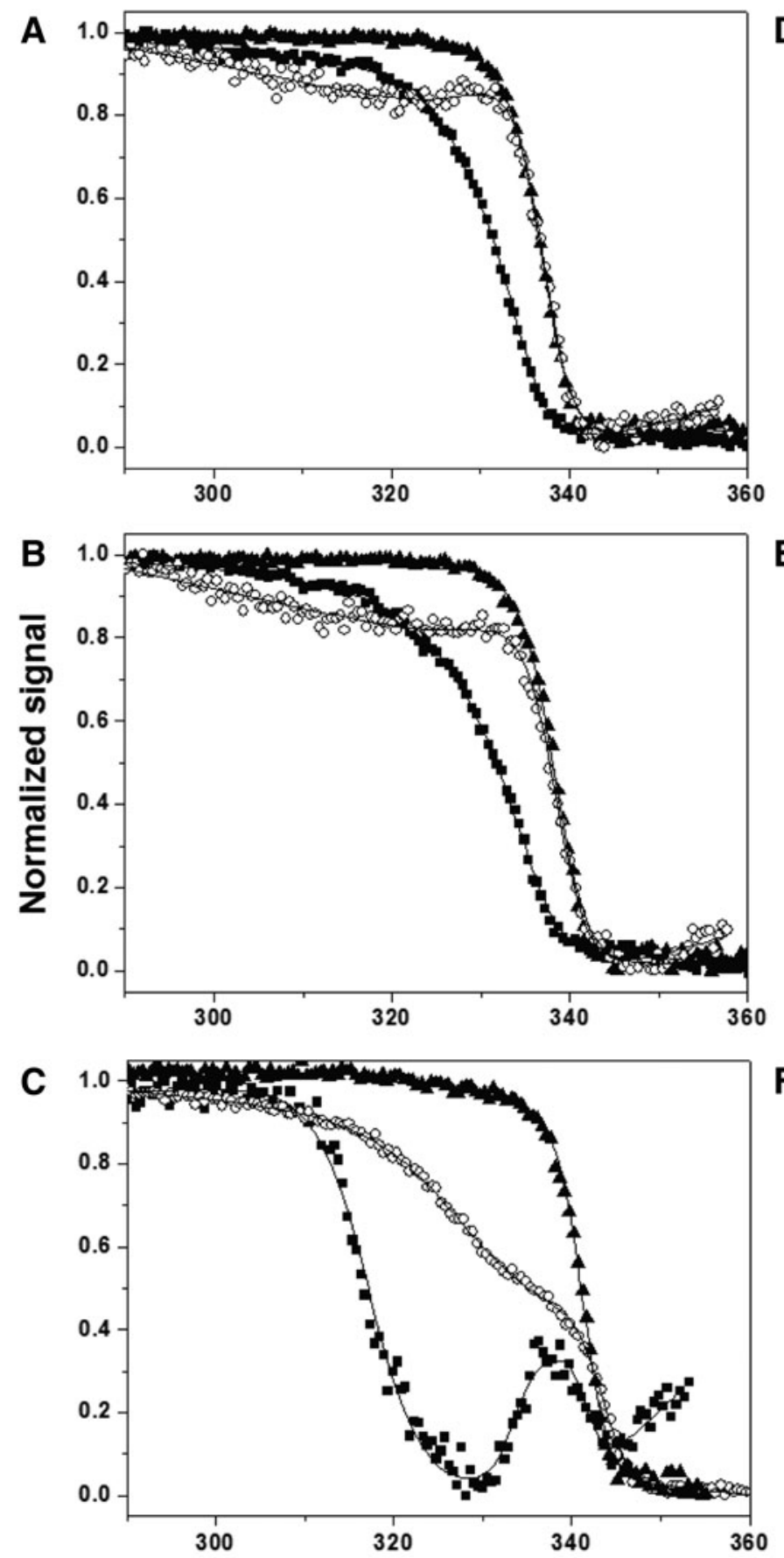
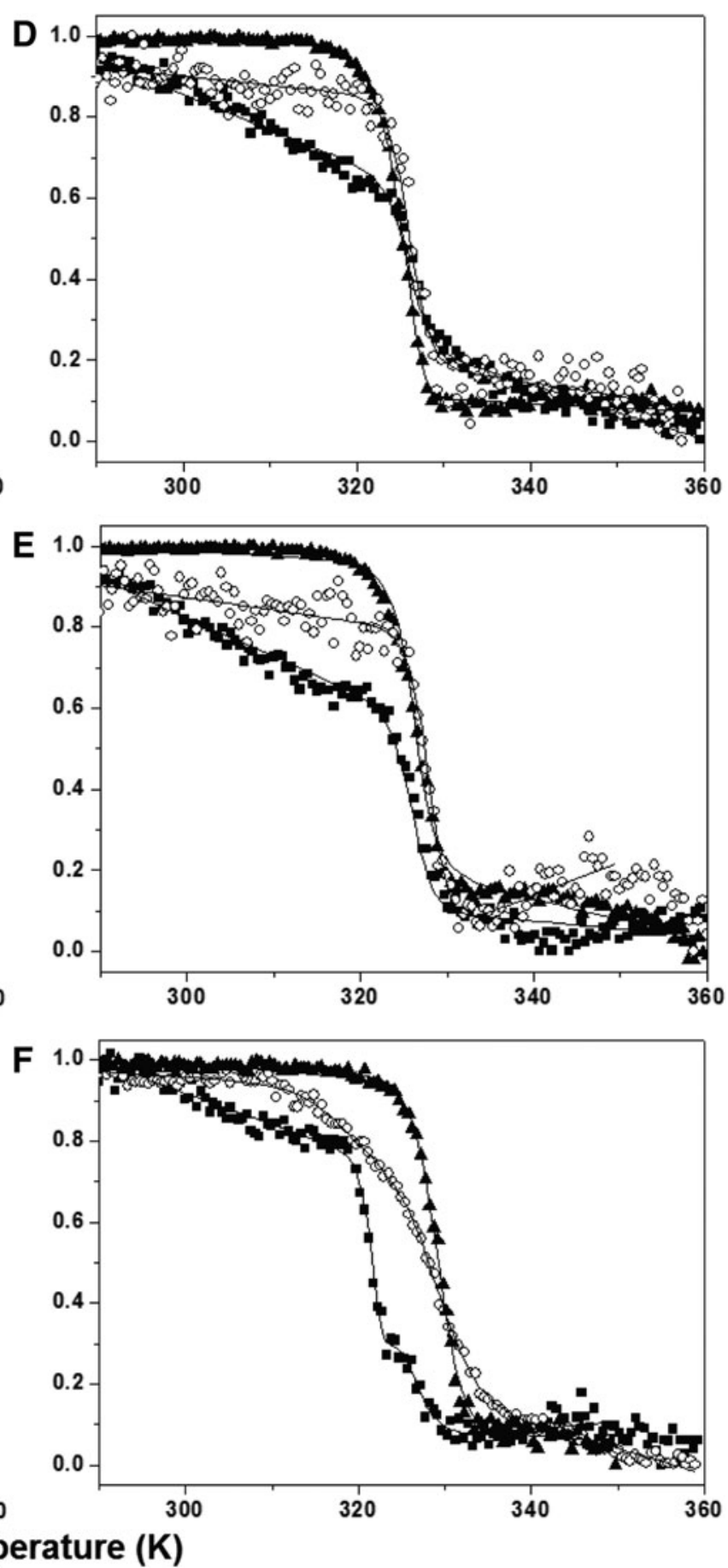

SUPPLEMENTARY FIG. S3. Thermal unfolding curves for $\mathrm{hAIF}_{\Delta 1-1010 x}$ at (A) pH 7.4 and (B) pH 7.0, for hAIF $\mathrm{h}_{\Delta 1-}$ $770 x$ at (C) pH 6.2, and for their respective CTCs (1:100 protein hAIF:NADH ratio) at (D) pH 7.4, (E) pH 7.0, and (F) pH 6.2. Thermal denaturation was monitored by far-UV CD $(210 \mathrm{~nm}$, white circles $)$, near-UV CD (300 nm, black squares; or $410 \mathrm{~nm}$ in the CTC), and flavin fluorescence emission (black triangles, $530 \mathrm{~nm}$ ). The curves are roughly normalized from 0 to 1 , and their global fits to three-state (for $\mathbf{A}, \mathbf{B}$, and $\mathbf{F}$ ), four-state $(\mathbf{C})$, and two-state (for $\mathbf{D}$ and $\mathbf{E}$ ) unfolding models are represented by the continuous lines. Curves were recorded in $50 \mathrm{~m} M$ potassium phosphate at a final ionic strength of $150 \mathrm{mM}$. CD, circular dichroism; CTC, charge transfer complex; UV, ultraviolet. 


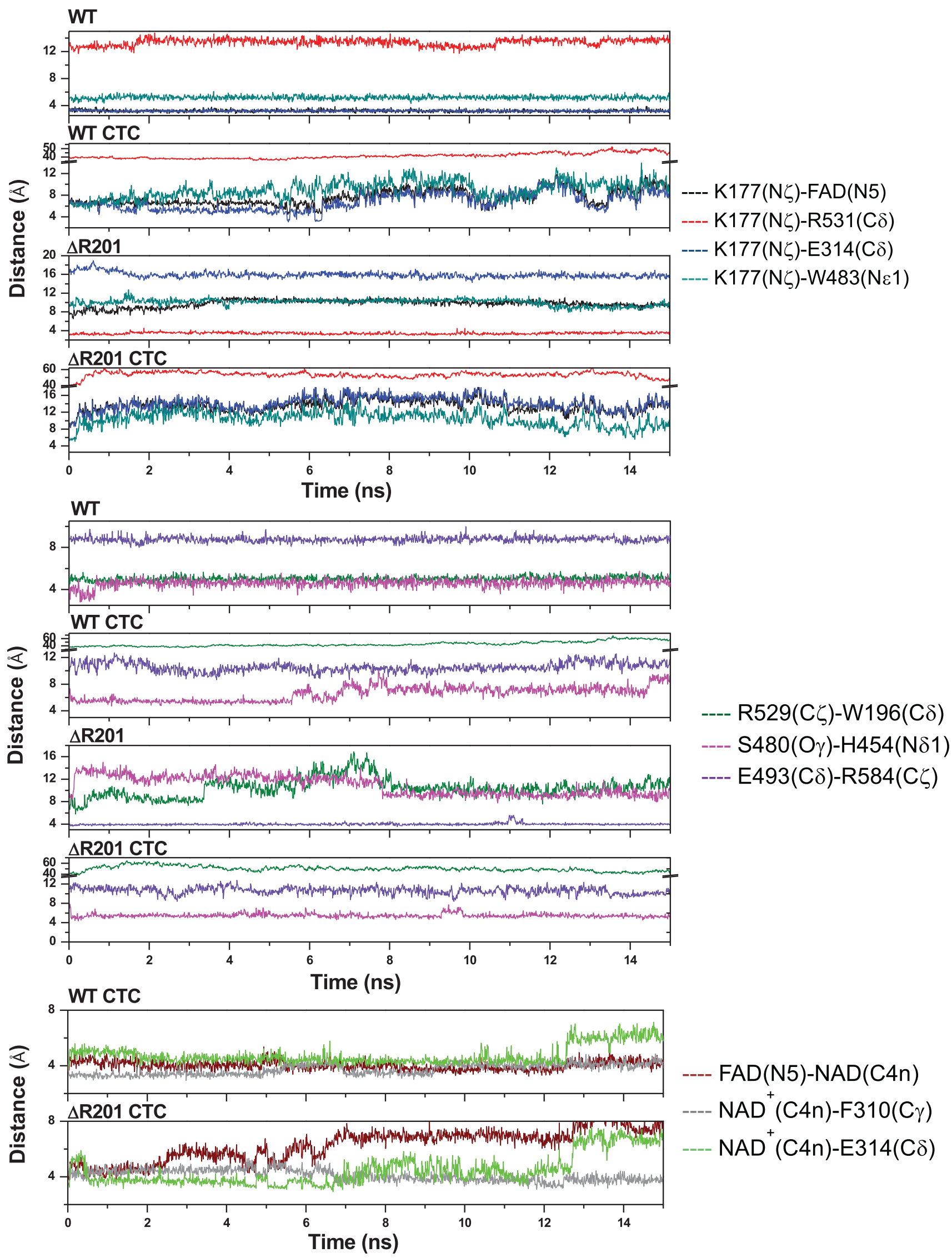

SUPPLEMENTARY FIG. S4. Dynamics of relaxation of models of hAIF 1 101 variants. Time evolution of selected distances along representative relaxation MD simulations of models for WT hAIF ${ }_{\Delta 1-101 \text { ox }}$, the $\Delta \mathrm{R} 201$ variant and their corresponding CTC complexes. 
A
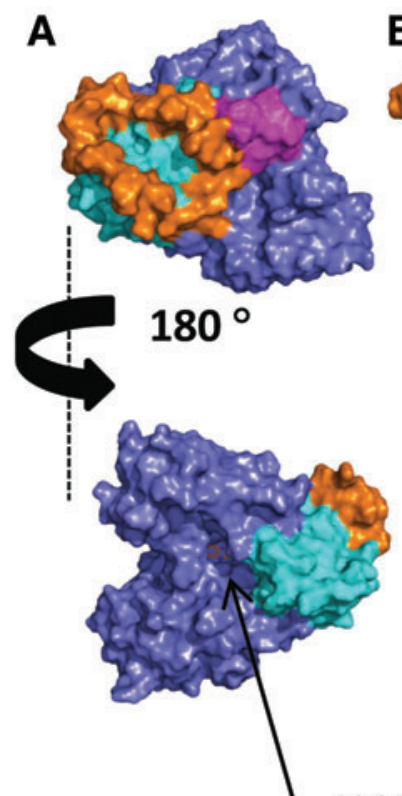

NADH

binding channel

\section{E}

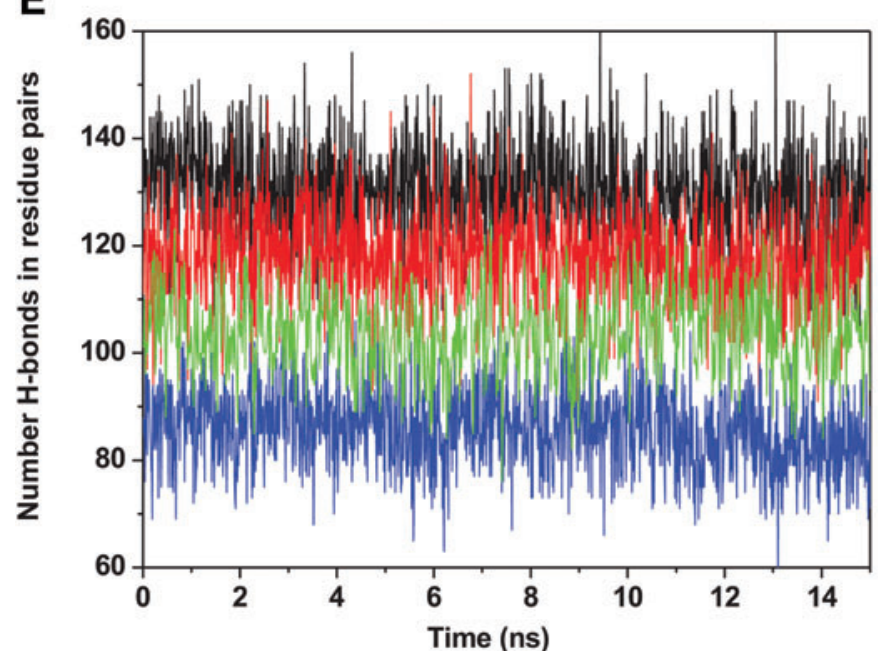

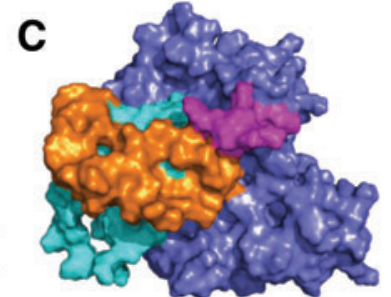
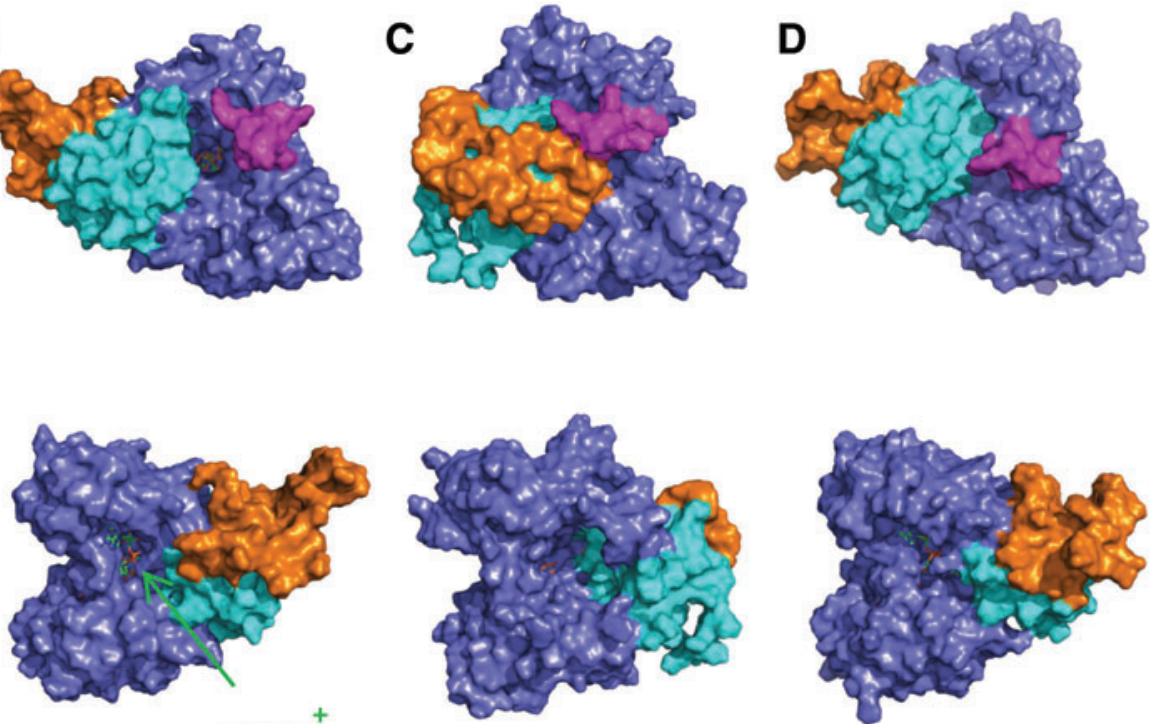

NAD
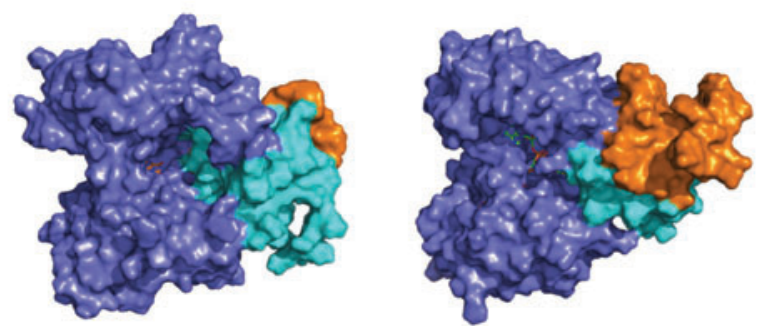

$\mathbf{F}$

\begin{tabular}{|l|c|c|}
\hline & $\begin{array}{c}\text { Molecular } \\
\text { Surface } \\
\text { Area } \\
\left(\AA^{2}\right)\end{array}$ & $\begin{array}{c}\text { Solvent } \\
\text { Accesible } \\
\text { Surface } \\
\text { Area }\left(\AA^{2}\right)\end{array}$ \\
\hline WT $_{\text {ox }}$ & 55836 & 18687 \\
\hline WT CTC & 56260 & 20641 \\
\hline$\triangle R 201_{\text {ox }}$ & 56710 & 22840 \\
\hline$\triangle R 201 C T C$ & 57279 & 21014 \\
\hline
\end{tabular}

SUPPLEMENTARY FIG. S5. Conformational changes in hAIF $_{\Delta 1-1010 x}$ induced by CTC formation and R201 deletion. Surface representation of the representative model structures of (A) WT hAIF ${ }_{\Delta 1-101 \text { ox }}$, (B) WT CTC, (C) $\Delta$ R201 $\mathrm{hAIF}_{\Delta 1-101 \mathrm{ox}}$, and (D) $\Delta \mathrm{R} 201 \mathrm{CTC}$ after modeling of the missing C-loop residues (546-558), minimization, equilibration at $300 \mathrm{~K}$, and short MD relaxation ( $15 \mathrm{~ns})$ at $300 \mathrm{~K}$. The oxidoreductase domain surface is in violet with its $\beta$-hairpin in pink, whereas the apoptotic domain surface is in light blue with the C-loop segment in orange. The FAD and NAD ${ }^{+}$are shown in sticks with carbons in orange and green, respectively. (E) Number of H-bonds along the MD simulation production for the different AIF forms. Color code as in (F). (F) Summary of molecular and solvent surface area at the end of representative MD relaxations for each hAIF form. 

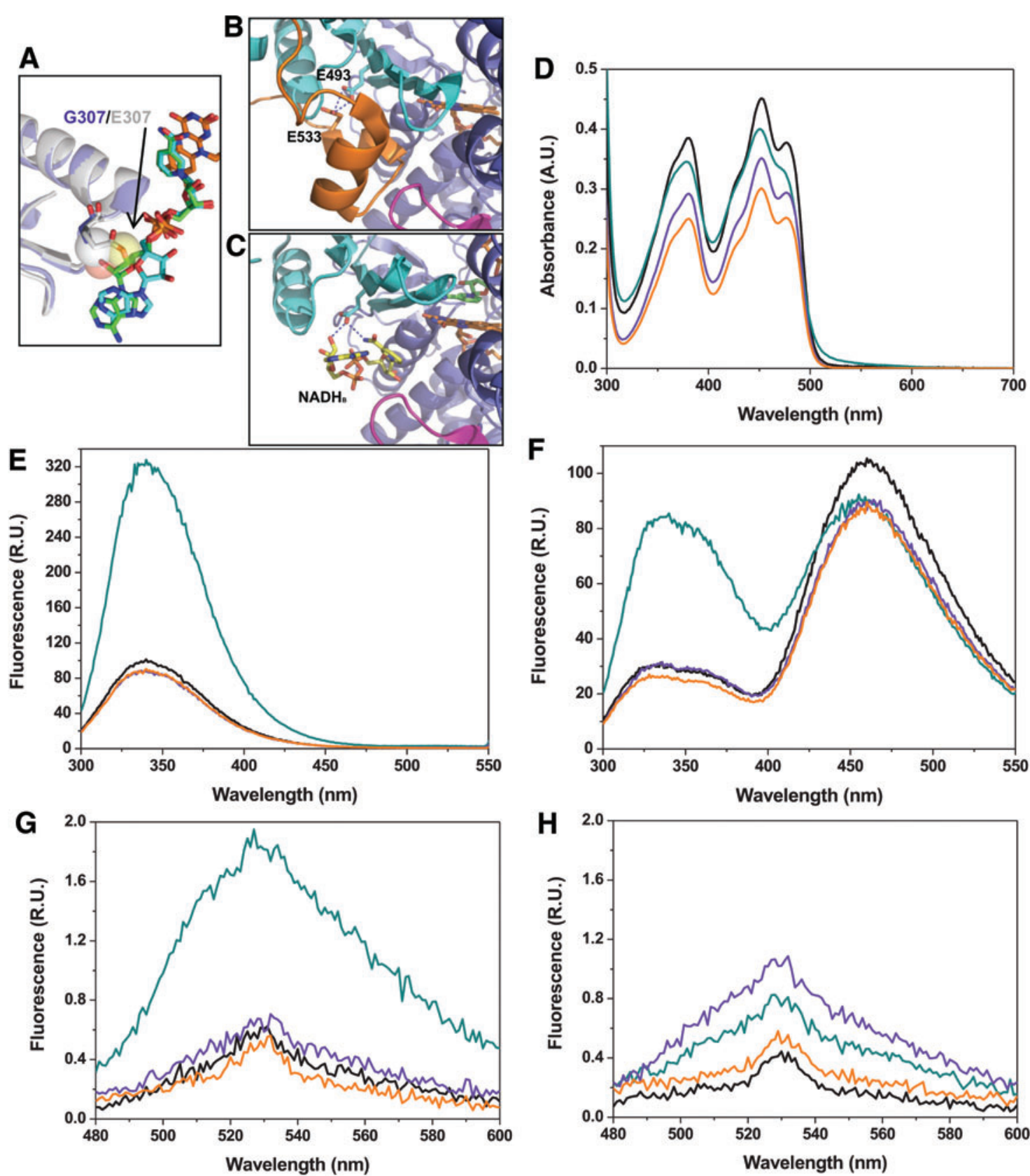

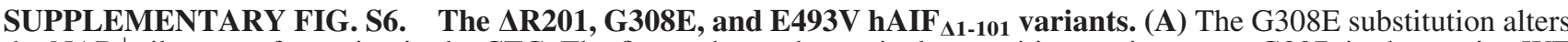
the $\mathrm{NAD}^{+}$ribose conformation in the CTC. The figure shows the equivalent position environment, G307, in the murine WT CTC structure (PDB 3gd4) in violet with the $\mathrm{NAD}^{+}$in green sticks, and in the murine G307E CTC mutant structure in white and with the coenzyme in blue (PDB 5miv). Spheres show how the introduced Glu side chain uses the place of the

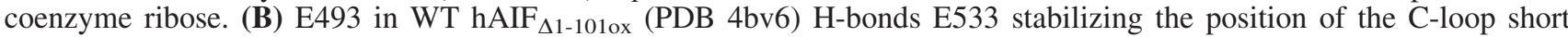
helixes. (C) In the WT CTC structure (PDB 4bur), E493 contributes to stabilize the coenzyme molecule that replaces the Cloop short helixes. Color code is as in Figure 3. (D) UV-visible spectra of WT $(33 \mu M), \Delta \mathrm{R} 201(33 \mu M)$, G308E $(26 \mu M)$, and E493V $(22 \mu M)$ hAIF $_{\Delta 1-101 \text { ox }}$ variants. (E) Fluorescence emission spectra in the aromatic residues region of WT, $\Delta \mathrm{R} 201, \mathrm{G} 308 \mathrm{E}$, and $\mathrm{E} 493 \mathrm{~V}$ hAIF 1 1010x variants $(2 \mu M)$ recorded at $10^{\circ} \mathrm{C}$ with excitation wavelength of $280 \mathrm{~nm}$. (F) Fluorescence emission spectra in the aromatic residues region of $\mathrm{hAIF}_{\Delta 1-101}$ variants $(2 \mu M)$ in the presence of $200 \mu M$ NADH recorded at $10^{\circ} \mathrm{C}$ with excitation wavelength of $280 \mathrm{~nm}$. (G) Fluorescence emission spectra in the flavin region of $\mathrm{hAIF}_{\Delta 1-101 \mathrm{ox}}$ variants $(2 \mu M)$ recorded at $10^{\circ} \mathrm{C}$ with excitation wavelength of $450 \mathrm{~nm}$. (H) Fluorescence emission spectra in the flavin region of $\mathrm{hAIF}_{\Delta 1-101}(2 \mu M)$ in the presence of $200 \mu M$ NADH recorded at $10^{\circ} \mathrm{C}$ with excitation wavelength of

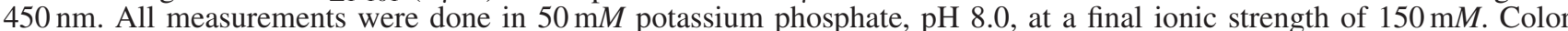
code: WT (black line), $\Delta \mathrm{R} 201$ (dark cyan line), G308E (violet line), and E493V (orange line). 
A

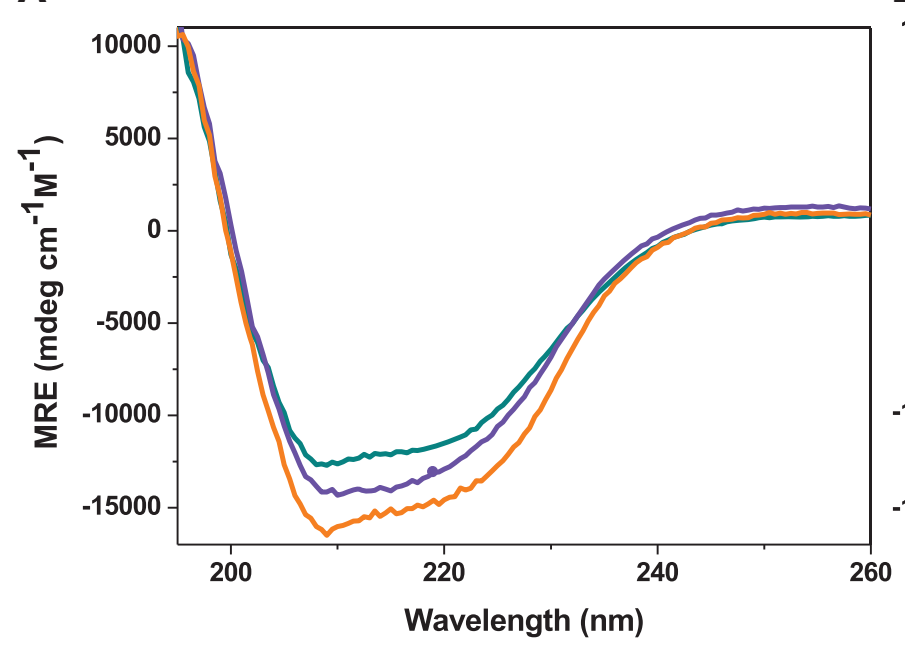

C

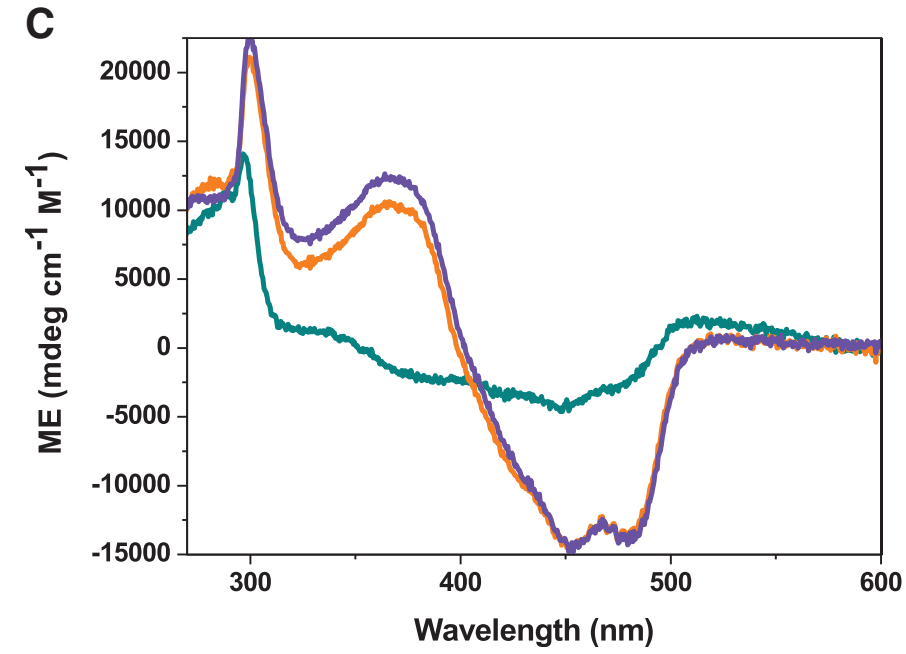

B

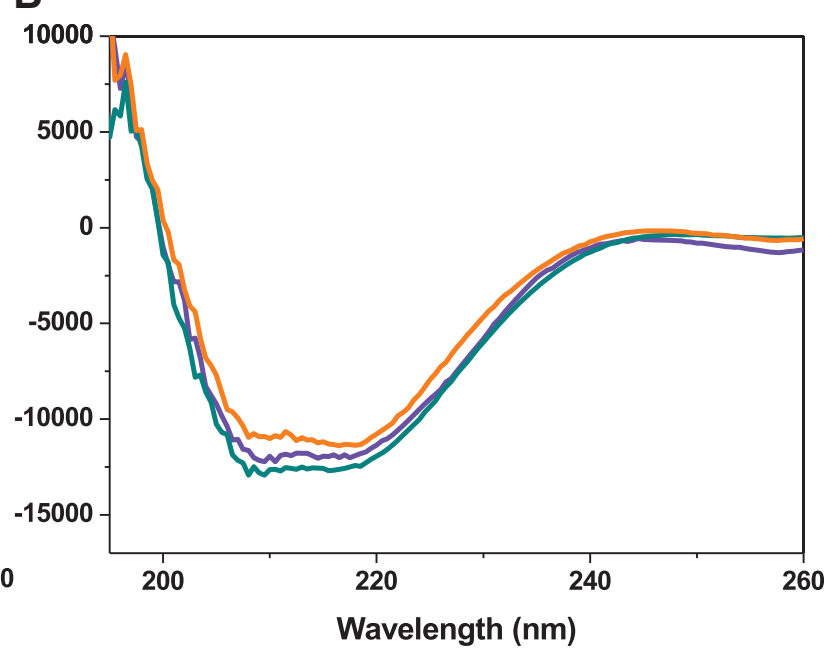

D

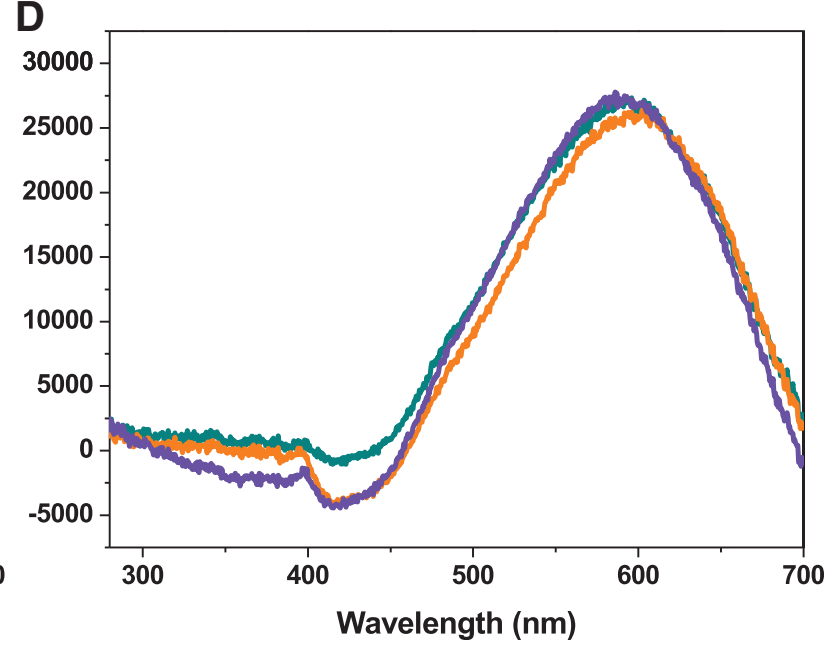

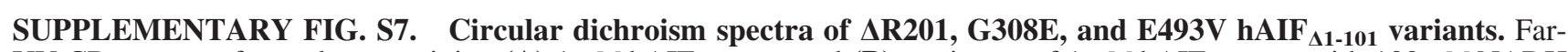
UV CD spectra of samples containing (A) $1 \mu M \mathrm{hAIF}_{\Delta 1-1010 \mathrm{x}}$ and (B) a mixture of $1 \mu M \mathrm{hAIF}_{\Delta 1-1010 \mathrm{x}}$ with $100 \mu M \mathrm{NADH}$ for $\triangle \mathrm{R} 201$ (dark cyan line), G308E (violet line), and $\mathrm{E} 493 \mathrm{~V}$ (orange line) variants. Near-UV/vis CD spectra of samples containing (C) $20 \mu M \mathrm{hAIF}_{\Delta 1-101 \text { ox }}$ and (D) a mixture of $20 \mu \mathrm{M} \mathrm{hAIF}_{\Delta 1-1010 \mathrm{ox}}$ with $2 \mathrm{~m} M \mathrm{NADH}$ for $\Delta \mathrm{R} 201$ (dark cyan line), $\mathrm{G} 308 \mathrm{E}$ (violet line), and $\mathrm{E} 493 \mathrm{~V}$ (orange line) variants. Spectra were recorded at $25^{\circ} \mathrm{C}$ in $50 \mathrm{mM}$ potassium phosphate $\mathrm{pH}$ 8.0 at a final ionic strength of $150 \mathrm{mM}$. 

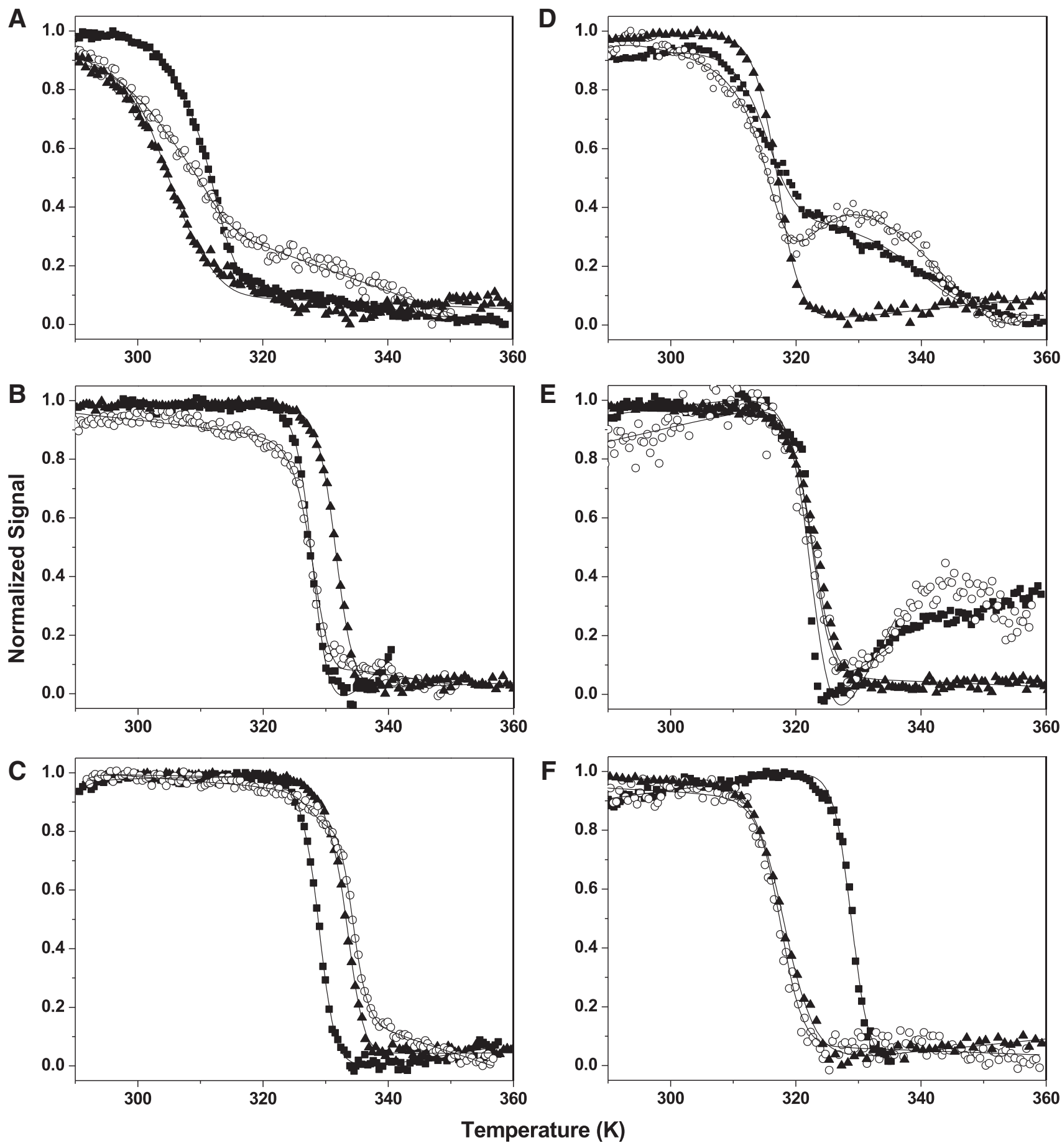

SUPPLEMENTARY FIG. S8. Unfolding properties of $\mathbf{h A I F}_{\Delta 1-101}$ variants. Thermal unfolding curves for (A) $\Delta$ R201, (B) G308E, and (C) E493V hAIF $41-101$ ox and for (D-F) their corresponding CTC (1:100 hAIF:NADH ratio). Thermal denaturation was monitored by far-UV CD $(210 \mathrm{~nm}$, white circles $)$, near-UV CD $(300 \mathrm{~nm}$ in (A-C), black squares) and vis CD $(410 \mathrm{~nm}$ in (D-F), black squares), and flavin fluorescence emission (black triangles). The curves are shown roughly normalized from 0 to 1 , and their global fits to three-state unfolding models are represented by continuous lines. Curves were recorded in $50 \mathrm{mM}$ potassium phosphate, $\mathrm{pH} 8.0$, at a final ionic strength of $150 \mathrm{mM}$. 


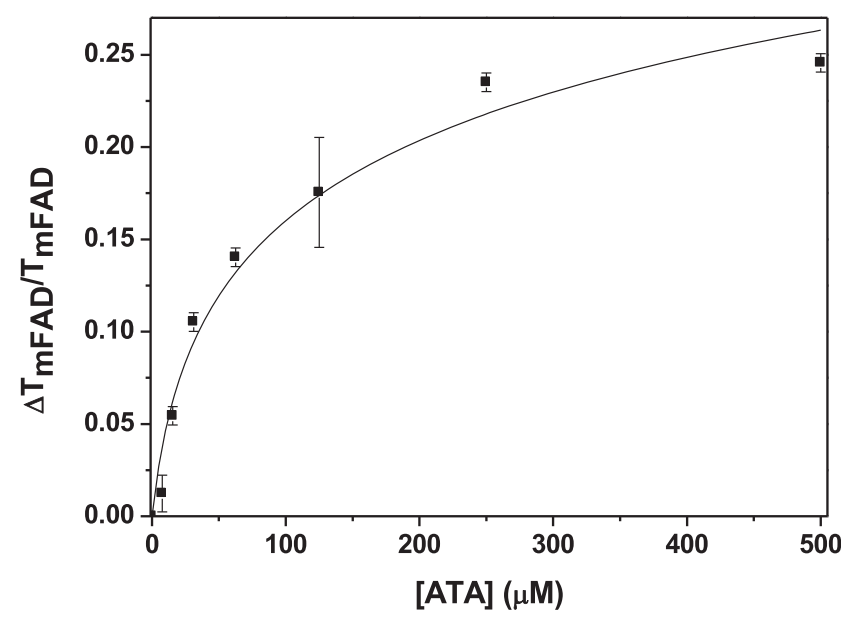

SUPPLEMENTARY FIG. S9. Interaction of hAIF with ATA. Dose-response curve for the dependence of the WT $\mathrm{AIF}_{\triangle 1-101 \mathrm{ox}} \mathrm{T}_{\mathrm{mFAD}}$ on the ATA concentration. A total of $1 \mu M$ hAIF $_{\Delta 1-101 \text { ox }}$ was mixed with increasing concentrations of ATA in 96-well plates. Experiments were done in triplicate. The ATA dissociation constant, $K_{\mathrm{d}}{ }^{\mathrm{ATA}}$, was determined by fitting the data to the equation (S1) $\frac{\Delta T_{m F A D}}{T_{m F A D}}=\frac{n R T_{m F A D}^{0}}{\Delta \mathrm{H}_{0}} \ln \left(1+\frac{[\mathrm{ATA}]}{K_{d}^{A T A}}\right)$, where $\Delta \mathrm{T}_{\mathrm{mFAD}}$ estimates the extent of the ATA-induced protein destabilization $\left(\Delta \mathrm{T}_{\mathrm{mFAD}}=\mathrm{T}_{\mathrm{mFAD}}{ }^{0}-\mathrm{T}_{\mathrm{mFAD}}\right)$; with $\mathrm{T}_{\mathrm{mFAD}}{ }^{0}$ and $\mathrm{T}_{\mathrm{mFAD}}$ being the midpoint denaturation temperatures in the absence and presence of ligand, respectively, $\Delta \mathrm{H}_{0}$ is the unfolding enthalpy of the protein in the absence of ATA, and $n$ is the number of ligand molecules bound per hAIF molecule. 

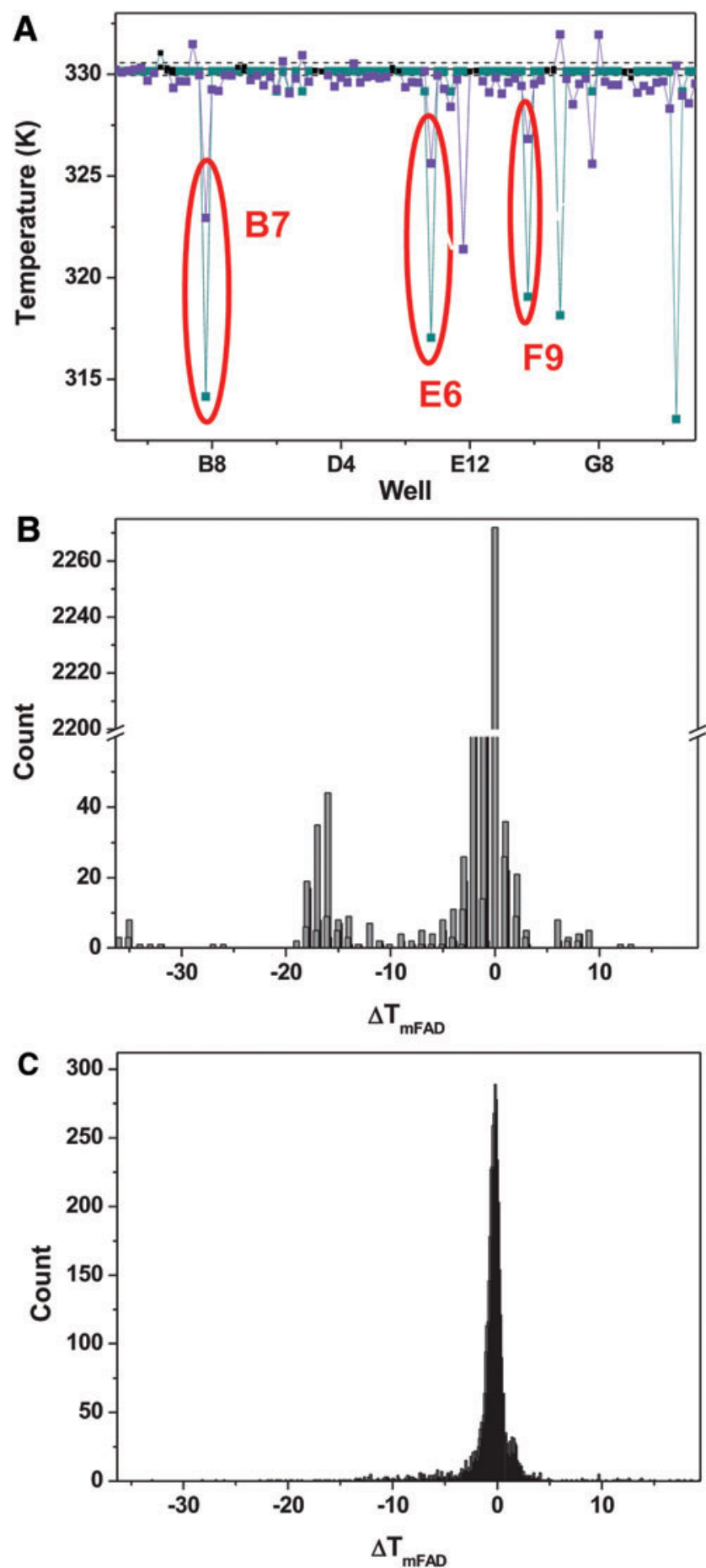

SUPPLEMENTARY FIG. S10. ThermoFAD HTS screening for compounds binding $\mathrm{hAIF}_{\Delta 1-1010 x}$. (A) Compound-induced decrease in $\mathrm{T}_{\mathrm{mFAD}}$ for $\mathrm{hAIF}_{\Delta 1-101 \mathrm{ox}}$ thermal FAD release upon unfolding as detected in a typical assay in a single 96-well plate. Black squares represent $\mathrm{T}_{\mathrm{mFAD}}$ values for wells at columns 1 and 12 on each plate, which were used for controls in the absence of compound. $\mathrm{T}_{\mathrm{mFAD}}$ values for controls are indicated as a continuous black line, whereas corresponding $\mathrm{SD}$ values are shown as dashed black lines. For samples containing compounds, violet and cyan squares represent $\mathrm{T}_{\mathrm{mFAD}}$ values calculated using, respectively, the midpoint method and the inflection point analysis. Wells identified as containing potential hits by both methods are marked with a red circle. Experiments were performed in $50 \mathrm{~m} M$ potassium phosphate, $\mathrm{pH}$ 8.0 , with $1 \mu M$ hAIF $_{\Delta 1-1010 x}, 100$, or $500 \mu M$ of the compound and $2.5 \%$ to $12.5 \%$ DMSO. (B) and (C) show the $\Delta \mathrm{T}_{\mathrm{mFAD}}$ histograms of all 11,424 compounds calculated using the inflection point analysis method and the midpoint analysis method, respectively. FAD, oxidized form of flavin adenine dinucleotide. 

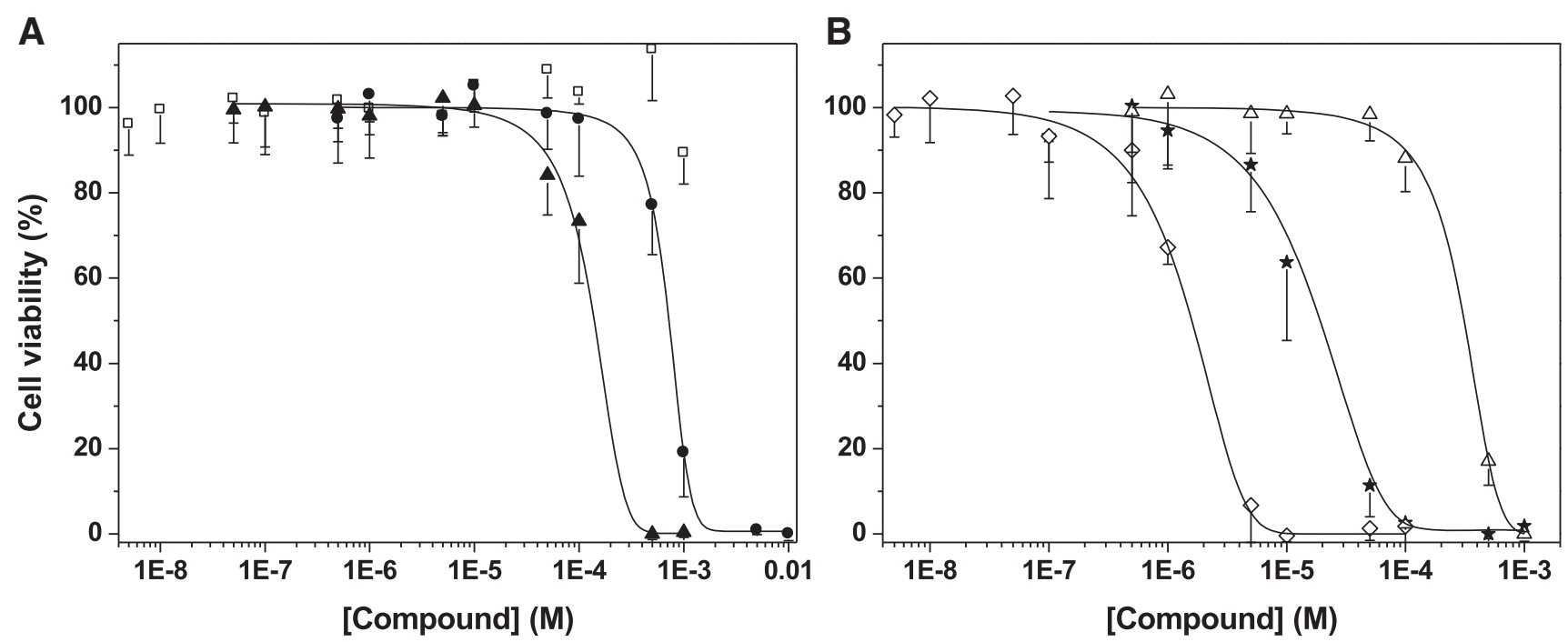

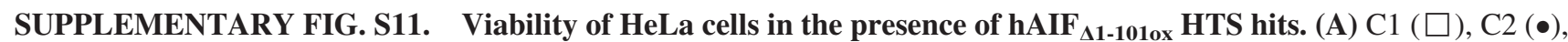
and C5 $(\boldsymbol{\Delta})$. $(\mathbf{B})$ C8 $(\star)$, C9 $(\diamond)$, and C11 $(\Delta)$. HeLa cells were grown for 24 hours, then treated with different concentrations of each compound and incubated for another 24 hours. Means \pm SD of at least three independent experiments are shown for each compound at each of the assayed concentrations. Dose-response dependence data were fitted to sigmoidal curves to determine $\mathrm{EC}_{50}$ values. 

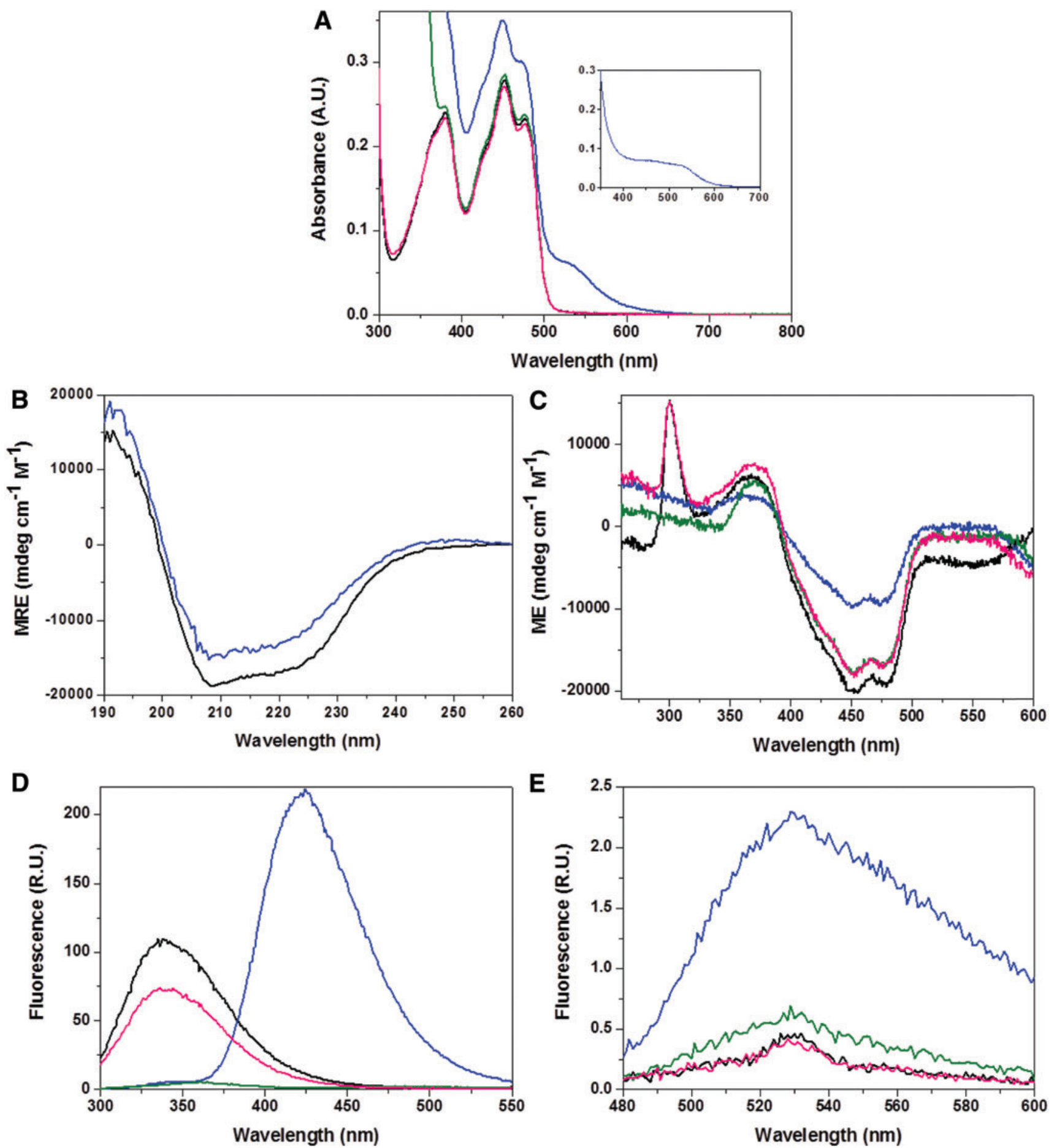

SUPPLEMENTARY FIG. S12. Effect of binders on the spectroscopic properties of hAIF A1-101 $_{\text {. }}$ (A) Visible absorption spectra of $\mathrm{hAIF}_{\Delta 1-101 \mathrm{ox}}(\sim 20 \mu M)$ and in mixtures containing ATA $(100 \mu M), \mathrm{C} 2(500 \mu M)$, or C11 $(100 \mu M)$. The inset shows the absorbance spectra of ATA $(500 \mu M)$. (B) Far-UV CD spectra of hAIF $\operatorname{LI1-1010x}(1 \mu M)$, and when containing ATA $(500 \mu M)$. (C) Near-UV CD spectra of hAIF (C1-101ox $_{2}(20 \mu M)$ and in the presence of ATA, C2, or C11 (all at $\left.500 \mu M\right)$. (D) Fluorescence emission spectra in the aromatic residues region of $\mathrm{hAIF}_{\Delta 1-101 \mathrm{ox}}(2 \mu M)$ in the presence of ATA, C2, and $\mathrm{C} 11$ (all at $500 \mu M)$. (E) Fluorescence emission spectra in the flavin region of $\mathrm{hAIF}_{\Delta 1-101}(2 \mu M)$ and in the presence of ATA, C2, or C11 (all at $500 \mu M$ ). Spectra were recorded in $50 \mathrm{mM}$ potassium phosphate, $\mathrm{pH}$ 8.0, at a final ionic strength of $150 \mathrm{~m} M$. CD spectra were recorded at $25^{\circ} \mathrm{C}$. Fluorescence spectra were recorded at $10^{\circ} \mathrm{C}$ with excitation wavelength at $280 \mathrm{~nm}$ for the aromatics region and at $450 \mathrm{~nm}$ for the flavin region. Free $\mathrm{hAIF}_{\Delta 1-101 \mathrm{ox}}$ is shown as a black line whereas mixtures with ATA, $\mathrm{C} 2$, and $\mathrm{C} 11$ are shown as blue, green, and pink lines, respectively. 


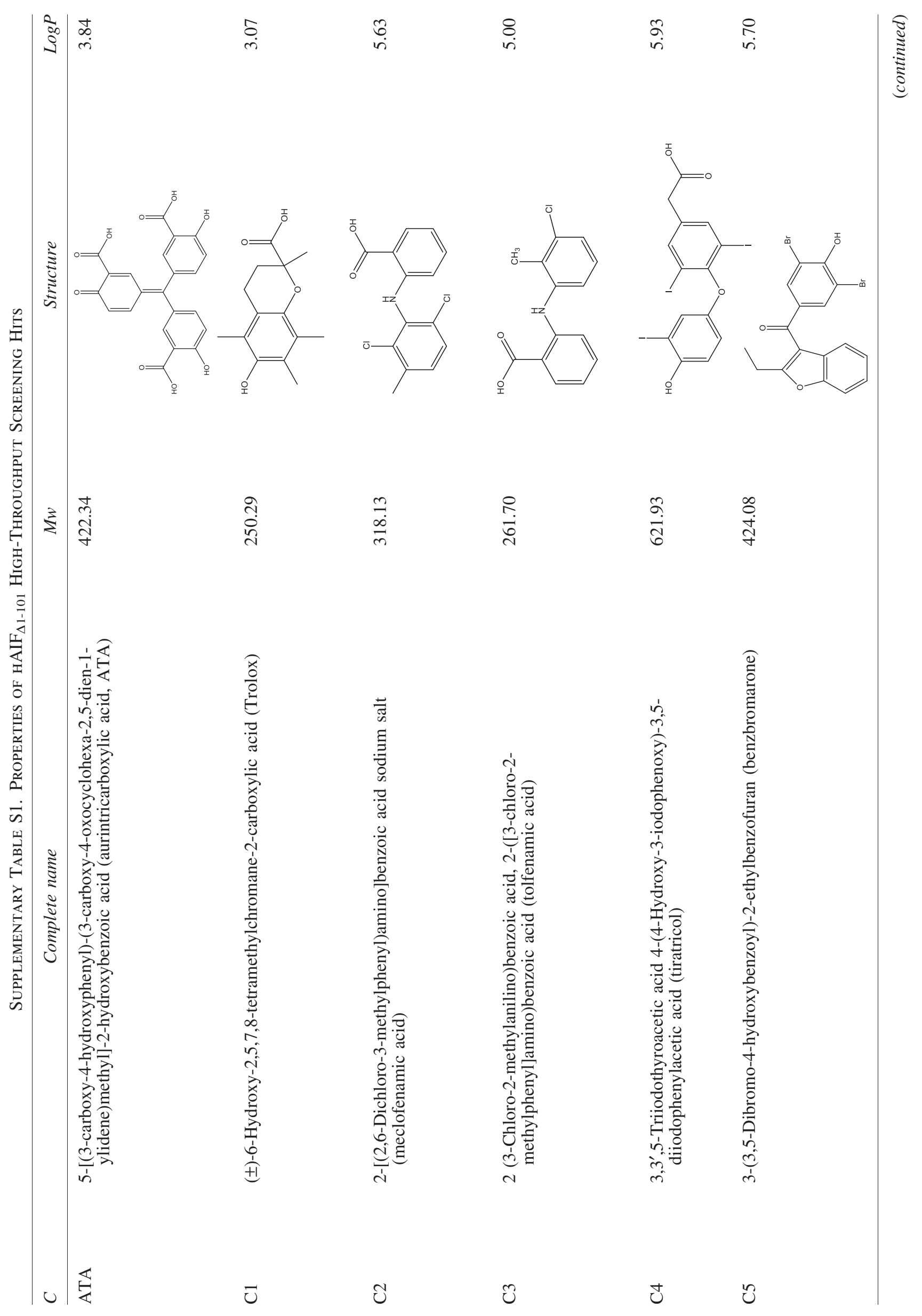




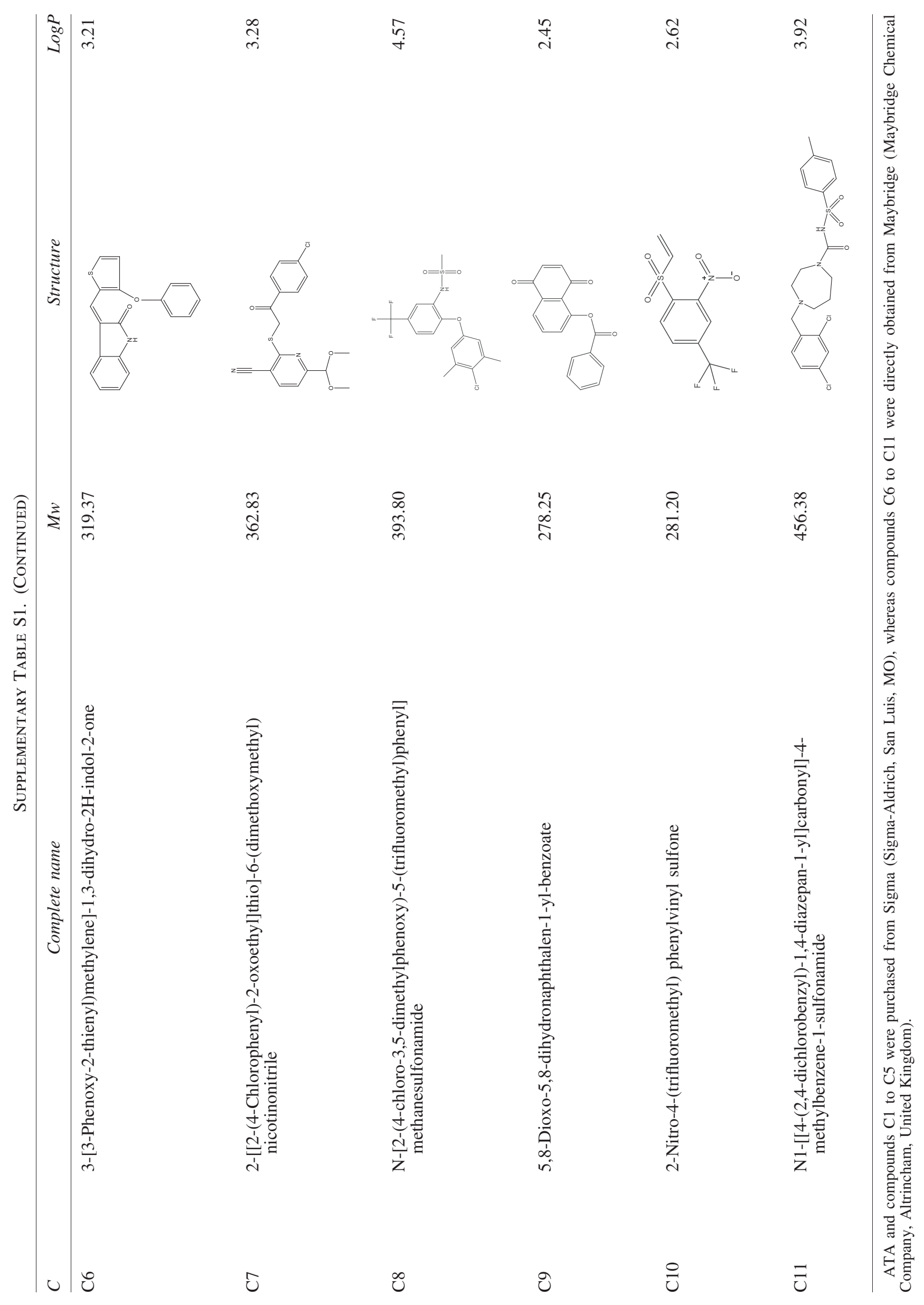


Supplementary Table S2. EfFect of Aurintricarboxylic ACID, C2, AND C11 ON THE THERMal STABILITY OF HAIF $\mathrm{H}_{\Delta 1-1010 x}$

\begin{tabular}{lcc}
\hline Compound & $T_{m 1}(K)$ & $T_{m 2}(K)$ \\
\hline- & $332 \pm 1$ & $337 \pm 1$ \\
ATA & $317 \pm 1$ & $328 \pm 1$ \\
C2 11 & $329 \pm 1$ & \\
\hline
\end{tabular}

Values in the table were obtained by the global fitting of the near$\mathrm{CD}$ and fluorescence thermal denaturation curves. Data were obtained in $50 \mathrm{~m} M$ potassium phosphate, $\mathrm{pH} 8.0$, at a final ionic strength of $150 \mathrm{~m} M$, from 283.15 to $363.15 \mathrm{~K}$. Protein concentrations were $\sim 2 \mu M$ and $\sim 20 \mu M$ for fluorescence and near-UV CD, respectively.

\section{Supplementary Reference}

S1. Cooper A and McAuley-Hecht KE. 1993. Microcalorimetry and the molecular recognition of peptides and proteins. Phil Trans R Soc Lond A 345, 23-35, 1993. 


\section{AUTHOR QUERY FOR ARS-2018-7658-VER9-VILLANUEVA_1P}

AU1: Please note that gene symbols in any article should be formatted as per the gene nomenclature. Thus, please make sure that gene symbols, if any in this article, are italicized.

AU2: Please check the edit of the title.

AU3: Please identify (highlight or circle) all authors' surnames for accurate indexing citations.

AU4: Please check the expansion of "IMS" as "intermembrane mitochondrial space."

AU5: The Publisher requests for readability that no paragraph exceeds 15 typeset lines. Please check for long paragraphs and divide where needed.

AU6: Please rewrite "After 24 hours of MNNG treatment, loss of cell viability reaches $\sim 100 \%$, independently on the HTS hits absence or presence" for clarity.

AU7: Please rewrite "Thus, the FAD and NADH natural ligands might synergically contribute to in vivo partially overcome the $\Delta$ R201 unfolding negative effect by enhancing protein stability" for clarity.

AU8: In Ref. 17, please mention the name and location of the publisher.

AU9: Institution is given in affliation but is not given in corresponding author's address. Please check.

AU10: Please rewrite "Relevant interactions in the WT model are shown in blue dashed lines, whereas the $\Delta$ R201 structures also shown in blue the increase of the corresponding WT distances and in red dashed lines new interactions" for clarity. 